\title{
Recommendations for biomechanics in the physical education teacher education curriculum
}

Susan M. Ross

West Virginia University

Follow this and additional works at: https://researchrepository.wvu.edu/etd

\section{Recommended Citation}

Ross, Susan M., "Recommendations for biomechanics in the physical education teacher education curriculum" (2010). Graduate Theses, Dissertations, and Problem Reports. 3110.

https://researchrepository.wvu.edu/etd/3110

This Dissertation is protected by copyright and/or related rights. It has been brought to you by the The Research Repository @ WVU with permission from the rights-holder(s). You are free to use this Dissertation in any way that is permitted by the copyright and related rights legislation that applies to your use. For other uses you must obtain permission from the rights-holder(s) directly, unless additional rights are indicated by a Creative Commons license in the record and/ or on the work itself. This Dissertation has been accepted for inclusion in WVU Graduate Theses, Dissertations, and Problem Reports collection by an authorized administrator of The Research Repository @ WVU.

For more information, please contact researchrepository@mail.wvu.edu. 
Recommendations for Biomechanics in the Physical Education Teacher Education Curriculum

\author{
Susan M. Ross
}

Dissertation submitted to the College of Physical Activity and Sport Sciences at West Virginia University in partial fulfillment of the requirements for the degree of

Doctor of Philosophy in Kinesiology with an emphasis in Physical Education Teacher Education

Andrew Hawkins, Ph.D., Chair Sean Bulger, Ed.D., Co-chair Kristen Dieffenbach, Ph.D. Richard Walls, Ph.D. Robert Wiegand, Ed.D.

Department of Coaching and Teaching Studies

\author{
Morgantown, West Virginia \\ 2010
}

Keywords: Professional Preparation; Teacher Education; Curriculum; Biomechanics Copyright 2010 Susan M. Ross 


\begin{abstract}
Recommendations for Biomechanics in the Physical Education Teacher Education Curriculum
\end{abstract}

Susan M. Ross

The purpose of this study was to determine the critical biomechanics competencies physical educators need to learn, and delineate learning environments and instructional methods for delivering core biomechanics competencies within the physical education teacher education curriculum. An initial list of theoretical and applied biomechanics competencies was constructed using the knowledge and skills recommended by the Guidelines and Standards for Undergraduate Biomechanics and three textbook sources. A two-round, modified Delphi procedure involved the repeated circulation of a survey to a small panel of content experts. The study sample included biomechanics specialists, physical education teacher educators, and K-12 physical education teachers. The Delphi panel members rated each survey item in terms of theoretical importance and pedagogical relevance using a five-point Likert scale. The data collected during the second round of questioning provided a final measure of consensus regarding the critical strength of each biomechanics competency. An item had to receive a mean rating of at least four or higher in the areas of importance and relevance by at least $75 \%$ of all individual ratings in order to be considered essential in the preparation of prospective physical educators. An open response question was incorporated into the second Delphi round asking panel members to recommend three learning environments and instructional methods for delivering core biomechanical knowledge into the physical education teacher education curriculum. The results of the study provided a conceptual framework upon which physical education teacher educators can make future curricular decisions in the area of biomechanics. 


\section{DEDICATION}

This dissertation is dedicated to my father, and in memory of my mother:

Roger and Gerry Ross

Their unconditional love, faith in God, and unwavering support continues to inspire me. 


\section{ACKNOWLEDGEMENTS}

I wish to express my deepest gratitude and appreciation to the respected people who assisted and inspired me along this journey. I acknowledge my chair, Dr. Andrew Hawkins, whose exceptional model of professionalism, integrity, and many blessings have made a profound impact on me as a teacher and leader. I will do my best to pay it forward. Dr. Bulger, my co-chair, whose mentorship has played an instrumental role in focusing my ideas and shaping me as a scholar. It has been a great honor to learn under your guidance. I also wish to extend my gratitude to my committee members, Dr. Kristen Dieffenbach, Dr. Richard Walls, and Dr. Robert Weigand, for their insightful comments, encouragement, and steadfast support throughout the course of this research project. Dr Walls, thank you for carefully reading and helping me sort out the technical details of my work. My sincere appreciation also goes to Dr. Lynn Housner, whose professional support will always be remembered.

A special acknowledgment goes to the Delphi panel members, Dr. Pamela Betchel, Dr. Bonnie Blankenship, Dr. Bonnie Mohnsen, Dr. Mark Byra, Dr. Jacalyn Lund, Dr. Kathy LaMaster, Dr. Inez Rovegno, Dr. Deborah Tannehill, Dr. Judith Rink, Dr. Amy Woods, Dr. Michael Bird, Dr. Janet Dufek, Dr. Jean Eckrich, Dr. Joseph Hamill, Dr. Roger James, Dr. Duane Knudson, Dr. Kathy Knutzen, Dr. Kathy Ludwig, Dr. Carla Murgia, Dr. Pamela Russell, Dr. Darla Smith, Joanna Faerber, Holly Guntermann, Jennifer Higgins, Ernest Holcombe, Debbie Holcombe, Dr. Ulrike Kerstges, Tecca Kilmer, Deborah Riga, Lisa Summers, and Deb Walter. This research project would not have been possible without their dedication and insightful contributions.

A special acknowledgment goes to my best friend and future colleague Amanda Metcalf. Amanda, thank you for supporting me, motivating me, making me laugh when I felt like crying. Thank you for showing me the little things really do matter and the big things will all soon pass. Thank you for freely contributing your time to help me in various facets of my research project. Without your mentorship and genuine support, this would still be a work in progress. I would also like to thank my friends, Amy Sidwell (Superwoman) and Justine Vosloo (J.J.), who have shared with me three years of challenges and helped make my time at West Virginia University a fun and rewarding experience. During our moments together... I loved it, embraced it, and will miss you both very much.

And my brother Dave, thanks for being a fan as far back as I can remember. I am very blessed to have a big bro as kind and supportive as you. 


\section{TABLE OF CONTENTS}

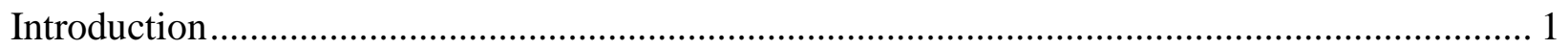

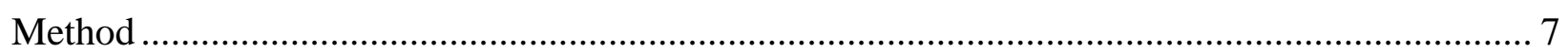

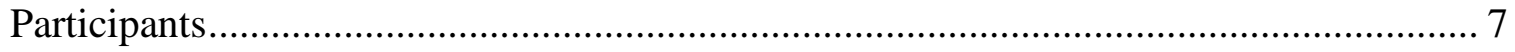

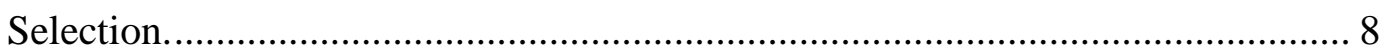

Recruitment .......................................................................................... 9

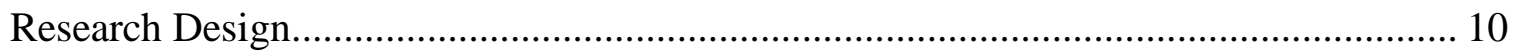

Instrumentation and Pilot Study............................................................................ 11

Content development. ................................................................................... 11

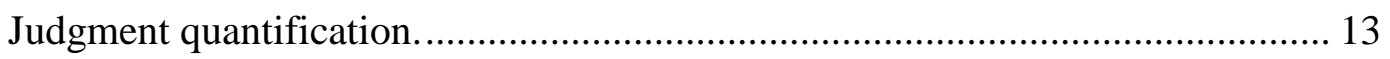

Delphi Administrative Procedures.................................................................................. 14

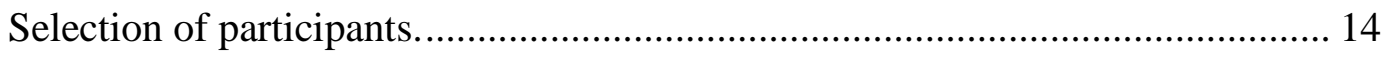

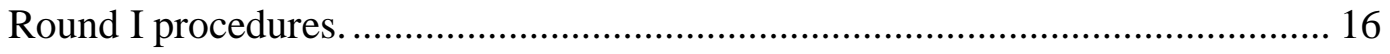

Round II procedures................................................................................... 17

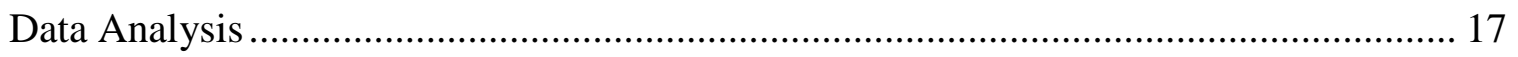

Critical biomechanics competencies................................................................. 18

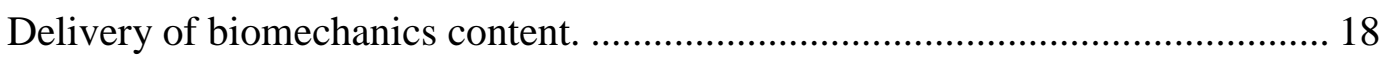

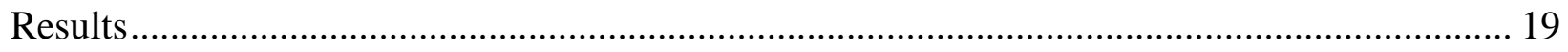

Critical Biomechanics Competencies ......................................................................... 20

Application of biomechanics to human movement. ............................................. 20

Qualitative analysis of movement...................................................................... 21

Quantitative analysis of movement................................................................... 22

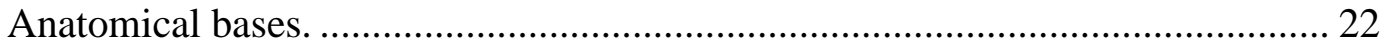




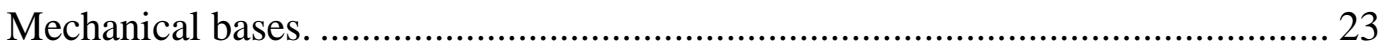

Motor skill principles and applications...................................................... 23

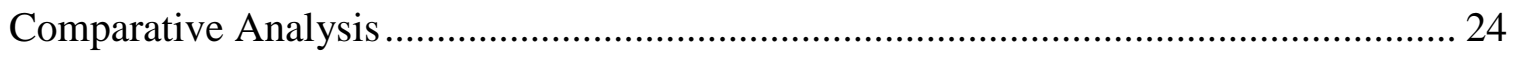

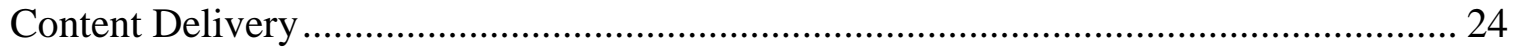

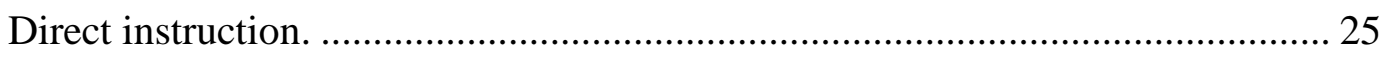

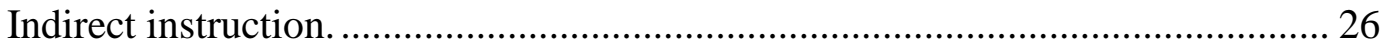

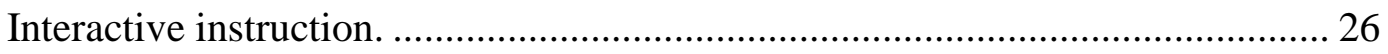

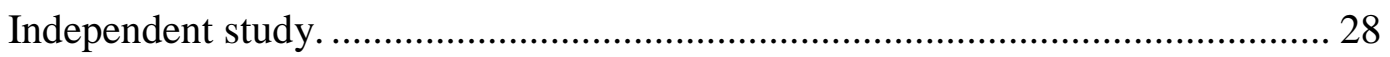

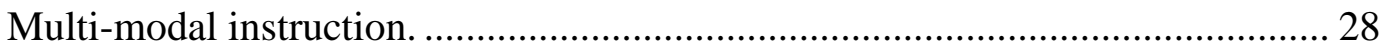

Alternative curriculum models. ................................................................ 29

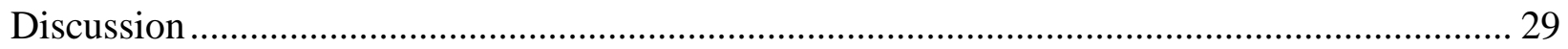

Biomechanical Content in Physical Education Teacher Education ............................... 30

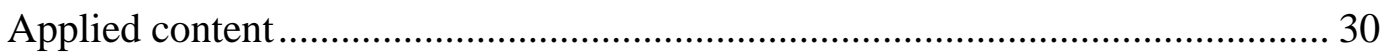

Theoretical and scientific prerequisite content .............................................. 31

Delivery of Biomechanics Content in Physical Education Teacher Education ................ 37

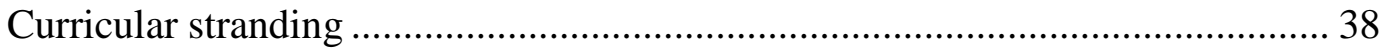

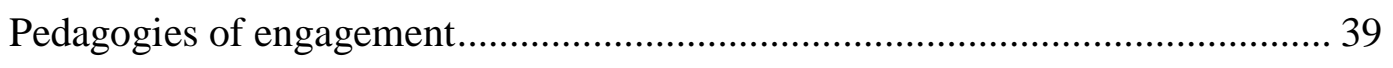

Lecture with student centered activities............................................. 39

Video-based instruction ............................................................... 41

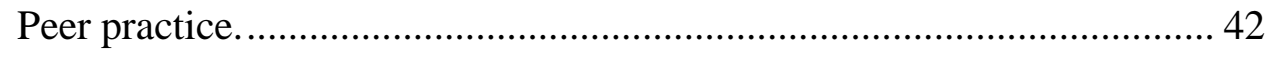

Problem-based learning. ................................................................ 43

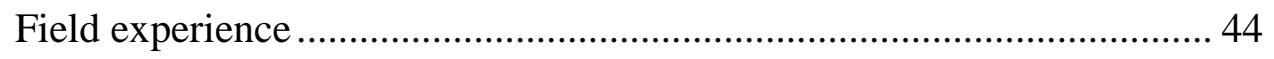

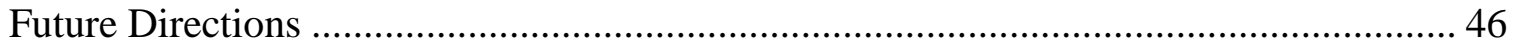




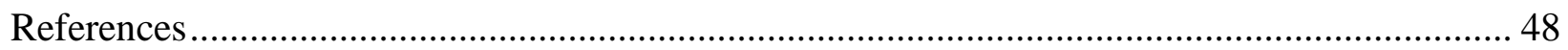

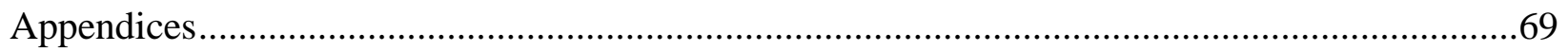

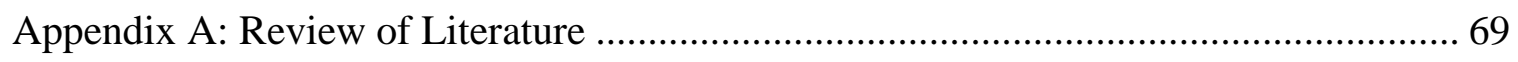

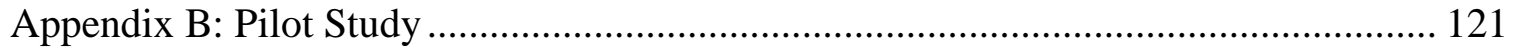

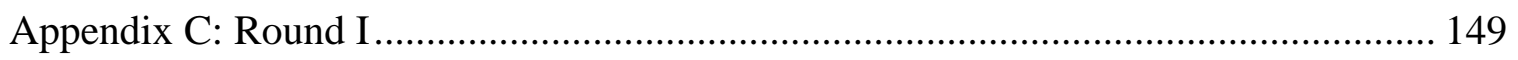

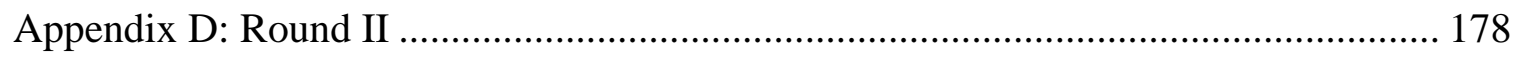

Appendix E: Delivery of Biomechanics Content...................................................215 


\section{List of Tables}

Table 1. Biomechanics core content areas and broad-based competencies.....................................56

Table 2. Biomechanics core content areas and specific competencies ......................................57

Table 3. PETE subdisciplinary Delphi investigations ...............................................................60

Table 4. Final list of biomechanics competencies and associated group ratings .............................61 


\section{Introduction}

The present success of biomechanics owes much to the emergence of doctoral programs, increase in scholarly writing and research, and the formation of discipline-oriented academies over the past 40 years. Although course work in biomechanics continues to play a major academic role in preparing physical educators, the scope of biomechanics knowledge has become incrementally larger to inform a number of other occupational contexts, such as physical therapy, occupational therapy, athletic training, and engineering (Hamill, 2007; Rink, 2007). Consequently, course work must be organized and applied in ways to meet the needs of undergraduate majors with a variety of occupation goals unrelated to teaching. Although this provides prospective physical educators with a broad educational background, it also widens the gap between what they need to know and what they are expected to apply in teaching school-age children and adolescents (Rink, 2007). The essential value of biomechanical knowledge becomes diminished when practicing physical educators are unable to integrate critical biomechanical concepts and principles into professional practice. Although there has been substantial scholarly discussion concerning the theory to practice disconnect of subdisciplinary knowledge in physical education teacher education (PETE), a brief description of literature will provide greater insight into the nature of the theory to practice gap in the area of biomechanics.

Although it is generally assumed that biomechanics course work provides physical educators with the knowledge and skills necessary to analyze movement, evaluate motor performance, and apply the most appropriate intervention (NASPE, 2003), there is ample evidence suggesting physical educators who have completed a basic course in biomechanics are unable to apply the knowledge in practice (Behets, 1996; Biscan \& Hoffman, 1976; Imwold \& Hoffman, 1983; Knudson, Morrison, \& Reeve, 1991; Siedentop, Doutis, Tsangaridou, Ward, \& 
Rauschenbach, 1994; Stroot \& Oslin, 1993; Williams \& Tannehill, 1999). Although recent research is limited, the previous identified studies (Behets, 1996; Biscan \& Hoffman, 1976; Imwold \& Hoffman, 1983; Stroot \& Oslin 1993) combined with findings from Knudson, Morrison, \& Reeve (1991) suggest a standalone undergraduate biomechanics course is insufficient for developing skill analysis competency in physical educators.

As biomechanical knowledge become more diverse in terms of subject matter, pedagogical scholars have argued for years there is gap between what physical educators are taught in an undergraduate biomechanics course and what they are expected to apply in professional practice (Hoffman, 1984; Knudson, 2003). Although there are biomechanics course instructors who care about making theory to practice connections, the primary issues revolve around the appropriateness of the content, and the "how to" approach in helping prospective physical educators apply course content in the practice setting. According to Knudson (2003), the call for a pedagogical kinesiology (undergraduate biomechanics) previously made by Hoffman (1977) in bridging the gap remains unfulfilled with historical roots grounded in lack of consensus concerning appropriate content and applications of the content in an undergraduate biomechanics course.

Qualitative analysis of movement is recognized as one of the most important professional skills and application of biomechanics concepts and principles in physical education (Hoffman, 1977; Knudson \& Morrison, 2002; NASPE, 2003, 2008). Likewise, teacher educators acknowledge the importance exposing prospective physical educators to biomechanical content and learning experiences that will help them analyze movement qualitatively in the practice setting (Hoffman, 1977; Hudson, 1995; Knudson \& Morrison, 2002; Lounsbery \& Coker, 2008; Morrison \& Harrison, 1997; Reeve, 2000). Although the major outcome goal of a biomechanics 
course is developing skill analysis competence (NASPE, 2003), revisions of the undergraduate standards and guidelines over the years have resulted in a de-emphasis on qualitative analysis in achieving course goals. For example, the initial Guidelines and Standards for Undergraduate Kinesiology (now Biomechanics) (NASPE, 1980) clearly emphasize an introductory biomechanics course should focus on qualitative analysis of motor skill activities and exercise programs, leading to applying qualitative analysis in the physical education setting. Conversely, the most recent version of the guidelines and standards (NASPE, 2003) articulate a theoretical understanding of the content may take on "different forms at different academic institution" and "analytic methods can range on a continuum from quantitative to quantitative" in achieving course outcomes (NASPE, 2003, p. 1). As a result, Hamill (2007) has questioned the appropriateness of the competencies suggesting the outcomes are global in nature, and implementation of the course content is open to interpretation by the course instructor.

Among the influences that impact the academic focus of an undergraduate biomechanics course serving prospective physical educators are the departmental affiliation (Hamill, 2007), textbook selection (Hamill, 2007; Knudson, 2007; Rink, 2007), and, instructor background (Knudson, 2003; Lounsbery \& Coker, 2008; Reeve, 2000; Rink, 2007). According to Hamill (2007), the depth of treatment given to the competencies and emphasis placed on qualitative analysis may be influenced by the focus of the department. For example, Hamill (2007) added that a biomechanics course taught within an exercise science department may solely emphasize a quantitative approach, while a course taught within the PETE curriculum may emphasize a qualitative approach. Knudson (2003) noted that political and financial pressures to employ education technology and computer assisted instructional methods has reinforced the use of quantitative analysis applications within departments. Rink (2007) acknowledged the fact that 
textbook authors have responded to the wide spectrum of learners served in undergraduate courses by publishing generic content which is far removed from teacher preparation.

Scholars have also proposed the background and specialization of the course instructor influences the extent to which relevant biomechanical theory to practice applications are made for prospective physical educators (Knudson, 2003; Lounsbery \& Coker, 2008; Reeve, 2000; Rink, 2007). Biomechanics course instructors whose training and interests are not in pedagogy (Hoffman, 1977; Rikli, 2006) often have limited backgrounds in qualitative movement analysis (Reeve, 2000) and a tendency to “model their predecessor” by employing instructional methods with a strong emphasis on quantitative problem solving (Knudson, 2003). Siedentop (2009) suggests course instructors with a non-pedagogy background typically favor a quantitative approach because it is the dominant application for research in biomechanics. This questionable instructional environment provides future physical educators with inappropriate practice opportunities for applying complex biomechanical concepts in the physical education setting. However, it must be acknowledged that biomechanics is only one subdiscipline charged with delivering course content for all students of kinesiology, not just physical educators. Course content, textbook selection, and theory to practice application decisions made by the instructor must serve the needs of a variety of majors, thus, reinforcing the need to seek alternative solutions for helping physical educators make contextually relevant application of biomechanics content.

To counter the problem associated with the gap between theory and practice, a variety of proposals have been made based on the premise there is a critical need to incorporate qualitative analysis training in the PETE curriculum. The proposed solutions for making biomechanics theory to teaching physical education connections have been based on curricular initiatives and 
instructional methods. Scholars have suggested PETE programs (a) infuse qualitative analysis into the PETE curriculum (Morrison \& Harrison, 1997), (b) change course requirements to at least four credit hours which include a laboratory component (Ives \& Knudson, 2007), (c) add a separate qualitative movement analysis course (Bain \& Poindexter, 1981; Morrison \& Harrison, 1997), (d) re-design teaching methods courses to include learning to teach and analyze skills (Pinheiro \& Simon, 1992), and (e) have a PETE faculty member teach the course with a focus on applying biomechanical principles to a variety of physical activity settings (Rink, 2007).

Other proposed solutions relating to the delivery of biomechanics content include: (a) video based instructional methods (Gangstead \& Beveridge, 1984; Morrison \& Harrison, 1997; Nielsen \& Beauchamp, 1992; Stroot \& Oslin, 1993; Wilkinson, 1991, 1996; Williams \& Tannehill, 1999), and (b) early field observations in the physical education setting (Pinheiro, 2000). Furthermore, Hudson (1995) recommended organizing and delivering course content around 10 core biomechanical principles that are easily observed and communicated by the physical education teacher to the student; whereas, Knudson (2007) proposed using nine general biomechanical principles for delivering content.

Although numerous strategies have been proposed in the literature, there is a need to identify what content is essential for prospective physical educators when evaluating the effectiveness of the PETE curriculum for future physical education teachers. It is equally important to construct a PETE curriculum that will enable prospective physical educators to integrate and use critical knowledge skillfully in the practice context. A challenge for PETE scholars is to seek out an alternative research design that will allow greater collaboration among an interdisciplinary group of professionals in reaching consensus about curricular content and teacher preparation concerns. 
Recently, Bulger and Housner (2007) employed a two round modified Delphi method to determine the critical theoretical and applied exercise science competencies that prospective physical education teachers need to learn within the undergraduate PETE curriculum. The Delphi method initiated important discussion among various experts across professional landscapes by means of series of questionnaires. The investigation sought to generate consensus of expert opinion concerning the most critical knowledge in the area of exercise science for inclusion in the PETE curriculum. Within this study the researchers looked at a list of anatomy and biomechanics competencies in relation to their role within exercise science. The results revealed that only 10 out of 23 initial anatomy and biomechanics competencies were identified as being important and relevant in the preparation of prospective physical education teachers.

The purpose of the present study was to expand on the investigation conducted by Bulger and Housner (2007) by generating consensus among biomechanics specialists, teacher educators, and practicing physical education teachers regarding the most critical biomechanical competencies that prospective physical educators need to learn within the PETE curriculum. A secondary aim of the study was to generate a list learning environments and associated instructional methods for delivering core biomechanics content to prospective teachers within the PETE curriculum. The present study is a part of an existing line of Delphi investigations (Bulger \& Housner, 2007; Metcalf, 2010; Ross, Metcalf, Bulger, \& Housner, 2010) systematically looking at subdisciplinary knowledge in relation to the PETE curriculum. This current study seeks to close the gap between what physical educators need to know about movement in the area of biomechanics, and what they are expected to apply in promoting skillful movement, physical activity and fitness in the school setting. 


\section{Method}

The Delphi method is a structured communication process aimed at generating knowledge from a group of experts by means of a series of survey questionnaires, referred to as rounds (Clayton, 1997). The primary purpose of the Delphi method is to achieve consensus of opinion among experts over a particular issue when the available information is relatively incomplete (Jones \& Hunter, 1995; Oloki \& Pawlowski, 2004). It has been suggested that the Delphi method is the most beneficial means for advancing scholarly inquiry about critical needs, assumptions, emerging issues, possibilities, goals, and future directions (Ulrich, 2001). According to Lindstone (1978), the Delphi method is most appropriate when: (a) the problem does not lend itself to analytic techniques, but can benefit from the subjective judgments of a group, (b) face-to-face interaction is not possible among individuals who need to interact, and (c) time and cost make frequent group collaboration infeasible. The modified Delphi (closed ended questionnaire), as opposed to the traditional Delphi (open ended questionnaire) is considered the most appropriate option if information concerning the area under investigation is available (Kerlinger, 1973). A modified Delphi enables the researcher to structure the communication process around a predetermined set of concepts/principles/statements that serve as a framework for focusing experts’ discussion.

\section{Participants}

The first phase of the Delphi investigation involves the identification and selection of participants who will serve as expert panel members. The inherent value of the Delphi rests in the use of expert knowledge; therefore, one of the most important aspects of the selection process is determining the primary qualifications of the participants in relation to the issue under investigation. The organization of the Delphi panel began by developing specific “expertise” 
criteria, determining an appropriate panel size, and establishing a means of recruiting panel members for participation in the study. Scholars have suggested an important criterion for participant selection is their subject matter knowledge and practical experience in the field of inquiry (Powell, 2002; Skulmoski, Hartmon, \& Krahn, 2007), as well as their membership in a relevant professional association (Murray \& Hammons, 1995). Although there are no universally agreed criteria for the size of the expert panel, scholars recommend that a panel members (a) include 10 to 30 members, depending on the nature of subject being explored (Adler \& Ziglio, 1996; Parente \& Anderson-Parente, 1987), and (b) come from a homogenous population within the same discipline, while incorporating a smaller number of participants from different professional and social stratifications (Clayton, 1997).

Selection criteria. The participants were selected based on their unique perspectives concerning the theoretical and applied value of biomechanics in the preparation of physical education teachers. To address the issue under investigation, the expert panel included individuals with expertise in biomechanics, physical education teacher education, and teaching K-12 physical education. Biomechanics specialists who teach undergraduate biomechanics courses were assumed to have the highest degree subject matter expertise regarding the survey content. Physical education teacher educators who were members of the curriculum and instruction academy were assumed to have the highest degree of expertise in preparing prospective physical educators for teaching school-based physical education, as well as knowledge of the PETE curriculum development process. School-based physical education teachers were assumed to have the highest degree of expertise in applying biomechanical concepts and principles in the practice setting. A final panel group of 24 experts were randomly 
selected and recruited from a larger pool of qualified Delphi participants meeting the following criteria:

- Biomechanics specialists $(\mathrm{n}=8)$ who teach undergraduate biomechanics and are current members of the Biomechanics Academy of the National Association for Sport and Physical Education, and/or the American Society for Biomechanics.

- Physical education teacher educators $(n=8)$ who are listed as members of the Curriculum and Instruction Academy of the National Association for Sport and Physical Education.

- K-12 Physical education teachers $(n=8)$ who have been recognized as a district Physical Education Teacher of the Year through the National Association for Sport and Physical Education Teacher of the Year Program.

Recruitment. Prospective Delphi panel members were invited to participate in the study by a letter of invitation sent through e-mail and follow-up telephone contact. The letter outlined the importance of the study, the modified Delphi method, panel member qualifications, and the estimated amount of time required to complete the study. Invited panel members were asked to send a reply e-mail within 7 days indicating their willingness to participate in the Delphi study. A follow-up telephone contact was made to address additional questions or concerns potential participants may have had regarding the nature of the study, and reinforce the significance of their contribution to the study. Upon each refusal or non-response within a two-week time period, another potential Delphi participant was randomly selected from the list until the required number of panel members agreed to participate. Participants agreeing to participate were sent a message acknowledging their consent to participate, along with the Delphi investigation 
schedule. Approval from the Institute Review Board for the Protection of Human Subjects was obtained prior to data collection.

\section{Research Design}

The study employed a pilot study followed by a two-round modified Delphi protocol as a means of deriving consensus among a panel of experts regarding the essential biomechanics competencies that should be included in the undergraduate PETE curriculum. A secondary aim of the Delphi study was to identify potential learning environments and instructional methods for delivering core biomechanics content to physical educators within the PETE curriculum. The Delphi process consisted of two rounds of iterative questioning in which panel members were asked to rate a series of biomechanics competencies in terms of their theoretical importance and pedagogical relevance for prospective physical education teachers. For the purpose of this study, theoretical importance and pedagogical relevance were adapted from the definitions proposed by Bulger and Housner (2007). Theoretical importance referred to the "item's value as a theoretical underpinning of the physical education teaching profession” (Bulger \& Housner, 2007, p. 60). Pedagogical relevance referred to the "item's practical or applied significance in relation to the administration of a K-12 physical education program” (Bulger \& Housner, 2007, p. 60). Each competency's importance and relevance was rated using the following 5-point Likert scale: (5) strongly agree, (4) agree, (3) no opinion, (2) disagree, and (1) strongly agree. These data were collected and analyzed using SurveyMonkey, a web-based survey instrument. A customized open-ended question was incorporated into the final Delphi round to formulate a list of possible learning environments and instructional methods for delivering biomechanics content to prospective physical education teachers in the undergraduate PETE curriculum. 


\section{Instrumentation and Pilot Study}

The purpose of the pilot study was to construct a valid survey instrument that was used during the actual modified Delphi study. The process of content validation in the pilot study consisted of two stages: (a) content development, and (b) judgment quantification.

Content development. The content development stage consisted of concept identification, competency generation, and instrument construction (DeVellis, 1991). Following an extensive review of the literature on recommended biomechanical concepts and principles for teaching physical education, the researcher developed a survey instrument based on a preestablished set of competencies derived from two nationally approved sources and three textbooks. It is recommended in literature to use a pre-established set of items if available to ensure important statements are included by the researcher that otherwise might be omitted, and decrease panel member attrition (Kerlinger, 1973; McCampbell \& Stewart, 1992). The nationally approved sources on the survey questionnaire included the first Guidelines and Standards for Undergraduate Kinesiology endorsed by the Kinesiology Academy and NASPE (1980), and the most current version of the Guidelines and Standards for Teaching Undergraduate Biomechanics endorsed by the Biomechanics Academy and NASPE (2003). These competencies represented the content recommended for an undergraduate biomechanics course which includes the following areas: (a) anatomical considerations, (b) mechanical considerations, and (c) applications of biomechanics to human movement. Although there have been only minor revisions between the initial and current sets of standards and guidelines for teaching biomechanics, the 1980 version of the guidelines was included in the pilot phase due to the explicitness of the competencies. According to Umbach (2005), measurement error can be 
reduced and response rates increased when questions are precise and avoid having participants respond to two questions in one.

Competencies were also derived from a variety of textbook sources, including Basic Biomechanics (Hall, 1999), Kinesiology: Scientific Basis of Human Motion (Hamilton, Weimar, \& Luttgens, 2008), and Qualitative Analysis of Human Movement (Knudson \& Morrison, 2002). Keeping in mind the goal of developing the survey content was to identify and generate a list of competencies in the area of biomechanics most directly related to teaching physical education, the researcher included a number of survey items from textbooks relative to conducting a qualitative analysis of movement and applying biomechanical concepts and principles to a variety of motor skills. Qualitative analysis of movement has been regarded as one of the most important professional abilities of physical education teachers (Hoffman, 1977; Knudson, 2007; Lounsbery \& Coker, 2008) and is strongly linked to an undergraduate biomechanics course (NASPE, 1980, 2003). Because qualitative analysis of movement is interdisciplinary in nature, a number of competencies incorporated on the survey may be closely aligned with other subdisciplinary areas, such as motor development, motor learning, and pedagogy. The involved textbook competencies were limited to those thought to be most directly related to the theoretical and applied content of biomechanics and its application to skill development, physical activity, and fitness in the school-based setting.

The instrument was constructed using the features of SurveyMonkey, a web-based survey tool. The biomechanics concepts and competencies were organized in a sequence and format consistent with the nationally approved guidelines and standards, as well as textbooks. The final survey instrumentation contained 20 concepts followed by 108 key competencies in the following content areas: (a) introduction to biomechanics (b) application of biomechanics to 
human movement, (c) qualitative analysis of human movement, (d) quantitative analysis of human movement, (e) anatomical bases of human movement (joint structure and function, muscle mechanics, and neuromuscular function), (f) mechanical bases of human movement (basic considerations, movement kinematics, movement kinetics), and (g) motor skills: principles and applications. A section was provided in the instrument during the pilot study for expert reviewers to evaluate each competency for content validity and clarity, as well as the total instrument for completeness.

Judgment quantification. The second stage of the pilot study, judgment quantification, is the systematic process of selecting, informing, and using experts to evaluate the content validity and completeness of the survey items and instrument (Lynn, 1986). The survey instrument was pilot tested on nine participants who were randomly selected from the pool of potential Delphi panel members. The nine panel experts were representative of the three subgroups serving in the actual Delphi study which included: three biomechanics specialists, three physical education teacher educators; and three K-12 physical education teachers. Participants were invited to participate through a letter of introduction sent through email highlighting the significance of the pilot study, the nature of their role, criteria for evaluating survey items and instrument, and the approximate time requirements (see Appendix B). The panel selection process was completed once nine participants, three from each subgroup, agreed to serve as expert reviewers in the pilot study. These participants were excluded from participation in the actual Delphi study that followed.

A draft of the survey items was pilot-tested using the group of panel members who agreed to participate in the pilot study. Each panel member was asked to (a) evaluate the initial 108 survey items for content validity and completeness, and (b) examine the feasibility of online 
survey instrument. The initial 108 biomechanics competencies were rated using a five-point Likert scale using the following criteria: (5 or 4) - item is a valid theoretical or applied biomechanics competency that could potentially be incorporated within the PETE curriculum, (3) - neutral or undecided, (2 or 1) - item lacks theoretical or applied content validity and should be deleted from the survey because it lacks curricular importance. As part of the review process, participants were asked to suggest revisions for competencies that were not an adequate representation of the content or were unclear. In judging the completeness of the instrument, participants were asked to evaluate whether the entire set of competencies sufficiently represents the available body of knowledge in the area of biomechanics.

The data collected during the pilot study were summarized and used to formulate a list of biomechanics competencies that was employed during the modified Delphi study. Each survey item had to receive a mean rating of at 3 or higher in the area of content validity by at least seven of the nine reviewers in order remain on the survey for the modified Delphi study.

\section{Delphi Administrative Procedures}

The administration procedures described in this section have been adapted from the generalized research protocol described by Bulger and Housner (2007). These administrative procedures are described in the following sections (a) Selection of Participants, (b) Round I Procedures, and (c) Round II Procedures.

Selection of participants. The previously described steps in selecting and recruiting potential Delphi participants were applied prior to the first round of the Delphi investigation. The initial list of potential Delphi panel members included 51 biomechanics specialists, 44 teacher educators, and 72 physical education teachers. The selection of potential biomechanics specialists serving as panel members was conducted through a three round nomination process. 
The initial list of potential biomechanics panel members consisted of three committee members of the Biomechanics Research Academy Committee of NASPE, and 10 Ruth B. Glassow Biomechanics Award recipients. During the first round of nominations, an email was sent to the initially identified list of 13 potential panel members describing the purpose of the study and biomechanics expertise criteria. Each individual was asked to nominate three other potential biomechanics specialists based on the previous outlined expertise requirements. After three iterations of nominations the pool of biomechanics specialists was developed.

Physical education teacher educators serving as potential Delphi panel members were selected from a list of members of the Curriculum and Instruction Academy of the National Association for Sport and Physical Education. These members have been recognized for their significant scholarly contributions to curriculum and instruction in the study of and/or application of the art and science of human movement and physical activity.

Physical education teachers serving as potential Delphi panel members were selected from a list of physical education teachers of the year award candidates through the National Association for Sport and Physical Education district teacher of the year program. Qualified physical education teacher candidates were required to (a) hold a current American Alliance for Health, Physical Education, Recreation and Dance membership, and (b) currently teach physical education in a K-12 setting, as well as hold a valid teaching certification at the time of selection.

A total of eight participants from each subgroup were randomly selected and invited to participate as panel members. Four biomechanists, three teacher educators, and four physical education teachers turned down requests to participate. Upon each refusal, another name was randomly selected until the 8 panel members within each subgroup agreed to participate. As a predetermined mortality standard (Bulger \& Housner, 2007), it was decided that the results of the 
study would be considered compromised if 20 percent or more of participants returning round one surveys did not complete the second round. Twenty-two out of the 24 panel members completed both rounds of the survey circulation; therefore, participant attrition was not a negative factor in the study.

Round I procedures. During round I, panel members rated a series of biomechanics competencies in terms of their theoretical importance and pedagogical relevance for prospective physical education teachers. Participants were sent an email containing (a) a summary of instructions, (b) an e-mail attachment containing a description of the Delphi process, and (c) instructions on accessing the online survey (see Appendix C). Panel members serving as teacher educators and physical education teachers also received an email attachment of biomechanics terms and definitions for added clarity on survey terminology specific to the field of biomechanics. Upon entering the survey web page, participants received an introduction to survey objectives, instructions for completing survey, and a specific date and time for survey completion. Due to the extensive list of survey items to be evaluated, panel members were given three weeks to complete the first round of the survey. Within two weeks after the administration of the online survey, Delphi panel members who had not completed the survey received a telephone call to confirm the receipt of the email, answer any remaining questions, and prompt the timely completion of the survey. As a contingency plan for non-respondents, participants failing to complete the survey within the three week time allotment were (a) sent a friendly email reminder requesting the completion of the survey, (b) allocated a five-day extension as a means of securing the highest possible return rate, and (c) telephoned to reiterate the value of their contribution to the study. Following the completion of all first round survey questionnaires, 
participants' responses were recorded in a Microsoft Office Excel database, and the mean group rating was calculated for each item.

Round II procedures. The purpose of the second round of questioning was (a) to provide participants with feedback in the form of individual and group mean ratings for each survey item based on the first round of questioning, and (b) have each participant re-evaluate and rate each survey item a second time in light of the overall group statistical average. The administration procedures for the return of the surveys, data recording, and provisions for feedback followed the same protocol as in the first round. The addition of an open-ended question was added to the end of the second round survey requiring panel members to identify three possible learning environments and instructional methods for those learning environments for delivering core biomechanics content to prospective physical educators within the undergraduate PETE curriculum. All panel members were provided with reference material (see Appendix D) clearly defining learning environments and instructional methods to ensure the meaning of the terminology was clear among all Delphi panelists. A final research report was sent to each Delphi panel member following the completion of data analysis.

\section{Data Analysis}

The modified Delphi method was the research technique of choice for generating a list of critical theoretical and applied competencies in biomechanics these expert panel members judged as important and pedagogically relevant for prospective physical education teachers.

Additionally, expert panel members were asked to identify learning environments and associated instructional methods for delivering critical biomechanics content to prospective physical education teachers in the undergraduate PETE curriculum. 
Critical biomechanics competencies. The data collected during the second round of the Delphi investigation were entered, analyzed and evaluated using SurveyMonkey, a web-based survey instrument. These data were recorded in a Microsoft Office Excel data base and the mean group rating was calculated for each item. The results of these data from the second round of questioning were used to derive consensus from the panel members regarding what biomechanics competencies were critical. For this study, an item needed to be rated both theoretically important and pedagogically relevant in the second round of the study in order to be considered an essential competency for the PETE undergraduate curriculum. In light of previous recommendations (Bulger \& Housner, 2007; Jacobs, 1996), in order to achieve consensus, each survey item had to receive a mean rating of at least 4 or higher in the areas of importance and relevance by $75 \%$ of panel members. Any item failing to meet this criterion was not considered a critical biomechanical competency for inclusion within the undergraduate PETE curriculum.

The guidelines and standards for teaching undergraduate biomechanics were originally developed by a task force of biomechanics experts who also obtained feedback from the Alliance for Health, Physical Education, Recreation and Dance (NASPE, 1980), and there have only been minor revisions over the years. An evaluation of the final competencies derived from expert consensus across the subgroups may actually validate the current standards and guidelines for teaching undergraduate biomechanics or reveal discrepancies in views within each expert panel group. The results of these data were also compared with the undergraduate biomechanics guidelines and standards endorsed by NASPE $(1980,2003)$.

Delivery of biomechanics content. The second round survey of this study contained an open-ended question at the end of the survey asking panel members to recommend up to three learning environments and instructional methods for those learning environments for delivering 
core biomechanics content to physical educators within the undergraduate PETE curriculum. For the purpose of this study, learning environment was operationally defined as the specific context in which core biomechanics content is integrated within the PETE curriculum, such as activitybased courses, adapted physical education courses, basic instruction courses, clinical experiences, after-school physical activity programming, and so forth. Instructional methods were operationally defined as the methods used or "how to" approach in helping prospective physical educators understand and be able to apply core biomechanics content in the targeted learning environment. Delphi panel member responses were categorized in accordance with a theoretical instructional model adapted from Saskatchewan Education (1991) which categorizes a particular instructional method according the level of cognitive, social, and affective engagement of the learner. The framework was intended to provide a pre-established categorization system in structuring panel members' responses and unifying instructional terminology variables among all Delphi panelists.

\section{Results}

Feedback obtained from the pilot phase resulted in a total of 107 out of 108 survey items meeting the pre-established criteria and included on the final version of the survey questionnaire. Changes in wording of five competencies were also made based on the piloting feedback and no additional competencies were added by panelists. The final survey instrument included a comprehensive list of 107 theoretical and applied biomechanics competencies that were judged by Delphi panel members for possible inclusion in the undergraduate PETE curriculum.

The results of the second round of the modified Delphi study reflected expert panel member consensus regarding the competencies that should be kept. Following the completion of the second and final round, expert panel member consensus determined 41 out of the original 
107 competencies were critically important and pedagogically relevant in preparing prospective physical education teachers. The findings from the study resulted in establishment of the following six essential content areas: (a) Application of Biomechanics to Human Movement, (b) Qualitative Analysis of Movement, (c) Quantitative Analysis of Movement, (d) Anatomical Bases, (e) Mechanical Bases, and (f) Motor Skill Principles and Applications. The Delphi panel members did not reach a consensus of agreement on the four competencies related to the content area Introduction to Biomechanics. Although two of the introductory competencies relating to defining biomechanics terms (e.g. statics, dynamics, kinetics) and differentiating between qualitative and qualitative movement analysis approaches satisfied the criteria for theoretical importance, they were not considered highly pedagogically relevant for those preparing to teach in the physical education setting. Thus, the consensus derived content areas and associated competencies as presented in Tables 1 and 2 will be the focus of discussion in the subsequent section.

\section{Critical Biomechanics Competencies}

Application of biomechanics to human movement. The Delphi panel members reached a consensus of agreement regarding all four applied biomechanics to human movement competencies. The response group means for these competencies ranged from 4.59 to 4.77 for theoretical importance and from 4.45 to 4.68 for pedagogical relevance (see Table 4). The percentage of panel members who rated those competencies as being of essential importance and relevance ranged from $91-100 \%$. The four applied competencies considered to be valuable in preparing physical educators were considered general-based competencies associated with systematically analyzing movement through qualitative and/or quantitative techniques. These

critical competencies included applied knowledge of (a) movement observation, (b) analysis of 
anatomical and mechanical movement factors, (c) evaluation of performance technique, and (d) correcting performance errors for the purpose of improving skill performance.

Qualitative analysis of movement. As revealed in Table 2, the Delphi panel members reached group consensus regarding 10 of the 15 qualitative analysis of movement competencies. The competency group means for this category ranged from 4.00 to 4.55 for theoretical importance and from 4.00 to 4.50 for pedagogical relevance (see Table 4). The percentage of panel members who rated the competencies as being of essential importance and relevance ranged from $82-100 \%$. The findings indicate that prospective physical educators need the knowledge, skills, and abilities to: (a) plan for analyzing movement qualitatively, (b) identify the key elements of an observational strategy, (c) evaluate and diagnose movement performance qualitatively, and (d) identify the most appropriate strategy for improving skill performance (e.g., feedback, task modification, mechanical guidance).

This issue of defining a qualitative analysis strategy for physical educators is also addressed within a number of the selected biomechanics competencies. Physical educators need the ability to (a) identify critical features of various motor skills, (b) integrate qualitative analysis with planning and teaching, (c) evaluate strengths and weaknesses of skill performance, and (d) use appropriate cue words and phrases for improving performance. Additionally, physical educators need the ability to prescribe appropriate task modifications and feedback strategies based on the ability of the performer.

A number of competencies that were considered non-critical pertained to the role of the senses and perception during movement observation, research guidelines for augmented feedback, as well as identifying the functions of feedback. Although these competencies are 
associated with qualitative analysis, one panel member suggested they may be more aligned with motor learning coursework.

Quantitative analysis of movement. The Delphi panel members reached group consensus regarding one of the 11 quantitative analysis of movement competencies (see Table 2). Response means for this competency were 4.41 for theoretical importance and 4.41 to for pedagogical relevance (see Table 4). The percentage of panel members who rated the competency as being of essential importance and relevance was 100\%. The Delphi panel members confirmed that quantitative analysis techniques should be employed to develop physical educators’ ability to think critically about strategies for movement performance problems. Interpreting data and graphs, as well as solving quantitative problems involving vector quantities, angular qualities, kinetic concepts, and static equilibrium were not considered pedagogically relevant for physical educators.

Anatomical bases. A consensus of agreement was reached among Delphi panel members regarding 9 of the 22 anatomical bases competencies (see Table 2). The group means for anatomical competencies ranged from 4.27 to 4.64 for importance and from 4.00 to 4.55 for relevance (see Table 4). The percentage of panel members who rated those competencies as being of essential importance and relevance ranged from 86-100\%. From a theoretical standpoint, physical educators need to comprehend the structure and function of joints (e.g., actions, range of motion, stability) and the types of muscular contractions occurring in any given joint action. Perhaps most notable, physical educators should have the knowledge and skills to observe a joint's range of motion, assess flexibility, and prescribe safe and effective stretches using knowledge of joint structure and function. The competencies relating to neuromuscular function did not meet the criteria for consensus and are probably more applicable to 
professionals seeking careers in physical therapy, occupational therapy, athletic training, and corporate fitness programming.

Mechanical bases. The Delphi panel members reached group consensus regarding seven of the 17 mechanical bases competencies (see Table 2). The group means for mechanical bases competencies ranged from 4.09 to 4.50 for theoretical importance and from 4.00 to 4.45 for pedagogical relevance (see Table 4). The percentage of panel members who rated those competencies as being of essential importance and relevance ranged from $77-100 \%$. The critical competencies reveal physical educators need a more complete understanding of the external and internal forces that affect goal oriented movement and apply selected principles of mechanics (e.g., law of inertia, law of acceleration, law of action-reaction) to improve performance, reduce injury, evaluate movement efficiency, and select proper equipment. Additionally, physical educators should be able to apply variables of angles, release height, and velocity to projectile activity and to enhance skill performance. A number of competencies relating to using kinematic variables (e.g., speed, velocity, acceleration) in analyzing movement performance, and defining basic kinetic terminology (e.g., force, torque, moment of inertia, radius) were considered important knowledge for physical educators, but lacked pedagogical relevance.

Motor skill principles and applications. As indicated in Table 2, the Delphi panel members reached group consensus regarding 10 of the 34 motor skill principles and applications competencies. These competencies’ group means ranged from 4.00 to 4.36 for theoretical importance and from 4.00 to 4.41 for pedagogical relevance (see Table 4). The percentage of panel members who rated those competencies as being of essential importance and relevance ranged from $82-100 \%$. Several competencies specifically relating to understanding applying concepts and principles of biomechanics were rated critical by Delphi panelists. 
In summary, physical educators should understand the anatomical and mechanical factors associated with performing selected object control skills (e.g., throwing, striking, kicking) and locomotor skills, and apply this knowledge through qualitative analysis techniques. Additionally, physical educators should comprehend how basic principles (e.g., gravity, angular momentum, angle of projection) influence the flight path of bodies unsupported. A number of competencies relating to applying anatomical and mechanical factors to standing posture, pushing and pulling movement, aquatics, receiving impact were not considered to be critical for those preparing to teach physical education in school-based settings.

\section{Comparative Analysis}

Within this study, 33 competencies derived from the both the 1980 and 2003 versions of the Undergraduate Guidelines and Standards (NASPE, 1980, 2003) were included on the survey questionnaire. Panel members rated 16 (48\%) of the 33 biomechanical competencies endorsed by NASPE as being critical in preparing prospective physical educators at the conclusion of the second Delphi round.

\section{Content Delivery}

During the second round of the modified Delphi study, panelists were asked to recommend three learning environments and instructional methods specific to those learning environments for delivering core biomechanics content to prospective physical education teachers. The expert panel members recommended a total of 38 instructional methods and a variety of learning environments for delivering content within the PETE curriculum. Panel members' responses were categorized according to a theoretical instruction model adapted from Saskatchewan Education (1991). Two additional categories titled Multimodel Instruction and Alternative Curriculum Models were added based on the responses provided by panel members. 
These recommendations were divided into the following categories: (a) Direct Instruction, (b) Indirect Instruction, (c) Interactive Instruction, (d) Experiential Learning, and (e) Independent Learning, (f) Multimodal Instruction, and (g) Alternative Curriculum Models.

Direct instruction. Direct instruction is widely recognized as a highly teacher-directed method of instruction that has received substantial support in literature (Brophy \& Good, 1986; Housner, 1990; Rosenshine \& Stevens, 1986). The process for direct instruction is typically characterized by a sequence of several teaching functions, such as: (a) communicating clear lesson objectives, (b) providing clear explanations, demonstrations or visual representations of new concepts or skills, (c) providing a progression of teacher-structured practice activities, (d) questioning to check for student understanding, (e) delivering performance enhancing feedback, and (e) providing students with well-supervised guided practice opportunities. Specific examples of direct instructional methods include structured overviews, drill and practice, demonstration lecture, didactic questioning, and mastery lecture.

Despite the popularity of direct instructional methods, only one Delphi panel member offered a suggestion concerning the sole use of direct instruction for delivering biomechanics content within the PETE curriculum. This recommendation represents only 2.70\% (1 of 38) of the total responses. Although the panel member did not provide any specific biomechanics content suggestions, the member recommended using a demonstration lecture in combination with didactic questioning in a gymnasium setting. It should be acknowledge that the use direct instructional methods followed by more student-centered methods (e.g., peer teaching, video analysis, problem-based learning) was supported by a number of Delphi panelists and is further described as Multimodal Instruction. 
Indirect instruction. Indirect instruction is commonly referred to as a learner-centered instructional approach in which the process of learning is equally important as the product of learning. Paris and Combs (2000) propose the following five distinguishing features that highlight the teachers role in learner-centered instructional environments: (a) the teacher is focused on the individual needs, thought and feelings of the individual learners, (b) the teacher actively engages students in the learning process, (c) the teacher is a guide as opposed to a director, (d) the teacher facilitates student learning through interactive decision making, and (f) the teacher is a reflective decision maker. Examples of indirect instructional methods include a range of activities, such as case studies, concept mapping, reflective discussion, reflective writing, and problem solving.

The use of indirect instructional methods was supported by 21.05\% (8 of 38) of the total responses. Recommended instructional methods in this category included the use of case studies, guided discovery, problem solving scenarios, and reflective writing in the form of lesson planning. Panel members suggested four learning environments when using indirect instructional methods, which included elementary and secondary field experiences, biomechanics class, teaching activity-based courses, a separate analysis of human motion class, and the gymnasium.

Interactive instruction. Interactive instruction was operationally defined as an instructional strategy that actively engaging learners in the content through discussion, sharing, or interacting among participants (e.g., teacher-learner, learner-learner) in a range of groupings, such as whole class, small groups, and partners. Interactive instruction is predominately differentiated by indirect instruction in that more focus is placed on the process of learning the content in the context of a highly interactive higher education learning environment. In this study, 28.94\% (11 of 38) of the recommended instructional methods related to interactive 
instruction. A total of seven panel members recommended instructional methods associated with various forms of peer practice, including peer observation, systematic observation of peerteaching behaviors, and peer teaching. The responses provided by panelists reflected strong agreement that activity-based PETE courses should serve as a learning environment in which prospective physical educators: (a) observe peers performing various movement skills, (b) identify critical features of observed skills, and (c) determine critical features (strengths and weaknesses) of the observed skills that need to be corrected to improve performance or reduce the risk of injury. The responses provided by teacher educators and practicing physical education teachers also expressed the importance of giving feedback to peers in correcting movement errors. Other proposed learning environments included a secondary teaching methods course, motor development course, and laboratory-related settings. The use of video technology for a range of purposes, such recording peers performing skills, and systematically analyzing movement technique of peers, was as a common learning medium across all contexts advocated by six panel members.

Experiential learning. Bulger and Housner (2007) define experiential learning in terms of the type of experience, including internships, clinical observations, field trips, and teaching practicum. Experiential learning can also be viewed as an activity-oriented, highly studentcentered approach with emphasis placed on the learning process, rather than the final outcome (Saskatchewan Education, 1991). Although there are many ways to conceptualize experiential learning, the role of the instructor is typically placed on organizing a particular set of learning experiences in an alternative or authentic context that is conducive towards meeting particular educational goals. 
In this study 23.68\% (9 of 38) of the recommended instructional methods related to the use of experiential learning for delivering biomechanics content to prospective physical educators. Panel members recommended providing prospective physical educators with learning opportunities in authentic P-12 physical education settings, as well as after-school sport and physical activity-related contexts. The responses provided by panelists suggest experiential learning goals for prospective physical educators should evolve around: (a) observing and recording the type of teacher feedback given to young children to improve movement, (b) teaching and analyzing the movement technique of children in physical education class, (c) teaching high school students how to assess their own performance, and (d) qualitatively analyzing selected movement skills.

Independent study. Independent study was operationally defined by the researcher as the planned learning by a student, partnership, or small group of students under the guidance of the course instructor. Specific examples of independent study activities include journal writing, learning logs, portfolio development, term papers, and research projects. Despite the proposed role of independent study in developing self-directed learners (Grow, 1991), panel members did not provide any recommendations regarding this teaching-learning approach. Perhaps independent learning strategies are better suited for graduate level courses due to the theoretical and scientific nature of biomechanics content.

Multi-modal instruction. Multi-modal instruction was operationally defined by the researcher as a teaching-learning approach in which more than one instructional method is employed within a single instructional episode. The responses provided by the panelists reinforced the notion that teaching prospective physical educators typically involves incorporating more than one method in helping students understand and be capable of applying 
biomechanical concepts and principles. Of the total responses, 18.42\% (7 of 38) promoted the use of a multimodal form of instruction in a range of learning environments, such as a biomechanics course, activity-based course, and a separate movement analysis course. All seven panelists recommended employing direct instructional methods (e.g., mastery lecture, demonstration, structured overview) to cover or illustrate biomechanical concepts and principles. Following direct instruction, a myriad of instructional approaches were recommended to actively engage students in content, including laboratory-based learning, peer teaching, and field experience. More specifically, one panelist recommended prospective physical educators learn about biomechanical concepts through direct instructional methods, such as lecture, and subsequently provide "hands-on experiences" to illustrate the important concepts "with many different sports and every-day activities.”

Alternative curriculum models. Two Delphi panel members offered suggestions concerning the use of alternative curriculum models for delivering biomechanics content within the PETE curriculum. The recommendations for curriculum revision represented 5.26\% (2 of 38) of the total responses. These panel members recommended integrating biomechanics content into specific courses within the PETE curriculum to help prospective physical educators "realize the interdisciplinary nature of understanding and improving movement” and apply biomechanics content after graduation.

\section{Discussion}

This research project was designed to assist PETE faculty in identifying the most important and relevant biomechanical content in preparing prospective physical education teachers. This study was also intended to inform the PETE curriculum development process by demonstrating how PETE programs can effectively integrate core biomechanical knowledge 
within the undergraduate curriculum, and design learning experiences that complement the professional role of physical education graduates. The results of this study represent the collective agreement and recommendations of a group of 22 experts comprised of biomechanists, teacher educators, and K-12 physical education teachers.

\section{Biomechanical Content in Physical Education Teacher Education}

The content identified and ideas expressed in this Delphi study represent an important link between the biomechanics body of knowledge and physical education teachers' role in promoting skillful movement, physical activity, and fitness among youth in the school setting. The initial list of 107 potentially significant competencies in biomechanics was reduced to a final list of 41 items. The final list of biomechanics competencies as presented in Table 1 and Table 2 can be used to (a) inform expectations for student learning and performance, (b) provide a better understanding of appropriate instructional approaches, (c) guide appropriate assessment, (d) inform the PETE curriculum development process, and (e) inform in-service teacher training efforts.

Applied content. The National Association for Sport and Physical Education (NASPE, 2003) endorsed a set of guidelines and standards in the form of competencies for instructors charged with teaching an undergraduate biomechanics course. Given the goals and needs of a variety of a kinesiology majors served in introductory courses, only four general-based applied competencies titled Application to Human Movement, serve to guide what preservice professionals should be able to do as a result of undergraduate biomechanics coursework (see Table 1). These four applied competencies are relative to observing, analyzing, and evaluating human movement qualitatively and/or quantitatively across a diverse range of contexts and individuals. The applied competencies are proposed to contribute to practitioners who are 
preparing to work in a range of environments, such as athletic, clinical, educational, and other work-related settings (NASPE, 2003). It is reasonable to suggest that the applied biomechanics competencies are viewed as important long-term goals necessary for facilitating skillful movement in professional practice.

The findings from this study reflect the importance of providing physical educators with learning experiences that will enable them to achieve the long-term goal of applying biomechanics general-based competencies. However, the applied competencies proposed by NASPE (2003) provide insufficient direction for course instructors and PETE curriculum planning faculty charged with selecting appropriate content and learning experiences that will enable physical education graduates to meet these judicious goals. Rink (2007) pointed out that athletic trainers may need a stronger focus on quantitative analytic approaches to movement analysis, whereas, physical educators need more time "practicing and observing movement, and applying mechanical principles to real world settings” (p. 106). Students preparing to teach physical education also need a stronger emphasis on qualitative movement applications across developmental levels, fitness levels, and body types. These issues of practical application are not typically addressed in introductory biomechanics courses which tend to place emphasis on the most efficient and skillful execution of movement using an adult error correction model.

Theoretical and scientific prerequisite content. Given the general nature of the “applied “competencies endorsed by NASPE (2003), expert panelists evaluated competencies derived from the biomechanics guidelines and standards and textbook sources that could be used as building blocks en route to achieving long-term goals for physical educators. For example, panel members examined more specifically what prerequisite content (e.g., anatomical factors, mechanical factors, motor skills relations) and applications (qualitative and/or quantitative) 
would enable physical educators to achieve the long-term goal of systematically analyzing and evaluating the movement responses of school-age youth in the dynamics of the gymnasium. Consensus generated among panelists clarified specific biomechanical competencies or a collection of cognitive prerequisites that may serve to guide prospective physical educators in the process of developing the analytical competence needed to correct movement problems and reduce the risk of injury. The findings revealed that prospective physical educator's knowledge of a number of specific biomechanics competencies relative to joint structure and function, linear and angular motion, Newton's laws of motion and gravitation in relation to motor skills were found to be essential prerequisites for diagnosing and solving movement problems in the K-12 school setting. The knowledge and skills described in Table 2 demonstrate the biomechanical content and competencies that potentially contribute to the process of teaching K-12 physical education and achieving long-term goals. Although the argument can made regarding the importance of covering a broader range of biomechanics content, the value of critical biomechanics content may lost if they are not linked to the educational and practical needs of physical educators within the PETE curriculum.

An interesting finding was the difference in views between teacher educators and the other two Delphi subgroups (practicing physical education teachers and biomechanics specialists) concerning the importance of defining and describing basic anatomical and mechanical movement terminology. For example, both K-12 physical educators and biomechanics specialists viewed theoretical knowledge related to describing joint actions and planes of movement, as well as defining basic kinematic terms (e.g., distance, displacement, velocity) as important in preparing physical educators; whereas, teacher educators collectively viewed the knowledge as non-critical. The differences in views may be based on the notion 
teacher educators did not view knowledge of defining movement through linear and angular measurements as making a powerful contribution in the process of teaching school-age youth. Conversely, all three Delphi subgroups judged a foundation of factual knowledge and conceptual understanding of kinetics as "usable” knowledge in order to teach effectively. These findings suggest the concepts related to the forces associated with motion are the kinds of theoretical knowledge important for teaching physical education, whereas, information concerning the time it takes to carry out an activity contributes to a lesser degree to the process of teaching.

The beginning PETE teacher preparation standards (NASPE, 2008) clearly articulate physical education graduates should be capable of analyzing and correcting "critical elements of motor skills and performance concepts.” Nationally accredited physical education teacher training institutions, or those seeking accreditation, are charged with providing evidence on how teacher candidates meet this judicious goal. However, there has been a remarkable decline in research and discussion among the biomechanical and pedagogical community over the past 20 years regarding viable teacher training strategies for developing of skill analysis competence among prospective physical educators. The stagnant stage of development is unfortunate considering teaching skillful movement is one of the most important professional responsibilities of a physical educator. It should not be assumed physical education graduates will naturally develop the ability to analyze and correct movement without sufficient teacher training. Concerns about insufficient teacher preparation in the area of skill analysis has sparked more recent calls for a renewed commitment for PETE programs to systematically address qualitative analysis in the curriculum (Loundsbery \& Coker, 2008; Reeve, 2000).

Of equal importance is the alignment of movement analytic methods with the demands faced by K-12 practitioners. The results of this study support previous literature (Hoffman, 1977; 
Knudson \& Morrison, 2002) with expert consensus determining physical educators should be predominately exposed to qualitative approaches when analyzing movement. Although qualitative analysis of movement is most strongly associated with the biomechanics content, it is truly interdisciplinary in nature. Collectively, the kinesiology subdisciplines of motor development, motor learning, biomechanics and pedagogy all play an important role in teaching different facets of qualitative analysis throughout the PETE curriculum. However, delivering the content in parts through different courses, rather than as a conceptual whole, may have resulted in fragmentation of this very important professional skill. The issue regarding the application of theory to practice appears to be perpetuated when different course instructors emphasize and expose physical educators to particular aspects of qualitative analysis relative to their discipline. For example, observation models (Seefeldt \& Haubenstricker, 1982; Roberton, \& Halverson, 1984) for analyzing motor skills are typically addressed in motor development courses; observation strategies for physical educators (Barrett, 1983; Hoffman, 1983) and ecological task analysis approaches (Balan \& Davis, 1993) for analyzing movement are associated with pedagogy-based coursework; feedback strategies for correcting movement are typically emphasized in of motor learning coursework (Magill, 1994, 2007); whereas, coursework in biomechanics may expose physical educators to a qualitative analysis approach that is more strongly associated with their discipline (Hay \& Reed, 1988; Hudson, 1995; McPherson, 1990). The theory to practice application problem of qualitative movement analysis appears to be further aggravated when prospective physical educators are exposed to different movement terminology across subdisciplinary course work. Additionally, there appears to be a lack of consensus concerning what qualitative analysis of movement means for physical education 
teachers substantiating the need for a developing unified definition and language system for preparing future educators.

Although each subdiscipline provides a unique perspective in understanding and analyzing movement qualitatively, the present findings reinforce the importance of providing teaching-learning experiences that allow prospective physical educators to apply qualitative analysis holistically (e.g., plan, observe, diagnose, intervene). The competencies judged as essential knowledge by expert panelists in this study represent an important initial attempt to define distinguishing features of a systematic approach for qualitatively analyzing movement that is strongly grounded in pedagogical theory. The responses provided by panelists revealed a distinct set of qualitative analysis of movement competencies based primarily on a model proposed by Knudson and Morrison (2002) that could potentially serve as a unified interdisciplinary qualitative analysis framework and language system for adoption by PETE programs. As revealed in Table 2, the 10 critical qualitative analysis competencies could be used in the development of a movement analysis course or be integrated into existing courses within the PETE curriculum. One panel member recommended having prospective physical educators take a separate Analysis of Human Motion Course in addition to an introductory biomechanics course.

Although qualitative analysis of movement has been widely advocated by the pedagogical community, the results of this study also support quantitative analysis applications in teacher preparation. For example, one panel member recommended using video technologies to compare and contrast the movement technique of two subjects of different developmental levels or body types performing the same skill. The overall findings reveal that analyzing movement quantitatively contributes to the prospective teachers' understanding about 
movement, or more specifically, what performers are doing in the movement environment. The advent of new human movement technologies, such Dartfish and Siliconcoach, appear be a promising interactive teaching-learning tool for helping future teachers understand what biomechanical concepts and principles are involved in improving movement performance through visual representations. Digital videography could be employed to provide opportunities for prospective physical educators to analyze both technical and tactical aspects of movement in a variety of sport and physical activity settings. More specifically, PETE programs could potentially incorporate digital videography into activity-based courses to provide prospective physical educators with the opportunity to qualitatively and quantitatively analyze particular strengths and weaknesses in their own performance, as well as that of peers.

In reality, preparing physical education graduates capable of promoting motor skill competence in the K-12 setting should not solely reside in an introductory biomechanics course. Given the increased importance of crossing subdisciplinary boundaries and exploring possible connections, prospective physical educators need to practice analyzing movement qualitatively and quantitatively across multiple learning environments during their entire undergraduate experience. Solving movement problems requires an extensive knowledge base concerning a wide repertoire of movement actions related to fundamental motor skills, sport-specific skills and exercise. In the context of physical education, students perform numerous movement responses (e.g., running, jumping, catching, throwing, dribbling, defending, striking) in a variety of movement patterns during a typical lesson. The analysis of motor skills becomes more complex during game situations where skill performance is influenced by changing environmental conditions. The ability to assess and provide the most appropriate intervention for so many skills, performed under so many changing conditions poses numerous challenges for physical education 
graduates. Accordingly, one panel member suggested "biomechanical content will be more valuable and recognized by physical educators before and after graduation" when the content is integrated throughout the PETE curriculum. However, total knowledge integration would require all parties involved in preparing physical educators to work in partnership in developing stronger models of teacher preparation that reinforce what physical educators should actually do in promoting skillful movement, physical activity and fitness among school age youth.

\section{Delivery of Biomechanics Content in Physical Education Teacher Education}

While many critiques have highlighted the fragmentation of professional preparation programs (Howey \& Zimpher, 1989; Zeichner \& Gore, 1990), there appears to be a clear need to design PETE programs that delineate learning environments and teaching methodologies based on promising assumptions about how practicing physical educators' best learn important subject matter. PETE scholars have argued for incorporating subdisciplinary knowledge and pedagogical knowledge within a variety of highly distinct learning environments (Wiegand, Bulger, \& Mohr, 2004). Additionally, findings from a large scale undergraduate teaching study conducted by Astin (1993) indicate the course instructor's delivery approach in the curriculum is actually more important than the content in terms of student learning. It is reasonable suggest the PETE curriculum will reap additionally benefits when relevant subdisciplinary content is linked with features of the delivery system.

Although there is no single effective approach to instruction, expert recommendations in this study reflects possible best ways to teach particular biomechanics content to prospective physical education teachers. The ideas reflect the notion that if critical biomechanics content is taught using specific instructional methods in particular settings, practicing physical educators will be better prepared to utilize that knowledge upon graduation. The results demonstrate that 
improved student learning of biomechanical content should involve (a) sequencing essential knowledge through curricular stranding, and (b) employing pedagogies that promote active student engagement in a variety of PETE learning environments.

Curricular stranding. Scholars have argued for an infusion strategy whereby biomechanical content is systematically infused throughout the entire undergraduate PETE curriculum (Lounsbery \& Coker, 2008; Morrison \& Harrison, 1997). To move beyond the fragmented treatment of essential knowledge, the results from this study provide insight into content areas, central themes or strands that could potentially be infused into distinct PETE curricular learning environments (see Tables 1 and 2). Curriculum stranding is the term metaphorically used to describe the infusion of critical knowledge and skills that are "typically introduced within the foundational semesters and systematically revisited in wide variety of instructional contexts” (Bulger, Mohr, Carson, \& Wiegand, 2001, p. 404). Two expert Delphi panelists suggested that infusing critical themes or perspectives in a wide variety of instructional contexts would optimize student learning of core biomechanical content. Although taking a stand alone biomechanics course was recommended by a number of panelists, it was also suggested that infusing specific content in other PETE settings would help prospective physical educators understand the interdisciplinary nature of improving movement.

The infusion of curriculum strands is supported by the results of this present study in which experts recommended integrating core biomechanical knowledge into specific learning contexts, such as activity-based courses, a motor development course, field experiences, an adapted physical education course, and a secondary methods course within the PETE curriculum. The responses provided by panel members demonstrate how core biomechanical knowledge can be systematically woven throughout the entire learning experience of prospective physical 
educators in their coursework and field experiences. The subsequent section provides further insight into how and where critical biomechanical subject matter can be stranded within the PETE curriculum.

Pedagogies of engagement. Research on teacher effectiveness has demonstrated that actively engaging students in appropriate content is a fundamental principle of effective instructional practice (Gage \& Berlinger, 1992; Walls \& Cather, 1987). The term "pedagogies of engagement” is used in this study to refer to engaging teaching-learning modes that enable prospective physical educators to acquire the knowledge, skills and dispositions to respond effectively as a novice professional educator. The notion of "engagement" does not imply one instructional method is more effective than another method. Pedagogies promoting engagement can occur in the classroom through direct instructional methods (e.g., drill and practice, didactic questioning, guided thinking), interactive instruction (e.g., peer practice, cooperative learning groups, role playing) or experiential learning opportunities in the K-12 school setting. The findings from this study revealed five promising pedagogies that can be used to help prospective physical educators make explicit connections between critical biomechanical knowledge and best practices in teaching physical education. These promising pedagogies include: (a) lecture with student centered activities, (b) video-based instruction, (c) problem-based learning, and (d) peer practice, and (e) experiential learning opportunities.

Lecture with student centered activities. Establishing a sequence of learning tasks from teacher-directed to more student-centered approaches was favored by a number of panel members. Lecture-based means of instruction were found appropriate for introducing prospective physical educators to, or illustrating the importance of, biomechanical concepts and principles in a biomechanics class or a course designed around the process of movement analysis. 
Subsequently, practicing teachers should apply these essential understanding in the context of biomechanics laboratory, activity-based course, or K-12 school setting. This sequence of instructional tasks in an undergraduate biomechanics course instructional episode may consist of a short lecture, question/answer session followed by an application task. The application task should allow the course instructor to measure student learning toward the desired learning competencies. For example, students may watch a video segment of a young performer dribbling a soccer ball and document the strengths and weaknesses in performance using biomechanical principles. The student finding should elucidate important information about the performer's movement behavior, such as sequence and timing a body segments, balance, force, and range of motion. While students are engaged in the application task, the instructor acts as a facilitator by observing, questioning, clarifying, redirecting, and providing feedback on students progress. Perhaps of upmost importance, the application task should: (a) have clear learning outcomes that are understood by all students, (b) incorporate accountability measures on student performance, and (c) connect students with appropriate biomechanical concepts and principles physical education graduates will use in teaching school-based motor skills, fitness and physical activities.

A second critical instructional sequence in enriching prospective physical educators understanding of movement concepts and principles is a dramatic change from traditional PETE models. The results of this study reflect the need to employ direct instructional methods to uncover the practical significance of biomechanical concepts, and subsequently provide opportunities for students to apply this information during field experiences or in activity-based courses. Although designing such teaching-learning experiences would pose numerous challenges, a tight coherence between course work and practical experience would help practicing teachers connect principles of biomechanics with principles of teaching. Creating such 
a coherent teaching-learning experience would require PETE faculty to work in partnership with biomechanics course instructors, public schools, and alterative sport and physical activity-related settings. A promising strategy for achieving this vision is an innovated model of instruction described in literature (Bulger, Mohr, Carson, Robert, \& Wiegand, 2000) focused directly on presenting well-defined theoretical concepts during a classroom session followed by a practical application experience working with school-age children in a community-based program.

Video-based instruction. Research on developing physical educator’s skill analysis competence has strongly centered on discriminating between correct and incorrect motor skill performance through video-based instructional methods (Beveridge \& Gangstead, 1988; Gangstead \& Beveridge, 1984; Morrison \& Harrison; 1997; Nielsen \& Beauchamp, 1992; Stroot \& Oslin, 1993; Wilkinson, 1991, 1996; Williams \& Tannehill, 1999). However, philosophical questions have been raised concerning the generalizability of video-based instruction for physical educators who will be required to observe numerous motor skills of a gymnasium full of movers (Imwold \& Hoffman, 1983). The findings from this study revealed video-based instruction is an important approach for helping prospective physical educators (a) observe the developmental sequence of motor skills and typical changes that are expected to occur within body segments, (b) compare and contrast the movement technique of various performers of different body types performing the same motor skills, and (c) assess and evaluate the strengths and weaknesses in movement performance. Panelists recommended these critical knowledge strands should be employed through indirect instructional methods in biomechanics and motor development course work.

The use of video-based instruction plays an important role in introducing prospective physical educators to distinct facets of analyzing movement qualitatively and quantitatively. The 
use of video may be superior for learning complex movement phenomena because it provides practicing teachers with a visual, thus mental representation of events that are not easily demonstrated. However, in light of previous arguments (Imwold \& Hoffman, 1983) applying these essential understandings requires task specific knowledge, practice, and real world experience. Provisions should be made for linking course work with early field experience, such as structured opportunities to observe youth in physical education class.

Peer practice. Providing opportunities for practicing teachers to actively engage in teaching-learning experiences through peer practice was a highly promoted instructional method by a number of panelists. For example, one panel member stated that peer teaching opportunities should expose "students to the process of observing and analyzing movement in a dynamic environment, as opposed to just watching." In addition to being an effective instructional method, the recommendations provided by panelists suggest peer practice opportunities should engage prospective teachers in biomechanical theoretical strands relative to: (a) identifying the critical features of movement skills; (b) employing a systematic observation strategy; (c) identifying and prioritizing strengths and weaknesses in movement technique, as well as aspects that increase injury potential; and (d) discovering strategies for improving movement performance, such as feedback and task modification. These critical knowledge strands were found to be best suited for activity-based courses with a teaching emphasis, biomechanics simulation laboratories, and elementary/secondary teaching methods courses within the PETE curriculum.

Several panel members suggested the use of video-taping in activity-based courses for the purpose of recording the skill performance of a peer and subsequently "completing a qualitative analysis of the video-tape.” One panelist reiterated the need for prospective physical educators to 
actually teach a small group of peers' lifetime sport skills and analyze video footage to determine if the feedback provided was effective in improving peer skill performance. While engaging in peer practice activities, another panel member recommended having prospective teachers perform skills with their non-dominant hand or foot to "create an environment where providing feedback becomes critical.” Recommendations to infuse biomechanical knowledge into pedagogical courses reinforce the need for devoting more credit hours towards activity-based classes within the PETE curriculum. For example, practicing teachers should not only learn how to play volleyball, but also how to teach, design effective learning experiences, analyze/diagnose skill performance, and provide performance enhancing feedback. If we aspire to prepare physical education graduates capable of delivering a valued K-12 physical education program, there is a need to design activity-based courses that will help prospective physical educators connect critical subdisciplinary content and pedagogical content during peer practice learning opportunities.

Problem-based learning. The idea of problem-based learning (P-BL) is born out of Platonic philosophy in which students are encouraged to find answers to a thought stimulating question while the instructor acts a learning facilitator. In biomechanics, P-BL is typically characterized as an instructional method in which students are a presented movement problem, question or scenario and work towards solving the problem. Movement problems encompass a wide range of scenarios which may be general or specific in nature. Examples of questions addressed by prospective physical educators may include: (a) What are the appropriate procedures for improving a joints range of motion during a soccer kick? Or, (b) What are the biomechanical principles associated with performing an overhand throw? 
The results of the study demonstrate P-BL is most appropriate for engaging students in biomechanical theoretical content through biomechanics course work, activity-based course work, and secondary teaching methods course work. Problem-based assignments should help prospective physical educators think critically about biomechanical knowledge strands related to applying biomechanical concepts and principles. For example, during an activity-based course the instructor may require prospective teachers to work in pairs to determine what technique a person should employ to increase the amount of height on a vertical jump. One panel member suggested PB-L could be used by having prospective teachers investigate and create a powerpoint presentation illustrating how a particular biomechanics principle is applied to various movement forms. It is logical to suggest PB-L instructional methods would be better suited for prospective teachers once they have acquired basic prerequisite knowledge relative to movement principles and concepts. Perhaps of critical importance is clarifying what questions are most appropriate for those preparing to teach physical education during the early stages versus the later stages of their preparatory program.

Field experience. Although field experiences may be characterized as a stand-alone student teaching experience at the end of the PETE program, panelists in this study recommended engaging teachers in early field experiences to provide opportunities for prospective physical educators to: (a) plan for qualitative analysis, (b) observe K-12 students, (c) observe and record teacher behaviors, (d) teach one or small groups of children, and (e) perform case studies. The cooperative blending of the university with school and community-based establishment was perceived as a viable vehicle for engaging prospective physical educators "real world" learning experiences. Biomechanical theoretical knowledge strands relative to conducting a qualitative analysis of motor skills with emphasis on planning, observing and 
improving movement performance through feedback and task modifications were strongly advocated by a number of panelists. For example, one expert recommended lesson planning as a possible strategy for cognitively engaging preservice physical educators in critical biomechanics content during an elementary field placement. This panel member suggested having "students plan a lesson effectively to include the proper technique, instructional progressions, instructional cues, and appropriate feedback for student learning.” Another panel member suggested having prospective physical educators observe a "K-12 PE instructor teaching motor skills to preschool children and record the type of feedback used to correct the children's movement.” One panelist recognized the importance of student diversity and inclusion by recommending prospective teachers observe an adapted physical class and "analyze accommodations put in place to allow adapted physical education students to be successful."

Although field experiences were recommended by a number of panelists, there is a need to hold students accountable for applying the content and pedagogies learned through their course work. Accordingly, three panel members suggested the use of learning logs, documenting qualitative analysis of movement results and providing recommendations, and post-lesson reflections. A second critical feature of field placements requiring prospective physical educators to teach children and adolescents is that they need to be well-supervised (Darling-Hammond, 2006). Ideally, prospective physical educators should be engaged in goal-directed field experiences that are well-supervised, make clear theory to practice connections, and help prospective teachers form accurate perceptions of instruction, student learning, and the relationship between them. 


\section{Future Directions}

The results of this Delphi study provide readers with a fresh perspective on the potential role of biomechanics within the PETE curriculum based on the collective wisdom of a panel of experts. Final consensus determined that $38 \%$ of the total 107 total biomechanical competencies were considered both theoretically important and pedagogically relevant for those preparing to teach physical education. It must be acknowledged that a different distribution of panel members may produce a different set of conclusions if presented the same research questions due to variations in individual backgrounds. Future research could better generalize the results by administering a modified version of the same questionnaire to another group of biomechanics specialists, teacher educators, and K-12 physical education teachers.

The results also revealed only $48 \%$ of the 33 of the biomechanical competencies endorsed by NASPE (1980, 2003) were considered critical in nature in preparing prospective physical educators. There appears to be a need for NASPE to bring together an interdisciplinary group of experts to collectively determine the biomechanical competencies that are most beneficial for the preparing physical educators within the PETE curriculum. With institutional barriers making collaboration among PETE faculty and their colleagues in biomechanics often difficult to sustain, PETE programs need to become intimately involved in defining the curricular content and educational experiences that operate within the PETE curriculum. It seems clear an understanding about movement involves an understanding of core biomechanical concepts and principles; whereas, an understanding how to teach movement in the context of games, sports, and various form of physical activity and fitness is the central focus of pedagogy. The results of this study suggest a blending of essential biomechanical content and pedagogy is a necessary ingredient for successful teaching. A shared level responsibility in the decision making process 
represents an initial critical step in addressing both the fragmentation of subject matter and misalignment issues characteristic of numerous PETE programs. The Delphi method represents an important potential alternative research design for facilitating interdisciplinary communication and achieving consensus on curricular issues that has historically plagued the PETE profession. 


\section{References}

Adler, M., \& Ziglio, E. (1996), Gazing into the oracle: The Delphi method and its application to social policy and public health (pp. 3-33). Bristol, PA: Jessica Kingsley Publishers.

Astin, A. W. (1993). What Matters in College? Four Critical Years Revisited. San Francisco, CA: Jossey-Bass.

Bain, L. L., \& Poindexter, H. B. W. (1981). Applying disciplinary knowledge in professional preparation. Journal of Physical Education and Recreation, 52(2), 40-41.

Balan, C. M., \& Davis, W. E. (1993). Ecological task analysis approach to instruction in physical education. Journal of Physical Education, Recreation, and Dance, 64(9), 54-61.

Barrett, K. R. (1983). A hypothetical model of observing as a teaching skill. Journal of Teaching in Physical Education, 3(1), 22-31.

Behets, D. (1996). Comparison of visual information processing between preservice students and experiences physical education teachers. Journal of Teaching in Physical Education, 16(1), 79-87.

Beveridge, S. K., \& Gangstead, S. K. (1988). Teaching experience and training in the sports skill analysis process. Journal of Teaching in Physical Education, 7, 103-114.

Biscan, D. V., \& Hoffman, S. J. (1976). Movement analsyis as a generic ability of physical education teachers and students. Research Quarterly, 47, 161-163.

Brophy J. \& Good, T. (1986). Teacher behavior and student achievement. In M.C. Wittrock (Ed.), Handbook of research on teaching (3rd ed.). New York: McMillan.

Bulger, S. M., \& Housner, L. D. (2007). Modified Delphi investigation of exercise science in physical education teacher education. Journal of Teaching in Physical Education, 26, 57-80. 
Bulger, S. M., Mohr, D. J., Carson, L. M., \& Wiegand, R. L. (2001). Infusing health-related physical fitness in physical education teacher education. Quest, 53, 403-417.

Bulger, S. M., Mohr, D. J., Carson, L. M., Robert, D. L., \& Wiegand, R. L. (2000). Preparing prospective physical educators in exercise physiology. Quest, 52, 166-185.

Clayton, M. J. (1997). Delphi: A technique to harness expert opinion for critical decisionmaking tasks in education. Educational Psychology, 17(4), 373-387.

Darling-Hammond, L. (2006). Constructing 21st-century teacher education. Journal of Teacher Education, 57(3), 300-314.

DeVellis, R. F. (1991). Scale development: Theory and applications. Newbury Park, CA: Sage Publications.

Gage, N. L., \& Berlinger, D. C. (1992). Educational psychology (5 ${ }^{\text {th }}$ ed.). Boston: Houghton Mifflin.

Gangstead, S. K., \& Beveridge, S. K. (1984). The implementation and evaluation of a methodological approach to qualitative sport skill analysis instruction. Journal of Teaching in Physical Education, 3(2), 60-70.

Grow, G. (1991). Teaching learners to be self-directed: A stage approach. Adult Education Quarterly, 41(3), 125-149.

Hall, S. J. (1999). Basic biomechanics ( $3^{\text {rd }}$ ed.), United States: McGraw-Hill.

Hamill, J. (2007). Biomechanics Curriculum: Its content and relevance to movement sciences. Quest, 59, 25-33.

Hamilton, N., Weimar, W., \& Luttgens, K. (2008). Kinesiology: Scientific basis of human motion, New York, NY: McGraw-Hill. 
Hay, J. G., \& Reid, J. G. (1988). The anatomical and mechanical bases of human motion. Englewod Cliffs, NJ: Prentice-Hall.

Hoffman, S. J. (1977). Toward a pedagogical kinesiology. Quest, 28, 38-48.

Hoffman, S. J. (1983). Clinical diagnosis as a pedagogical skill. In T. J Templin and J. K. Olson (Eds.), Teaching in physical education (pp. 35-45). Champaign, Ill: Human Kinetics.

Hoffman, S. J. (1984). Contributions of biomechanics to clinical competence: A view from the gymnasium. In R. Shapiro and J.R Marett (Eds.), Proceedings of the second national symposium on teaching kinesiology and biomechanics in sports (pp. 17-20). Colorado Springs: NASPE.

Housner, L. D. (1990). Selecting master teachers. Evidence from process-product research. Journal of Teaching in Physical Education, 9, 201-226.

Howey, K. R., \& Zimpher, N. L. (1989). Profiles of preservice teacher education: Inquiry into the nature of programs. Albany, NY: State University of New York Press.

Hudson, J. L. (1995). Core concepts in kinesiology. Journal of Physical Education, Recreation, and Dance, 66(5), 54-55, 59-60.

Imwold, C. H., \& Hoffman, S. J. (1983). Visual recognition of a gymnastic skill by experienced and inexperienced instructors. Research Quarterly for Exercise and Sport, 64, 167-17.

Ives, J. C., \& Knudson, D. (2007). Professional practice in exercise science: The need for greater disciplinary balance. Sports Medicine, 37(2), 103-115.

Jones, J., \& Hunter, D. (1995). Consensus methods for medical and health services research. British Medical Journal, 311, 376-380.

Kerlinger, E. N. (1973). Foundations of behavioral research (2nd ed.). New York: Holt, Rinehart \&Winston. 
Knudson, D. (2003). An integrated approach to the introductory biomechanics course. Physical Educator, 60(3), 122-133.

Knudson, D. V. (2007). Qualitative biomechanical principles for application in coaching. Sports Biomechanics, 6(1), 109-118.

Knudson, D. V., \& Morrison, C. S. (2002). Qualitative analysis of human movement. (2 ${ }^{\text {nd }}$ Ed.). Champaign, IL: Human Kinetics.

Knudson, D. V., Morrison, C. S., \& Reeve, J. (1991). Effects of undergraduate kinesiology courses on qualitative analysis ability. In J. D. Wilkerson, E. Kreighbaum, \& C. L. Tant (Eds.). Teaching kinesiology and biomechanics in sports (pp. 17-20). Ames: Iowa State University.

Lindstone, H. A. (1978). The Delphi technique. In J. Fowlers (Ed.), Handbook of futures research (pp. 273-300). West port, CT: Greenwood Press.

Lounsbery, M., \& Coker, C. (2008). Developing skill-analysis competency in physical education teachers. Quest, 60, 255-267.

Lynn, M. (1986). Determination and quantification of content validity. Nursing Research, 35, 382-285.

Magill, R. A. (1994). Influence of augmented feedback on skill learning depends on characteristics of the skill and learner. Quest, 46, 314-327.

Magill, R. A. (2007). Motor learning and control concepts and applications ( $8^{\text {th }}$ ed.). New York, NY: McGraw-Hill.

McCampbell, W. H., \& Stewart, B. R. (1992). Career ladder programs for vocational education: Desirable characteristics. Journal of Vocational Education Research, 17(1), 53-68. 
McPherson, M. N. (1990). A systematic approach to skill analysis. Sport Science Periodical on Research and Technology in Sport, 11(1), 1-10.

Metcalf, A. A. (2010). History, philosophy, and sociology of sport recommendations for the PETE curriculum (Unpublished doctoral dissertation). West Virginia University, Morgantown, WV.

Morrison, C. S., \& Harrison, J. M. (1997). Integrating qualitative analysis of movement in the university physical education curriculum. The Physical Educator, 54(2), 64-71.

Murray, J. \& Hammons, J. O. (1995). Delphi: A versatile methodology for conducting qualitative research. The Review of Higher Education, 18(4), 423-436.

National Association for Sport and Physical Education (NASPE) Kinesiology Academy. (1980). Guidelines and standards for undergraduate kinesiology. Journal of Physical Education and Recreation, 51(2), 19-21.

National Association for Sport and Physical Education (NASPE). (2003). National standards for beginning physical education teachers ( $2^{\text {nd }}$ ed.). Reston, VA: National Association for Sport and Physical Education.

National Association for Sport and Physical Education. (2008). National Initial physical education teacher education standards. Retrieved from http://www.aahperd.org/naspe/ grants/accreditation/upload/2008-National-Initial-PETE-Standards.pdf.

Nielsen, A. B., \& Beauchamp, L. (1992). The effects of training in conceptual kinesiology on feedback provision patterns. Journal of Teaching in Physical Education, 11(2), 126-138.

Okoli, C., \& Pawlowski, S. (2004). The Delphi method as a research tool: An example, design considerations and applications. Information and Management, 42, 15-29.

Parente, F. J., \& Anderson-Parente, J. (1987). Delphi inquiry systems. In G. Wright \& P. Ayton 
(Eds.), Judgmental forecasting (pp. 129-156). New York: John Wiley \& Sons.

Paris, C., \& Combs, B. (2000). Teachers' perspectives on what it means to be learner-centered. Paper presented at the annual meeting of the American Educational Research Association, New Orleans. Retrieved from http://www.eric.ed.gov/ERICDocs/data/ ericdocs2sql/content_storage_01/0000019b/80/16/8b/f5.pdf.

Pinheiro, V.E.D. (2000). Qualitative analysis for the elementary grades. Journal of Health, Physical Education, Recreation, and Dance, 71(1), 18-21.

Pinheiro, V. E. D., \& Simson, H. A. (1992). An operational model for motor skill diagnosis. Journal of Teaching in Physical Education, 11, 288-302.

Powell, C. (2002). The Delphi technique: Myths and realities. Journal of Advanced Nursing, 41 (4), 376-382.

Reeve, J. (2000). Qualitative analysis: Putting it all together. The Journal of Physical Education, Recreation, and Dance, 71(1), 16-17.

Rikli, R. E. (2006). Kinesiology - A “homeless” field: Addressing organization and leadership needs. Quest, 58, 288-308.

Rink, J. (2007). What knowledge is of most worth? Perspectives on kinesiology from pedagogy. Quest, 59, 100-110.

Roberton, M. A., \& Halverson, L. E. (1984). Developing children - their changing movement. Philadelphia: Lea \& Febiger.

Rosenshine B. \& Stevens, R. (1986). Teaching functions. In M.C. Wittrock (Ed.), Handbook of research on teaching (3rd ed.). New York: McMillan. 
Ross, S. M., Metcalf, A. A., Bulger, S. M., \& Housner, L. D. (2010). Modified Delphi investigation of motor development and learning in physical education teacher education. Manuscript in preparation.

Saskatchewan Education. (1991). Instructional approaches: A framework for professional practice. Regina, SK: Saskatchewan Education.

Seefelt, V., \& Haubenstricker, J. (1982). Patterns, phases, or stages: An analytic model for the study of developmental movement. In J. A. S. Kelso \& J. E. Clark (Eds.), The development of movement control and coordination. New York: Wiley.

Siedentop, D. (2009). Introduction to physical education, fitness and sport $\left(7^{\text {th }} \mathrm{ed}\right)$. New York, NY: McGraw-Hill.

Siedentop, D., Doutis, P., Tsangaridou, N., Ward, P., \& Rauschenbach, J. (1994). Don’t sweat gym! An analysis of curriculum and instruction. Journal of Teaching in Physical Education, 13, 375-394.

Skulmoski, G. J., Hartman, F. T., \& Krahn, J. (2007). The Delphi method for graduate research. Journal of Information Technology Education, 6, 1-21.

Stroot, S. A., \& Oslin, J. L. (1993). Use of instructional statements by preservice teachers for overhand throwing performance of children. Journal of teaching in physical education, 13, 24-45.

Ulrich, W. (2001). The quest for competence in systemic research and practice. Systems Research and Behavioral Science, 18(1), 3-28.

Umbach, P. D. (2005). Getting back to the basics of survey research. New Directions for Institutional Research, 127, 91-100. 
Walls, R. T., \& Cather, W. L. (1987). Principles of instruction. Emittsburg, MD: National Emergency Training Center.

Wiegand, R. L., Bulger, S. M., \& Mohr, D. J. (2004). Curricular issues in physical education teacher education. Journal of Physical Education, Recreation and Dance, 75(8), 47-55.

Wilkinson, S. (1991). A training program for improving undergraduate’s analytical skill in volleyball. Journal of Teaching in Physical Education, 11, 177-194.

Wilkinson, S. (1996). Visual analysis of the overarm throw and related sport skills: Training and transfer effects. Journal of Teaching in Physical Education, 16(1), 66-78.

Williams, E., \& Tannehill, D. (1999). Effects of a multimedia performance principle training program on correct analysis and diagnosis of throw-like movements. Physical Educator, 56(3), 143-154.

Zeichner, K. M., \& Gore, J. M. (1990). Teacher socialization. In W. R. Houston (Eds.), Handbook of research on teacher education (pp. 329-348). New York: Macmillan. 
Table 1

Biomechanics Core Content Areas and Broad-based Competencies

Content Areas Competencies

Application of

Biomechanics

- Observe and describe a movement technique accurately.

to Human

- Determine the anatomical and mechanical factors basic to the performance of an observed movement.

Movement

- Evaluate the appropriateness of a performer's technique with reference to the movement task.

- Identify factors that limit skillful performance and establish a priority for change in those factors most likely to lead to improvement in performance. 
Table 2

Biomechanics Core Content Areas and Specific Competencies

Content Areas Competencies

Qualitative Preparation: Gathering Relevant Knowledge:

Analysis of - Define the critical features of various motor skills and explain how they are identified in the preparation task of

Movement qualitative analysis of movement.

- Explain how preparation in qualitative analysis of movement is related to effective teaching and observation.

- Explain how preparing for qualitative analysis can be integrated with planning for teaching.

Observation: Developing a Systematic Observation Strategy:

- Identify key elements of a systematic observational strategy.

Evaluation and Diagnosis: Critical Thinking Within Qualitative Analysis:

- Explain why evaluation of performance errors is necessary for qualitative analysis.

- Discuss major difficulties in evaluating strengths and weaknesses of performance.

- Discuss strategies for prioritizing weaknesses that serve as performance diagnosis.

Intervention: Strategies for Improving Performance:

- Identify a variety of intervention strategies (e.g., feedback, task modification, mechanical guidance) used in qualitative analysis to improve performance.

- Describe how to develop appropriate cue words and phrases for improving skill performance.

- Identify the most appropriate intervention strategy (e.g., feedback, task modification, mechanical guidance) for improving skill performance across novice, intermediate, and expert performers.

Quantitative Analysis of Human

Movement
- Develop the ability to think critically about information and then develop effective strategies to problems relating to human movement and performance. 


\section{Anatomical}

Bases

Mechanical

Bases
Joint Structure and Function:

- Explain the relationship between joint structure and function.

- Name and demonstrate the actions possible in each joint in other than the anatomical starting position.

- State the factors contributing to joint range of motion and stability.

- Observe a joints range of motion qualitatively and state appropriate procedures for improving that range.

- Explain how the schedule of ossification of epiphyseal cartilage is related to the nature of activities suitable for different age groups.

- Observe human movement and explain the reasons for different joint actions and ranges of motion using knowledge of joint structure, stability, and mobility.

- Assess flexibility and create safe and effective stretches for the major muscle groups surrounding each joint.

Muscle Mechanics:

- Name the major muscles or muscle groups active in any given joint action.

- Identify the type(s) of muscular contraction (static, concentric, eccentric) occurring in any given joint action.

\section{Movement Kinematics:}

- Explain the kinematic relationships between linear and angular motion and apply this relationship to improve motor skill performance (e.g., striking, throwing, kicking) and equipment design (e.g., sport, rehabilitation, work environment).

- Describe how the variables of release height, angle, and velocity affect projectile motion and apply these variables to a projectile activity to optimize performance.

- Explain how to plan and conduct an effective qualitative human movement analysis.

Movement Kinetics:

- Identify Newton's laws of motion and gravitation and describe practical illustrations of the laws.

- Explain what factors affect friction and discuss the role of friction in daily activities and sports.

- Explain the effects of weight, normal reaction, friction, buoyancy, drag, and lift upon motor performance.

- Estimate the location of the center of gravity of persons in any position and describe how changes in location of the center of gravity and other mechanical factors that influence stability. 


\section{Motor Skill}

Principles and

Applications

\section{Standing Posture:}

- Name the values, if any, of good posture.

Moving Objects: Throwing, Striking, and Kicking:

- Classify activities involving sequential throwing, kicking, or striking patterns according to the nature of force applied.

- Name and discuss anatomical and mechanical factors that apply to representative throwing, kicking, or striking activities.

- Perform an analysis of someone engaging in a sequential throwing, kicking, or striking skill under each of these force application conditions: momentary contact, projection, continuous application.

- Plan and conduct a qualitative analysis of common object control skills.

\section{Locomotion: Solid Surfaces:}

- Describe the anatomical and mechanical nature of motor skills representative of the major types of locomotor patterns.

- Evaluate performance of motor skills representative of the major locomotor patterns in terms of application of the related biomechanical principles.

- Plan and conduct a qualitative analysis of someone performing a locomotor skill.

\section{Locomotion: Suspended and Free of Support:}

- Explain how each of the following influences the flight path of unsupported bodies: angle of projection, vertical velocity, gravity, and angular momentum.

\section{Impact:}

- State the principles related to avoiding injury while receiving impact and furnish an application for each.

*41 Total Biomechanics Competencies Kept (includes Tables 1 \& 2) 
Table 3

PETE Subdisciplinary Delphi Investigations

Sub-disciplines Progress

Exercise Physiology

Published

History, Philosophy, \& Sociology of Sport

Unpublished dissertation

Biomechanics

Unpublished dissertation

Motor Development \& Motor Learning

Manuscript in progress

Sport \& Exercise Psychology

Planned 
Table 4

Final List of Biomechanics Competencies and Associated Group Ratings

*Definitions as they relate to this study:

IMPORTANCE - ITEM SHOULD BE UNDERSTOOD BY ALL PROSPECTIVE K-12 PHYSICAL EDUCATION TEACHERS. RELEVANCE - ITEM IS APPLICABLE TO THE INSTRUCTION OF PHYSICAL EDUCATION IN A K-12 SETTING.

\begin{tabular}{|c|c|c|}
\hline Concepts \& Competencies & Importance & Relevance \\
\hline Section 2: Introduction to Biomechanics & GR & GR \\
\hline \multicolumn{3}{|l|}{ 1. The student will be able to: } \\
\hline $\begin{array}{l}\text { a. define and explain the terms biomechanics, statics, dynamics, kinematics, and kinetics in relation to human } \\
\text { movement. }\end{array}$ & 4.05 & 3.68 \\
\hline b. describe the scope of scientific inquiry addressed by biomechanists. & 3.64 & 3.14 \\
\hline c. distinguish between qualitative and quantitative approaches for analyzing human movement. & 4.05 & 3.91 \\
\hline d. explain how to formulate questions for qualitative analysis of human movement. & 3.82 & 3.77 \\
\hline \multicolumn{3}{|l|}{ Section 3: Application of Biomechanics Competencies to Human Movement } \\
\hline \multicolumn{3}{|l|}{ 2. The student will be able to: } \\
\hline a. observe and describe a movement technique accurately & 4.77 & 4.68 \\
\hline b. determine the anatomical and mechanical factors basic to the performance of an observed movement & 4.59 & 4.45 \\
\hline c. evaluate the appropriateness of a performer’s technique with reference to the movement task & 4.59 & 4.64 \\
\hline $\begin{array}{l}\text { d. identify factors that limit skillful performance and establish a priority for change in those factors most } \\
\text { likely to lead to improvement in performance. }\end{array}$ & 4.59 & 4.64 \\
\hline \multicolumn{3}{|l|}{ Section 4: Qualitative Analysis of Human Movement } \\
\hline \multicolumn{3}{|l|}{ 3. Preparation: Gathering Relevant Knowledge } \\
\hline $\begin{array}{l}\text { a. define the critical features of various motor skills and explain how they are identified in the preparation task } \\
\text { of qualitative analysis of movement. }\end{array}$ & 4.32 & 4.27 \\
\hline $\begin{array}{l}\text { b. explain how preparation in qualitative analysis of movement is related to effective teaching and } \\
\text { observation. }\end{array}$ & 4.00 & 4.05 \\
\hline c. explain how preparing for qualitative analysis can be integrated with planning for teaching. & 4.23 & 4.09 \\
\hline
\end{tabular}


4. Observation: Developing a Systematic Observation Strategy

a. explain how to compensate for perceptual limitations by planning a systematic observational strategy.

b. identify key elements of a systematic observational strategy.

c. identify several effective systematic observational strategies.

d. explain how all the senses can be integrated to improve observation.

3.95

4.14

3.82

3.62

4.32

5. Evaluation and Diagnosis: Critical Thinking Within Qualitative Analysis

a. explain why evaluation of performance errors is necessary for qualitative analysis.

b. discuss major difficulties in evaluating strengths and weaknesses of performance.

c. discuss strategies for prioritizing weaknesses that serve as performance diagnosis.

\section{Intervention: Strategies for Improving Performance}

a. identify a variety of intervention strategies (e.g., feedback, task modification, mechanical guidance)used in qualitative analysis to improve performance.

b. identify research supported guidelines for the provision of augmented verbal feedback.

c. list the functions of feedback as intervention in qualitative analysis.

d. describe how to develop appropriate cue words and phrases for improving skill performance.

e. identify the most appropriate intervention strategy (e.g., feedback, task modification, mechanical guidance) for improving skill performance across novice, intermediate, and expert performers.

4.32

4.18

4.09

4.55

3.50

3.91

4.27

4.41
4.14

4.00

3.95

4.09

3.77

3.71

4.41

3.41

3.55

4.36

4.50 


\section{Quantitative Reasoning and Problem Solving}

a. categorize classes of quantitative problems and select appropriate techniques for analysis and problem solving.

b. interpret graphs and simple models which are used to explain human movement.

c. demonstrate an awareness of and proficiency with various computational skills to effectively interpret and use quantitative information.

d. identify current technology used to quantify biomechanical variables in human movement.

e. solve quantitative problems involving vector quantities using both graphic and trigonometric procedures.

linear kinematic quantities.

g. solve quantitative problems related to kinetic concepts.

h. solve basic quantitative problems using the equations of static equilibrium.

i. solve quantitative problems relating to the factors that cause or modify angular motion.

j. list possible sources of error in recorded movement data.

k. develop the ability to think critically about information and then develop effective strategies to problems relating to human movement and performance.
3.00

3.59

3.14

3.50

2.32

2.59

2.59

2.73

3.09

2.68

3.00

1.95

2.14

2.23

2.14

2.23

2.59

2.91

4.41

\section{Section 6: Anatomical Bases}

\section{Joint Structure and Function}

a. name and define the fundamental planes and axes.

b. describe and demonstrate joint movement with respect to plane and axis of motion.

c. explain the relationship between joint structure and function.

d. name and demonstrate the actions possible in each joint in other than the anatomical starting position.

e. state the factors contributing to joint range of motion and stability.

f. classify joints according to structure and explain the relationship between joint structure and its capacity for movement.

g. observe a joints range of motion qualitatively and state appropriate procedures for improving that range.

h. explain how the schedule of ossification of epiphyseal cartilage is related to the nature of activities suitable for different age groups.

i. observe human movement and explain the reasons for different joint actions and ranges of motion using knowledge of joint structure, stability, and mobility.

j. assess flexibility and create safe and effective stretches for the major muscle groups surrounding each joint.

k. perform an anatomical analysis of the joint actions and planes of motion for a selected motor skill.

\begin{tabular}{l|l}
3.86 & 3.59 \\
4.05 & 3.77 \\
4.45 & 4.18 \\
4.41 & 4.14 \\
4.27 & 4.09 \\
4.18 & 3.82 \\
4.45 & 4.36 \\
4.27 & 4.00 \\
& \\
4.27 & 4.18 \\
4.64 & 4.55 \\
4.09 & 3.82 \\
\hline
\end{tabular}


9. Muscle Mechanics

a. name the major muscles or muscle groups active in any given joint action.

b. identify the type(s) of muscular contraction (static, concentric, eccentric) occurring in any given joint action.

c. explain the cooperative action of muscles in controlling joint actions and identify the role (agonist, antagonist, stabilizer, neutralizer) played by the muscle(s) in a given movement.

d. explain the force-velocity and length-tension relationships of muscle and recognize their application in static positions and dynamic movements.

4.41

4.50 training exercises that utilize this phenomenon.

f. describe the mechanical response of different muscle fiber types, the influence of training upon them, and the potential for muscle fiber type to influence performance.

\section{Neuromuscular Function}

a. name and define the basic structures (e.g., motor unit, muscle spindle and proprioceptors) of the neuromuscular system.

b. explain how the various receptors function, and describe the effect each has on musculoskeletal movement.

c. describe the anatomical bases for reflex acts and name and define examples of reflexes (e.g., stretch reflex, righting and supporting reflexes, reciprocal inhibition or co-contraction) affect human movement.

d. describe how recruitment and rate coding of motor units regulate muscle force production.

e. perform an analysis of the neuromuscular factors influencing the performance of a variety of motor skills.

\section{Section 7: Mechanical Bases}

\section{Basic Considerations}

a. define a movement system and determine the nature of the system's movement (i.e., linear, angular, general motion).

b. appropriately represent kinematic and kinetic quantities as vectors and use vectors, vector addition, and vector resolution to enhance the understanding of basic mechanical concepts (e.g., impact of the direction of resultant force application (external forces), the effect of changes in line of muscle pull upon the amount of force used to rotate a segment (internal forces). 


\section{Movement Kinematics}

a. define the basic terms of distance, displacement, speed, velocity, and acceleration as they relate to linear and angular motion in human movements.

b. use kinematic variables to compare the quality of various motor performances (e.g., across skill level, fitness level, gender, age, body size and type, etc.).

c. explain the kinematic relationships between linear and angular motion and apply this relationship to improve motor skill performance (e.g., striking, throwing, kicking) and equipment design (e.g., sport, rehabilitation, work environment).

d. describe how the variables of release height, angle, and velocity affect projectile motion and apply these variables to a projectile activity to optimize performance.

e. explain how to plan and conduct an effective qualitative human movement analysis.

f. use simple concepts of motion description (kinematics) to analyze human motion in qualitative terms.

g. identify and describe the uses of available instrumentation for measuring kinematic quantities.

\section{Movement Kinetics}

a. define basic terms (e.g., force, inertia, mass, and weight) as they relate to linear motion in human movement.

b. define basic terms (e.g., torque, moment, moment of inertia, moment arm, radius) as they relate to angular motion.

c. identify Newton's laws of motion and gravitation and describe practical illustrations of the laws.

d. identify and provide examples of the angular analogues of Newton's laws of motion.

e. explain what factors affect friction and discuss the role of friction in daily activities and sports.

f. explain the effects of weight, normal reaction, friction, buoyancy, drag, and lift upon motor performance.

GR

4.36

4.50

4.09

4.09

3.43

g. estimate the location of the center of gravity of persons in any position and describe how changes in location of the center of gravity and other mechanical factors that influence stability.

h. identify and explain the importance of impulse-momentum, work-energy, and the conservation of momentum to the production of effective human movements. 


\title{
Section 8: Motor Skills: Principles \& Applications
}

\section{Standing Posture}

a. identify and describe the skeletomuscular and neuromuscular antigravity mechanisms involved in volitional standing positions.

GR

b. summarize the similarities and differences that occur in the relation of the line of gravity to various body landmarks with good and poor anteroposterior segmental alignment.

c. discuss the factors that affect the stability and energy cost of erect posture.

d. explain the effects that the variables of age, body build, strength, and flexibility have on the alignment of body segments in the standing posture. Discuss the factors that affect the stability and energy cost of erect posture.

e. name the values, if any, of good posture.

f. perform biomechanical analyses on the posture of individuals of different ages and body builds.

\section{Moving Objects: Pushing and Pulling}

a. classify activities involving push or pull patterns according to the nature of the force applications.

b. name and discuss anatomical and mechanical factors and principles that apply to representative push or pull activities.

c. analyze the performance of someone performing a push-pull skill under each of these force application conditions: momentary contact, projection, or continuous application.

\section{Moving Objects: Throwing, Striking, and Kicking}

a. classify activities involving sequential throwing, kicking, or striking patterns according to the nature of force applied.

b. name and discuss anatomical and mechanical factors that apply to representative throwing, kicking, or striking activities.

c. perform an analysis of someone engaging in a sequential throwing, kicking, or striking skill under each of these force application conditions: momentary contact, projection, continuous application.

d. plan and conduct a qualitative analysis of common object control skills.

e. plan and conduct a quantitative analysis of common object control skills.

\begin{abstract}
and conduc
\end{abstract}




\section{Locomotion: Solid Surface}

a. identify and classify motor skills belonging in the categories that fall under the heading of moving one's body on the ground or on another resistant surface.

b. describe the anatomical and mechanical nature of motor skills representative of the major types of locomotor patterns.

c name and state anatomical and mechanical principles that apply to the locomotion patterns of walking, running, and jumping.

d evaluate performance of motor skills representative of the major locomotor patterns in terms of application of the related biomechanical principles.

e plan and conduct a qualitative analysis of someone performing a locomotor skill.

f plan and conduct a quantitative analysis of someone performing a locomotor skill.

4.09

4.05

4.36

4.36

3.09

18. Locomotion: The Aquatic Environment

a. identify factors that contribute to the propulsion of a swimmer.

b. identify factors that impede the progress of a swimmer.

c. explain how the propulsive and resistive factors identified affect the length or frequency of a swimming stroke.

d. complete a biomechanical analysis of a swimming stroke by identifying the anatomical and mechanical factors important to success in the selected stroke, as well as those factors that appear to limit the particular performance.

\section{Locomotion: When Suspended and Free of Support}

a. explain how each of the following influences the action of swinging bodies: weight of the body, length of the pendulum, angular momentum, potential-kinetic energy, centripetal-centrifugal force, and friction.

b. describe how to initiate pendular action, increase the height of a swing, alter the period, change grips, and dismount safely.

c. explain how each of the following influences the flight path of unsupported bodies: angle of projection, vertical velocity, gravity, and angular momentum.

d. describe how to initiate and control rotation of unsupported bodies.

e. analyze the performance of a suspension and a nonsupport movement.

\begin{tabular}{l|l}
4.05 & 3.82 \\
4.09 & 3.82 \\
3.82 & 3.41 \\
& \\
3.86 & 3.59 \\
& \\
\hline & \\
4.18 & 3.86 \\
& \\
& \\
& \\
4.86 & \\
4.18 & \\
4.14 & 3.68 \\
3.86 & 3.81 \\
\hline
\end{tabular}




\section{Section 8: Motor Skills: Principles \& Applications (cont.)}

a. name the common problems associated with the diverse forms of receiving impact

GR

GR

b. explain how the work-energy, impulse-momentum, and pressure-area relationships apply to receiving the impact either of one's own body or of external objects.

\begin{tabular}{l|l}
4.05 & 3.82 \\
3.55 & 3.36 \\
4.23 & 4.14 \\
4.05 & 3.77 \\
4.14 & 3.90 \\
\hline
\end{tabular}

\begin{tabular}{l|l}
4.05 & 3.82 \\
3.55 & 3.36 \\
4.23 & 4.14 \\
4.05 & 3.77 \\
4.14 & 3.90 \\
\hline
\end{tabular}

c. state the principles related to avoiding injury while receiving impact and furnish an application for each.

d. state the principles related to maintaining and regaining equilibrium while receiving impact and furnish an application for each.

e. state the principles related to accuracy and control while receiving impact and furnish an application for each. 


\section{Appendix A}

Biomechanics Recommendations for the Physical Education Teacher Education Curriculum Review of Literature 


\section{Review of Literature}

This review of literature provides some professional scholarship relevant to this study. The conceptual framework is arranged into the following sections: (a) Physical Activity and Biomechanics (b) Biomechanics and Physical Education Teacher Education, (c) Gap between Theory and Practice in Biomechanics, (d) The Delphi Method, and (e) Summary

\section{Physical Activity and Biomechanics}

The history of physical education contains a rich tapestry of influences, initiatives and developments which have substantially increased the scope of the physical education teacher education (PETE) curriculum. A primary issue shaping physical education curricular initiatives is the youth obesity crisis and associated long term health risks. Although childhood obesity is complex and multi-factorial in nature (American Heart Association, 1996; Bar-Or, 2000; Sallis, Prochaska, \& Taylor, 2000), instruction and programming focused on skill development, improving fitness, and enjoyable participation in a wide range of physical activities is recognized as an essential strategy for promoting the health and development of youth (American Heart Association, 1996; U.S. Department of Health and Human Services, 1997, 2000). Accordingly, a number of professional and governmental agencies have acknowledged the importance of promoting physical activity in school physical education programs (American Academy of Pediatrics, 1987; American College of Sports Medicine, 1988; American Heart Association, 1996; NASPE, 2004, 2008; Pate, Davis, Robinson, Stone, Thomas, \& Young, 2006; U.S. Department of Health and Human Services, 1996). McKenzie (1999) proposed that schools constitute a primary behavioral setting for promoting physical activity because they are costeffective, staffed with physical activity experts, housed with appropriate equipment and facilities, and reach nearly all children and adolescents. 
Physical education is one context where youth experience physical activity and have the opportunity to acquire the knowledge, skills, and behaviors to become physically activity adults (American Academy of Pediatrics, 2006). Whether physical activity is in the form of competitive sport, solitary exercise, or dance, the initial foundations for active living are laid through quality physical education instruction and positive experiences (Thomas \& Thomas, 2008). According to NASPE (2008, 2009a, 2009b), the ultimate purpose of any physical education program is helping children and adolescents develop the skills, knowledge and desire to enjoy a lifetime of physical activity.

\section{National Standards and Skillful Movement}

NASPE (2004) established standards for K-12 physical education programs concerning physical activity. The standards define what children and adolescents should know and be able to do as a result of a quality physical education program. Accordingly, these standards should be linked to the performance standards physical education teachers are expected to meet in delivering a quality physical education program. The six standards for school physical education programs issued by National Association for Sport and Physical Education include:

Standard 1: Demonstrates competency in motor skills and movement patterns needed to perform a variety of physical activities.

Standard 2: Demonstrates understanding of movement concepts, principles, strategies, and tactics as they apply to the learning and performance of physical activities.

Standards 3: Participates regularly in physical activity.

Standard 4: Achieves and maintains a health-enhancing level of physical fitness.

Standard 5: Exhibits responsible personal and social behavior that respects self and others in physical activity settings. 
Standards 6: Values physical activity for health, enjoyment, challenge, self-expression, and/or social interaction.

This set of guidelines was recently updated to reflect current public health concerns associated with inactivity among youth. The revised guidelines reinforce the need to focus more on concepts and principles of movement that enhance learning and performance, rather than knowing the benefits of physical activity (Corbin \& McKenzie, 2008). The most significant modification to these guidelines has been reflected in the first two standards (NASPE, 2004).

Standard 1: Standard one reflects the importance of motor skill development in quality physical education programs by emphasizing students should demonstrate competency in motor skills and movement patterns. This standard clearly defines motor skill competence as a salient characteristic of quality education programs that enhance a child's odds of future physical activity participation. The major assumption underpinning this standard is that learning is hierarchical (Gagne, 1968) and competence in fundamental motor skill and patterns establishes the foundation for successful engagement in more complex skills, such as those occurring in sport, games, dance, or ones chosen physical activity (Haywood \& Getchell, 2005; NASPE, 2004, 2009a, 2009b; Payne \& Isaacs, 2008).

Standard 2: Standard two emphasizes the importance of students' knowledge of movement concepts and principles, as well as their ability to apply them in physical activity situations. This standard defines the physical education content students should know in order to acquire self-directed physical activity behaviors. For example, at the elementary level emphasis is placed on recognizing and acquiring a basic movement vocabulary involving fundamental movement skills (e.g., locomotor skills, stabilizing skills, manipulative skills) and movement concepts (e.g., degrees of force, absorption of force, control, time). During later elementary 
years, students are expected to identify critical elementals motor skills and utilize simple biomechanical principles to provide feedback to a partner. As children transition into adolescence years, emphasis is placed on applying movement concepts/principles, such as production and absorption of force, to game strategies and real life physical activity situations. The student's ability to learn and apply critical concepts from disciplines of biomechanics, motor learning and development, exercise physiology, and sport psychology in the context of physical education is the core of Standard two (NASPE, 2004).

Essentially, the national standards for physical education (NASPE, 2004) programming set the stage for the specific disciplinary competencies preservice physical education teachers should be exposed to in the physical education teacher education (PETE) curriculum in promoting student achievement toward the national goals. Therefore, it is important to identify what disciplinary content knowledge and pedagogical skills physical educators need to promote motor skill competence and among children and adolescents.

\section{Biomechanics and Physical Education Teacher Education}

Course work in the area of biomechanics has historically been recognized as an important foundational component of the PETE curriculum (Hall \& Evans, 2003; Henry, 1964; Hoffman 2005; NASPE, 2001). Biomechanics is the science used by physical educators in studying movement technique for the purpose of improving motor skill performance. The primary goals of course work in biomechanics are to understand movement, analyze movement quantitatively and qualitatively, and apply appropriate movement interventions (Ives \& Knudson, 2007). It is generally assumed a solid understanding of biomechanical concepts is linked to effective teaching and assisting youth in optimal skill acquisition (Hall \& Evans, 2003). Wuest and Bucher (2009) contend "it is not possible to understand motor skill development without first knowing 
about the biological aspects underlying human movement, such as joint action, anatomical structures, and muscular forces” (p. 229). An understanding of biomechanical concepts helps the physical educator visually analyze how children and adolescents move and suggest alternatives to movement patterns that will improve performance or reduce injury (Strohmeyer, 2007). With a primary objective of developing motor skill competence in youth, qualitative analysis of movement is recognized as one of the most important professional skills and application of biomechanics in physical education (Hoffman, 1977; Knudson \& Morrison, 2002; NASPE, 2003, 2008).

Biomechanics is the science within kinesiology most strongly related solving movement problems through quantitative or qualitative analysis (Knudson \& Morrison, 2002). Quantitative analysis is a data driven approach often lacking theoretical grounding, whereas, qualitative analysis is a structured, multidisciplinary approach strongly rooted in pedagogical theory (Bartlett, 2007). Although there are strengths and weaknesses in both quantitative and qualitative analyses, the methodology employed generally depends on whether the analysis is being conducted by a researcher or practitioner (Bartlett, 2007).

\section{Quantitative Analysis}

Quantitative analysis involves measurements of biomechanical variables (e.g., joint angles, force, speed) using sophisticated devices, such as videography to record movement performance (Pinheiro, 1994). Quantitative analyses are predominantly used by researchers to aid in performance comparisons, predict injury risk, or provide numerical feedback based on recorded computer computations (Bartlett, 2007). Technological advances in computer coupled with improvements in instrumentation and software have greatly assisted movement analyst (Bartlett, 2007). For example, the advent of digital videography (e.g., video camera, recorder, 
play-back unit) allows for the immediate viewing of movement by the analyst and immediate feedback to performer.

According to Bartlett (2007), quantitative analysis of movement skills can be evaluated by comparing the techniques of different individuals. This analytic approach is also employed to compare a series of trials of the same individual during a training session or sporting competition for the purpose of identifying variables that contribute to successful performance. Unlike the past, quantitative analysis is predominately used in single-case designs because the results are unable to be generalized across performers (Bartlett, 2007). According to Siedentop (2009), examples of questions typically addressed using quantitative approaches include: "How do forces summate most efficiently to produce maximum performance in the discus throw? What variables influence human tolerance to externally imposed stress, such as is inflicted in football tackling? What are the performance patterns of world class spikers in volleyball” (p. 323)?

\section{Qualitative Analysis}

Qualitative analysis is considered a "systematic observation and introspective judgment of the quality of movement for the purpose of providing the most appropriate intervention to improve performance” (Knudson \& Morrison, 2002, p. 4). A qualitative approach is typically employed by physical educators and coaches in educational or sport-oriented settings (Bartlett, 2007; Siedentop, 2009). Examples of questions generally addressed using qualitative techniques include: What are the critical features of motor skills and movement patterns? What are the mechanical errors associated with performing motor skills and specialized sport skills at different developmental stages? How can mechanical errors in movement best be remediated? Can individual with different physiques safety perform the movement or exercise? 
Solving movement problems through qualitative analysis requires an extensive knowledge based about a wide repertoire of movement actions related to sport-specific skills and exercise. In the context of physical education, students perform numerous movement responses (e.g., running, jumping, catching, throwing, dribbling, defending, striking) in a variety of movement patterns during a typical lesson. The analysis of motor skills becomes more complex during competitive situations where skill performance is influenced by changing environmental conditions. The ability to assess and appropriately intervene requires an understanding of the mover's structural and functional characteristics, the task requirement, and environmental circumstances (Ives \& Knudson, 2007). Thus, the ability of physical educators to observe, analyze, evaluate and provide the most appropriate intervention for so many skills, performed under so many changing environmental conditions poses numerous challenges. A number of professionals, however, have addressed the difficult task of improving skill analysis competence of physical education teachers (Barrett, 1983; Gangstead \& Beveridge, 1984; Hoffman, 1977; 1984; Nielsen \& Beauchamp, 1992; Stroot \& Oslin, 1993; Wilkinson, 1991, 1996; Williams \& Tannehill, 1999). As a result, qualitative skill analysis models have been proposed that either focus on the process of observation (Barrett, 1983) or a more comprehensive view for solving movement problems (Balan \& Davis, 1993; Knudson \& Morrision, 2007; Pinheiro \& Simson, 1992). The ultimate purpose of the models is to provide physical education teachers and coaches with a comprehensive and structured approach for analyzing movement skills and solving movement problems in the physical education setting.

Observation models are based on the premise that the observer's knowledge about critical elements of the movement is central to making accurate instructional decisions in qualitative analysis. The Hypothetical Model of Observing proposed by Barrett (1983), describes a 
competent observer as (a) knowing what to focus on during the observation, (b) knowing how to observe, and (c) knowing the constraints influence the observation. Within this conception, knowledge of effective instruction and teacher preparatory behaviors, such as designing the instructional environment and class monitoring techniques are essential to judging movement responses. Observational competence is emphasized throughout the literature as a prerequisite for skill diagnosis, corrective feedback, and student learning (Barrett, 1983; Behets, 1996; Biscan \& Hoffman, 1976; Imwold \& Hoffman, 1983; Stroot \& Oslin, 1993).

Comprehensive qualitative analysis models integrate knowledge from the disciplines of biomechanics, motor development, motor learning, and sport pedagogy into a conceptual framework for teaching preservice physical education teachers how to analyzing movement. Knudson and Morrison $(1997,2002)$ advocated using comprehensive models of qualitative analysis that integrate the following four stages: (1) preparation, (2) observation, (3) evaluation and diagnosis, and (4) intervention.

The Integrated Model of Qualitative Analysis proposed by Knudson and Morrison incorporates the observational competence construct and expands the scope of qualitative analysis inquiry beyond verbal feedback in enhancing movement performance. In acknowledging that a variety of factors influence motor skill learning (e.g., student characteristics, teacher behaviors, environment), their model takes into account verbal feedback is not always the most appropriate technique in solving moving problems (Knudson \& Morrison, 2002; Magill, 1994). Therefore, a number of instructional methods and approaches influencing student learning of motor skills have been incorporated into the qualitative analysis equation, such as teacher modeling (Hawkins \& Wiegand, 1989; Magill, 1994), physical guidance (Hawkins \& Wiegand, 1989), and task modification (Balan \& Davis, 1993; Knudson \& 
Morrison, 2002; Rink, 2007). The distinct features of the comprehensive framework provide kinesiology professionals with a systematic approach for qualitative analysis of movement strongly grounded in pedagogical theory.

\section{Gap between Theory and Practice in Biomechanics}

PETE professionals are challenged with thinking about ways biomechanical theoretical knowledge can be transmitted into instructional practices that facilitate skill development in children and adolescents. With increased attention on the professional preparation of physical education teachers, beginning teachers are expected to know and apply biomechanical concepts related to skillful movement, physical activity and fitness in the K-12 school setting (NASPE, 2008). Furthermore, graduates must be able to "analyze and correct critical elements of motor skills and performance concepts” (NASPE, 2008, p. 1). It is generally assumed that the theoretical and applied biomechanical competencies addressed within the PETE curriculum contribute to the prospective teacher's ability to accurately assess motor performance and provide the most appropriate intervention. The legitimacy of this basic assumption has been questioned in literature with ample evidence suggesting physical educators who have completed a basic course in biomechanics are unable to apply the knowledge to solving movement problems in the school setting (Behets, 1996; Biscan \& Hoffman, 1976; Imwold \& Hoffman, 1983; Siedentop, Doutis, Tsangaridou, et al., 1994; Stroot \& Oslin, 1993; Wilkinson, 1991; Williams \& Tannehill, 1999).

According to Hoffman (1984), there is a gap between what physical educators are taught in an introductory biomechanics course and what they are expected to apply in professional practice. Although there are biomechanics course instructors who care about making connections between theoretical concepts and professional practice, questions still remain concerning the 
relevance of biomechanics content in the preparation of prospective physical educators. Ideally, physical educators should be exposed to qualitative applications of biomechanics concepts and principles across age groups, body types, skill levels, and fitness levels and activities. However, the biomechanical literature is weak in addressing the mechanical and musculoskeletal differences between obese and non-obese youth (Strohmeyer, 2007) which may influence how competencies are addressed in undergraduate biomechanics course. Additionally, a biomechanical emphasis is generally placed on the most efficient and skillful execution of movement (Strohmeyer, 2007), rather than a developmental perspective which is necessary for promoting skillful movement in children. Scholars also suggest the scientific and technical terminology used by biomechanics course instructors is not easily transferred (Hoffman, 1977) and communicated by physical educators in professional practice (Hoffman, 1977; Knudson, 2007). According to Knudson (2003), the call for a pedagogical kinesiology (undergraduate biomechanics) previously made by Hoffman (1977) in bridging the gap remains unfulfilled with historical roots grounded in lack of consensus concerning appropriate content and applications of the content in an undergraduate biomechanics course.

Although it was traditionally assumed an undergraduate biomechanics course would sufficiently develop skill analysis competence in physical educators (Loundsbery \& Coker, 2008), biomechanics is not the subdisciplinary content of teaching K-12 physical education (Rink, 2007). Biomechanists are challenged with defining a core body of knowledge and appropriate applications of content for all kinesiology students, not just physical educators. Analysis of the status of biomechanics has revealed a decline in physical education majors and an increase in non-teaching majors taking an introductory biomechanics course from 1977 to 1983 (Marett, Pavlacka, Siler, \& Shapiro, 1984). While biomechanists traditionally had their 
roots in physical education, growth in the scientific knowledge base had also lead to an increase in the specialization of course instructors, and a decrease in analysis of sport-related activities (Hamill \& Haymes, 2005). Accordingly, course work in biomechanics provides a number of kinesiology subdisciplines with the scientific knowledge base for studying movement technique which may neglect many unique features of the physical education profession.

Locke (1990) contended teacher educators have mistakenly accepted the notion that effective instruction in physical education is dependent on subdisciplinary knowledge with little debate or evidence. Thus, the proposed gap between biomechanics content and skill analysis competence of physical educators has been compromised by a failure to identify critical biomechanics theoretical and applied competencies as they apply to teaching physical education, and delivering the content in ways that are meaningful for students within the PETE curriculum.

\section{Theoretical and Applied Competencies}

The Kinesiology Academy (now the Biomechanics Academy) of NASPE (1980) issued national approved Guidelines and Standards for Undergraduate Kinesiology in response to the growing concern over diversity in content represented in undergraduate kinesiology courses. The First National Conference on Undergraduate Teaching of Kinesiology held in 1977 rendered the development of initial guidelines and standards (NASPE, 1980). A primary objective of the conference was to present the results of a national survey on the status of kinesiology (Marett, et al., 1984), review over 100 course outlines submitted by kinesiology instructors, and discuss appropriate content for inclusion in a basic undergraduate kinesiology course (NASPE, 1980). The results of the conference revealed great differences in opinions and confusion about what should be taught an undergraduate kinesiology course (NASPE, 1980). Consequently, a task force of five biomechanists was formed and charged with developing a provisional set of 
guidelines and standards with respect to the results of the national survey and their beliefs on appropriate course content, terminology, structure, and competencies. Upon seeking feedback from Kinesiology Academy members at the AAHPERD National Convention in 1978 and 1979, the Guidelines and Standards for Undergraduate Kinesiology (now Biomechanics) were endorsed by the Kinesiology Academy of the National Association for Sport and Physical Education in 1980 as the standardized course content for an undergraduate course in kinesiology. The purpose of the Guidelines and Standards for Undergraduate Kinesiology (NASPE, 1980) was to define the exit competencies that should result from taking an undergraduate kinesiology course. The Kinesiology Academy of NASPE identified the following application competencies upon course completion:

1. The student is able to observe and describe a movement technique accurately.

2. The student is able to determine the anatomical and mechanical factors basic to the performance of an observed movement.

3. The student is able to evaluate the suitability of a performer's technique with reference to the task at hand.

4. The student is able to identify those factors which limit performance and to establish a priority for change in those factors most likely to lead to improvement in performance.

The initial NASPE (1980) guidelines and standards clearly articulate an introductory biomechanics course should emphasize qualitative analysis of motor skill activities and exercise programs, leading to applying qualitative analysis in the physical education setting. The guidelines called for "command of the qualitative method of analysis through practice in observation of performance and discrimination in quality of performance based on sound 
theoretical knowledge” as a primary goal of an undergraduate introductory kinesiology courses (p.19).

The Biomechanics Academy of NAPSE (2003) revisions of the Guidelines and Standards over the years resulted in three significant changes for undergraduate preparation. First, although the current guidelines retained their focus on student learning outcomes, qualitative analysis was de-emphasized in achieving course objectives. For example, the initial guidelines called for a theoretical understanding of content and the ability to make practical applications mainly through qualitative techniques. Whereas, the recent guidelines propose the theoretical understanding of content may take on "different forms at different academic institution" and "analytic methods can range on a continuum from quantitative to quantitative” methods (NASPE, 2003, p. 1). Second, the current guidelines reinforce the need for applications and integrations of anatomical and mechanical concepts across, age, gender, skill and fitness levels (NASPE, 2003). Finally, "infusion of biomechanical concepts into other courses is desired" in accomplishing the minimum exit course goals (NASPE, 2003, p. 1).

Competency issues. While there is obvious merit to the development of guidelines for teaching an undergraduate biomechanics course, scholars have questioned the appropriateness of the competencies in the preparation of physical education teachers (Hoffman, 1984; Knudson, 2003, 2007; Phillips \& Clark, 1984). Hoffman (1984) contends the priority of the 1980 guidelines and standards are on the development of hard core theoretical knowledge or "knowing about" rather than applied knowledge or "knowing how to.” The academic bend of the guidelines is reflected in the conceptual competencies being more specific than the applied competencies (Hoffman, 1984). 
According to Knudson (2003, 2007), the guidelines and standards remains weak on how biomechanics instructors should teach the content. The most recent guidelines and standards only have 4 application competencies devoted to human movement which make up $16 \%$ of all exit competencies. Additionally, only 3 competencies in the content areas of anatomical and mechanical bases represent higher order thinking skills (e.g., assess, evaluate, apply), while 17 include basic knowledge comprehensive (e.g., identify, define, describe). Such higher order competencies include:

A.3. Anatomical Bases of Joint Structure and Function: Assess flexibility and create safe and effective stretches for the major muscle groups surrounding each joint.

B.3. Mechanical Bases of Movement Kinematics: Explain the kinematic relationships between linear and angular motion and apply this relationship to improve motor skill performance (e.g., striking, throwing, kicking) and equipment design (e.g., sport, rehabilitation, work environment).

B.4. Mechanical Bases of Movement Kinematics: Describe how the variables of release height, angle, and velocity affect projectile motion and apply these variables to a projectile activity to optimize performance.

Although the guidelines and standards are intended to provide kinesiology students with the "the knowledge and skills necessary to complete a systematic analysis and evaluation of human motor performance” (NASPE, 2003), further examination in relation to PETE should begin by asking: Do the theoretical and applied biomechanics guidelines reinforce pedagogical relevant applications in physical education?

According to Hamill (2007), the course outcomes of the current standards are global in nature, and implementation of the competencies is open to interpretation. Although there are 
biomechanics course instructors who are interested in teaching and having the guidelines appropriate applied by practitioners, the paucity of published resources for applying biomechanics content is cause for concern. Knudson (2003) acknowledges a lack of consensus among course instructors on what it means to make meaningful applications of biomechanical course content. This is cause for concern when physical educators are expected to apply the theoretical competencies stressed in biomechanics course work to skill development and the promotion of physical activity among children and adolescents. Physical education teachers need to experience more than just theoretical knowledge if they are expected to be capable of qualitatively analyzing movement in the physical activity setting (Langendorfor, Jenkins, Crawford, Young, \& Martins, 2000).

The major debate exists concerning whether meaningful applications should be employed using a quantitative or quantitative approach in an undergraduate course (Knudson, 2003; Siedentop, 2009). While many teacher educators acknowledge the importance of a qualitative approach for physical educators (Hoffman, 1977; Hudson, 1995; Knudson \& Morrison, 2002, Lounsbery \& Coker, 2008; Morrison \& Harrison, 1997; Reeve, 2000), course instructors with a non-pedagogical background favor a quantitative approach because it is the dominant application for research in biomechanics (Satern, 1999; Siedentop, 2009). A major assumption among course instructors who are responsible for teaching to a variety of majors is that their primary purpose is to provide students with the knowledge base, leaving it to PETE faculty to provide contextually relevant applications (Rink, 2007; Ross, 1981). Scholars generally agree that a stand alone biomechanics course does not adequately prepare physical educators to qualitatively analyze movement (Hoffman, 1977; Knudson, Morrison, \& Reeve, 1991; Lock, 1972). Accordingly, Knudson and Morrison (2002) suggest qualitative analysis training should not solely reside in an 
introductory biomechanics course, but be viewed as an interdisciplinary process. Furthermore, the guidelines and standards for an introductory biomechanics course propose infusing biomechanical concepts into other courses in order to accomplish the minimum exit course goals outcomes (NASPE, 2003).

The lack of agreement of appropriate application of content, combined with competencies largely based on knowledge acquisition, does not identify with the mission of preparing physical education teachers. There is reason to suggest the theoretical subject matter knowledge acquired in a stand alone undergraduate biomechanics course may be of little practical value for physical educators unless qualitative applications are reinforced elsewhere within the PETE curriculum. Although lecture-based means of transmitting knowledge may inform physical educators, pedagogy scholars recognize this will not prepare physical educators for professional practice (Bulger, Housner, \& Lee, 2008; Daniels, 1984; Hoffman, 1977; Robertson \& Heyden, 1985). Bulger and Housner (2007) suggest that disciplinary courses in PETE should utilize instructional methods that (a) encourage high levels of student engagement, (b) demonstrate pedagogical relevance of critical concepts, and (c) allow frequent practice opportunities in a variety of instructional contexts. Implementing this 21st century vision of teaching physical education calls for a stronger integration between course work and practice in helping prospective teachers make meaningful connections between the subject matter and future teaching responsibilities (Bulger, Mohr, Carson, Robert, \& Weigand, 2000; Darling-Hammond, 2006). It has been suggested that practicing physical education teachers need to demonstrate an understanding of theoretical competencies through contextually relevant applications (Hoffman, 1977; Vickers, 1987). Otherwise, physical educators will leave PETE programs with a great deal of specialized knowledge that has little relevance for teaching physical education (Rink, 2007). 


\section{Physical Education Teacher Training Recommendations}

Qualitative analysis of movement is recognized as one of the most important professional skills and application of biomechanics in physical education (Hoffman, 1977; Knudson \& Morrison, 2002; NASPE, 2003, 2008). The following outcomes from NASPE (2008) for PETE programs explicitly link content knowledge in biomechanics in the preparation of prospective physical education teachers:

1.1 Describe and apply physiological and biomechanical concepts related to skillful movement, physical activity and fitness. (p. 1)

1.5 Analyze and correct critical elements of motor skills and performance concepts. (p. 1)

2.1 Demonstrate personal competence in motor skill performance for a variety of physical activities and movement patterns. (p. 1)

2. 3 Demonstrate performance concepts related to skillful movement in a variety of physical activities. (p. 1)

The theoretical and applied biomechanics concepts acquired within the PETE program should contribute to the prospective physical education teacher's ability to promote student achievement toward the national standards. However, there is great concern that the concepts taught and instructional methods employed in an undergraduate biomechanics course have become increasingly distant from teaching physical education (Hoffman, 1977; Siedentop, 2009). Despite questions concerning the relevance of the theoretical and applied competencies, proposals have been made to close the gap between what physical educators need to know about movement and what they are being taught in the undergraduate curriculum. These proposals are based on the premise that there is a critical need to incorporate qualitative analysis training in the 
PETE program. In response to course work in biomechanics in many teacher training institutions being unresponsive to the needs of preservice physical educators, proposed solutions for making theory-to-practice connections in biomechanics and teaching physical education have been based on curricular initiatives and instructional methods.

Curriculum recommendations. Scholars recommend preservice physical education teacher be exposed to a curriculum that infuses qualitative analysis into the PETE curriculum (Bain \& Poindexter, 1981; Bulger, et.al., 2008; Knudson \& Morrison, 2002; Lounsbery \& Coker, 2008; Morrison \& Harrison, 1997; Pinheiro, \& Simon, 1992; Rikli, 2006;). The guidelines for undergraduate biomechanics also reinforce the importance of infusing biomechanics concepts in the preparation of practitioners (NASPE, 2003). Such proposals require interdisciplinary collaboration focused on identifying and developing strategies for delivering core biomechanics content in the PETE program (Hamill, 2007; Knudson \& Morrison, 2002).

Several scholars (Knudson \& Morrison, 2002; Lounsbery \& Coker, 2008) suggest there is a need to develop of a comprehensive qualitative analysis framework from multiple perspectives (e.g. motor development, motor learning, biomechanics) to optimize a more complete understanding of movement. Included in this strategy are: (a) designating a knowledgeable faculty member charged with helping PETE faculty develop teaching materials and strategies (Morrison \& Harrison, 1997), (b) targeting instructional contexts (including a variety of activity courses) for systematically infusing critical concepts (Bulger, et al., 2008; Lounsbery \& Coker, 2008), and (c) establishing benchmarks for performance assessments in movement analysis skills (Dodds, 1994; Lounsbery \& Coker, 2008).

Morrison and Harrison (1997) presented a framework for progressively infusing qualitative analysis into the PETE curriculum. They demonstrated how qualitative analysis could 
be woven in like a thread through disciplinary courses (e.g., biomechanics, motor learning and development, exercise physiology), activity classes, and methods courses. Within this framework, a motor development course would serve as the context for preservice physical education teachers to recognize and explore developmental changes in movement patterns. Understanding the role of senses and cognition in qualitative analysis, as well as provisions for accurate feedback would be presented in motor learning. The identification of critical elements and applying the principles of mechanics in movement analysis would be served through course work in biomechanics. Furthermore, teaching-methods courses would provide as a natural context for preservice teachers to practice skill analysis with peers or school-age youth (Morrison \& Harrison, 1997).

Ives and Knudson (2007) proposed changes in the design structure of a biomechanics course. They echoed prior recommendations of the initial Guidelines and Standards for Undergraduate Kinesiology (NASPE, 1980) by suggesting preliminary changes in course requirements for an undergraduate course in biomechanics should be made to improve competence in skill analysis. They recommended an applied biomechanics course should be at least four semester hours and include a required laboratory component. This course should be based on NASPE (2004) standards for teaching an introductory biomechanics course, and include hands-on experience aimed towards applying biomechanics theory to movement assessment and instruction (Ives \& Knudson, 2007).

Other proposed curricular alternatives in biomechanics have included: (a) the addition of a separate qualitative movement analysis course (Bain \& Poindexter, 1981; Morrison \& Harrison, 1997), (b) redesigning teaching-methods course so preservice teachers learn to teach and analyze skills (Pinheiro \& Simon, 1992), and (c) having a PETE faculty member teach the 
course with a focus on applying biomechanical principles to a variety physical activities (Rink, 2007).

Curriculum issues. Implementing a comprehensive qualitative analysis strategy throughout the PETE curriculum requires a common vision, a common language, and strong commitment to the preparation of physical education teachers. However, biomechanics course instructors are not solely responsible for teaching physical education students. Thus, the primary interests of the instructor may not be solely in line with the PETE curriculum. According to Knudson (2005), kinesiology professionals in general are typically trained in limited subdisciplinary areas and acquire few rewards in interdisciplinary collaboration. It has been suggested the greatest barrier in curricular reform is likely to be biomechanics instructors with limited background in qualitative analysis (Reeve, 2000), as well as teacher educators lacking the content expertise to effectively deliver the subdisciplinary concepts to PETE students (Wiegand, Bulger, \& Mohr, 2004).

Several inherent challenges in implementing a vision requiring collaboration among professionals from different disciplines discussed in literature include: (a) establishing a strong leader for managing the collaboration process, (b) overcoming communication barriers (Hoffman, 1977; Hudson, 1995; Knudson, 2003), (c) reaching consensus on a unified instructional approach for qualitative analysis (Knudson \& Morrison, 2002; Reeve, 2000), (d) developing time intensive curricular materials (Reeve, 2000), and (e) training activity course instructors who may have a limited background in qualitative analysis (Lounsbery \& Coker, 2008).

According to Knudson and Morrison (2002), scholars from biomechanics, motor development and learning, and sport pedagogy use different terminology in defining qualitative 
analysis. The inconsistent use of terminology across subdisciplines may present problems during the collaboration process. Terms such as error identification/detection, observation, task analysis, skill analysis, movement analysis, and systematic observation have all been used interchangeable in describing qualitative analysis across disciplinary landscapes (Knudson \& Morrison, 2002). Additionally, scholars from different subdisciplines also have different views on qualitative approaches (Reeve, 2000) and use different terminology for describing the same movement phenomena in qualitative analysis (Knudson, 2007). Furthermore, the scientific and technical terminology used by biomechanists is not easily transferred across contexts (Hudson, 1995), and communicated by physical educators into the practice setting (Hoffman, 1977; Knudson, 2007).

Increasing the course requirements for preservice physical education teachers in an already credit heavy undergraduate curriculum may not be a feasible option for most PETE programs (Reeve, 2000). Rink (2007) noted that "adding content without taking away leads to teaching to lower cognitive levels” (p. 105). From a curricular perspective, PETE professionals should first examine the relevance of biomechanics theoretical and applied course content in preparing physical educators prior to adding credit hours. Additional course work in biomechanics will have little value for preservice physical educators if further examination reveals a number of the disciplinary concepts lack a direct relationship to effective physical education teaching (Wiegand, Bulger, \& Mohr, 2004).

Instructional methods recommendations. The failure of prospective physical educators to consistently demonstrate the ability to solve movement problems in the practice setting ignited proposals for instructional methods to improve the qualitative analysis ability of students (Beveridge \& Gangstead, 1988; Gangstead \& Beveridge; 1984; Morrison \& Harrison; 1997; Nielsen \& Beauchamp, 1992; Stroot \& Oslin, 1993; Wilkinson, 1991, 1996; Williams \& 
Tannehill, 1999). Previous studies employed instructional methods that were predominantly video-based and delivered through one of the following conceptual frameworks: (1) general model (Gangstead \& Beveridge, 1984), (b) skill-specific model (Morrison \& Reeve, 1986), (c) visual discrimination training program (Wilkinson, 1991, 1996), (d) pattern-specific model (Nielson \& Beauchamp, 1992), and (e) performance principle training program (Williams \& Tannehill, 1999). The various instructional approaches employed within these studies were diverse in terms of how they categorized movement (e.g., sport skill specific, mechanical principles), as well as the visual focus of the observation (e.g., body segmental phase of movement, ranking critical elements, whole to part). Collectively, the studies revealed that students receiving specialized multimedia training in qualitative analysis were more accurate in skill diagnosis than those receiving no training.

Other proposed solutions for narrowing the gap between biomechanics and teaching physical education have focused on facilitating knowledge growth in preservice teachers through concept-based teaching (Knudson, 2003, 2007; Hudson, 1995) and early field observations in the elementary school environment (Pinheiro, 2000). Scholars contributing to the applied biomechanics literature recommend formulating a concise list of biomechanical concepts and principles that can be used as a theoretical structure for teaching and applying qualitative methods to all movements in an introductory course (Knudson, 2007; Hudson, 1995). For example, Hudson (1995) recommended organizing and delivering course content around 10 core biomechanical principles (e.g., balance, coordination, speed of motion) that are easily observed and communicated by the physical education teacher to the learner. Whereas, Knudson (2007) proposed using nine general biomechanical principles organized according to body motion principles and outcome-projectile principles. Pinheiro (2000) further suggested pedagogical 
relevant application using criteria sheets in field based settings containing the following features: (1) one-page criteria sheet, (2) three phases of the motor skill (preparatory, execution, and follow through), (3) illustrations depicting each phase of the skill, (4) description of critical elements of each skill, and (5) notations concerning errors.

Instructional method issues. Much of the studies on developing physical educator's skill analysis competence have centered on discriminating between correct and incorrect motor skill performance through video-based instructional methods. Although simulated designs were shown to improve skill diagnosis, Imwold and Hoffman (1983) argued that such instructional methods are not adequate measures of analytic competence for physical education teachers who are required to observe numerous motor skills in a dynamic movement environment. They further contend that qualitative analysis competence requires extensive, task specific knowledge, practice, and real-world experience (Imwold \& Hoffman, 1983). A major finding from Reeve’s (2000) study revealed 76 percent of preservice physical education teachers indicated that instructional methods utilizing both video observation analysis, combined with textbook readings was insufficient. This literature calls into question the generalizability of video-based instructional methods in the multi-faceted physical education environment.

Although the ultimate goal a biomechanics course is developing skill analysis competence, the instructional methods utilized by the course instructor are not solely aligned with the mission of preparing physical education teachers. A typical introductory biomechanics course is now charged with preparing a spectrum of learners within kinesiology departments who specialize in a variety of fields unrelated to teaching school children (Rink, 2007). This trend in kinesiology degree programs leading to allied health careers has resulted in only six percent of undergraduate biomechanics courses offered for specific majors (Satern, 1999). A review of 
published literature revealed three significant areas that impact the educational focus and instructional methods employed in an introductory biomechanics course: (1) departmental affiliation (Hamill, 2007), (2) textbook selection (Hamill, 2007; Knudson, 2007; Rink, 2007), and (3) instructor background (Knudson, 2003; Lounsbery \& Coker, 2008; Reeve, 2000; Rink, 2007).

According to Hamill (2007), the depth of treatment given to the competencies and emphasis placed on qualitative analysis are influence by the focus of the department. For example, Hamill (2007) added that a biomechanics course taught within an exercise science department may solely emphasize quantitative approach, while a course taught within the PETE curriculum may emphasize a qualitative approach. Knudson (2003) noted that political and financial pressures to employ education technology and computer assisted instructional methods has reinforced the use of quantitative analysis applications within departments.

Rink (2007) acknowledged the fact that textbook authors have responded to the wide spectrum of learners served in undergraduate courses by publishing generic content which is far removed from teacher preparation. The major assumption in textbook driven generic courses is to provide the content knowledge, while pedagogical applications are achieved elsewhere (Rink, 2007). According to Bain and Poindexter (1981), subdisciplinary specialists are often unwilling to sacrifice their course content for issues of practical application. However, course content, textbook selection, and application decisions made by the instructor must serve the needs of students in a variety of majors, thus, reinforcing the need to seek alternative solutions for helping physical educators make meaningful application of biomechanics content.

The issue of making meaning application of course content for physical educators in an introductory biomechanics course is also related to the academic background and specialization 
of the course instructor (Knudson, 2003; Lounsbery \& Coker, 2008; Reeve, 2000; Rink, 2007). Course instructors charged with teaching biomechanics whose roots are and interests are not in pedagogy (Hoffman, 1977; Rikli, 2006) often have limited backgrounds in qualitative analysis (Reeve, 2000). Accordingly, these instructors have a tendency to "model their predecessor" and replicate instructional methods as they were taught (Knudson, 2003). It has been suggested that the instructional methods employed may have a strong emphasis on quantitative problem solving (Knudson \& Morrison, 2002) through computer mediated instruction (Miller, 1997). This questionable instructional environment provides future physical educators with inappropriate practice opportunities for applying complex biomechanical concepts in the practice setting.

To further compound the problem for appropriately applying biomechanics competencies predominately through qualitative analysis techniques, there is lack of agreement concerning (a) core biomechanical principles and theories (Knudson, 2003), (b) appropriate instructional methods for preparing physical education teachers (Knudson, 2003), and (c) how to qualitatively analyze movement (Reeve, 2000).

\section{Implications for PETE Programs}

The nation's growing concern for the health and wellbeing of school-age youth has increased the need to identify how course content and application of that content in biomechanics contributes to the prospective physical educator's ability to promote achievement toward a physical activity lifestyle. Although it was traditionally assumed an undergraduate biomechanics course would sufficiently develop skill analysis competence in physical educators (Loundsbery \& Coker, 2008), further examination has demonstrated otherwise (Knudson, Morrison, \& Reeve, 1991). Given the higher standards called for in educational reform (NASPE, 2008, 2009a, 2009b), combined with limited curricular space, there is a need to close the gap between what 
physical educators need to know about movement in the area of biomechanics, and what they are expected to apply in promoting skillful movement in the school setting. Although proposals for curricular change and instructional methods would benefit from a systematic program evaluation, questions concerning the relevance of theoretical and applied competencies are of initial concern. To provide institutional direction and cohesion, it is necessary to clearly identify biomechanics competencies that can be used as building blocks en route to overarching PETE programmatic goals. These competencies should be expressed as statements articulating the specific knowledge and skills undergraduate physical educators should develop to administer a quality physical education program. Clarifying the biomechanics theoretical content physical educators should be exposed to will (a) inform expectations for student learning and performance, (b) provide a better understanding of the most appropriate instructional methods, (c) inform the curriculum development process, and (d) guide appropriate assessment. Bridging the gap between theory and practice also requires a closer look at how core biomechanics competencies can be appropriately linked and applied within the PETE curriculum. The Delphi method was found to be a well-suited research technique in accomplishing these goals.

\section{The Delphi Method}

\section{Overview}

The Delphi method is the research technique of choice for determining the critical competencies in biomechanics for inclusion in the physical education teacher education curriculum. The technique was also found suitable for identifying specific teaching-learning environments linking core biomechanics competencies in the PETE curriculum. The Delphi method is a structured communication process aimed at generating knowledge from a group of experts by means of a series of survey questionnaires, referred to as rounds (Clayton, 1997). The 
primary purpose of the Delphi process is to achieve consensus among experts over the issue under investigation (Jones \& Hunter, 1995; Okoli \& Pawlowski, 2004). It has been suggest that the Delphi method is the most beneficial means for advancing scholarly inquiry about critical needs, assumptions, emerging issues, possibilities, goals, and future directions when analytical techniques are not possible (Ulrich, 2001). According to Lindstone (1978), the Delphi technique is most appropriate when: (a) the problem does not lend itself to analytic techniques, but can benefit from the subjective judgments of a group, (b) face-to-face interaction is not possible among individuals who need to interact, and (c) time and cost make frequent group collaboration infeasible. The use of the technique attempts to overcome the disadvantages commonly associated with face-to-face discussion groups or committee decision making by carefully selecting individuals who have specific knowledge to contribute to the investigation (Clayton, 1997). Thus, an essential component of the Delphi technique is the selection of participants since the results depend on their knowledge, cooperation, and valuable ideas (Gordon, 1994).

\section{Areas of Application}

The Delphi method was initially developed by Norman Dalkey and Olaf Helmer at the RAND Corporation during the 1950's and 1960's for the purposes of military technology forecasting (Gordon, 1994; Sahakian, 1997), information gathering (Jeffery \& Hache, 1995), and group decision-making (Ziglio, 1996). Since its induction, the technique has become a widely used research tool in a variety of disciplines (Rowe \& Wright, 1999). The majority of research using the Delphi technique has been in the health care and educational setting (Skulmoski, Harman, \& Krahn, 2007). Traditionally, the Delphi technique was used in the health care setting to address barriers in research and development, as well as forecast future medical care in specific geographic regions (Lidstone \& Turloff, 1975). In the 1970’s, various forms of the 
Delphi emerged in the nursing profession (Lindeman, 1975). As a result, the awareness spread across the health care setting with examples revealed in dietetics (Matthews, Mahaffey, Lerner, \& Bunch, 1975), dentistry (Stheeman, van’t Hof, \& van der Stelt, 1995), physiotherapy (MilesTapping, Dyck, Brunham, Simpson, \& Barber, 1990), and pediatrics (Endacott, Edwards, Crouch, Castille, Dolan, Hamilton, et al., 1999). More recently, the Delphi method has been used in health care to address constituents of exemplary practice (Kennedy, 2004). In the educational setting, the Delphi technique has been implemented for a variety of educational applications, including curriculum development, institutional planning, distance education, competency evaluation, instructional, and teacher education (Clayton, 1997). In higher education, researchers have primarily used the Delphi method to: (a) develop goals and objectives, (b) improve curriculum, (c) assist in strategic planning, and (d) develop criteria (Murray \& Hammons, 1995). Bulger and Housner (2007) recently conducted a study to determine the critical theoretical and applied exercise competencies that prospective physical education teachers need to learn within the PETE curriculum and compiled a list of instructional methods recommended for the delivery of exercise science content. A modified version of the Delphi method was employed to initiate a meaningful discussion among various experts to inform the PETE curriculum development process in the area of exercise science. A list of anatomy and biomechanics competencies was also investigated within this study since the field of exercise science encompasses a broad range of theoretical and applied competencies related to various subdisciplines. The results revealed that only 10 out of 23 anatomy and biomechanics competencies were identified as being important and relevant in the preparation of prospective physical education teachers. An expansion of this area of inquiry curriculum in the area of biomechanical knowledge was part of this present investigation 


\section{The Delphi Process}

Delphi panel. The value of the Delphi rests in the use of expert knowledge to inform future decision making. Thus, defining the primary qualifications of the participants in relation to the issue under investigation and justifying their criteria for expertise is one of the most important administration functions of the Delphi researcher (Vernon, 2009). The level of expertise could vary from practitioners in the field to highly reputable researchers in the area under investigation. Scholars have suggested an important criterion for participant selection is their subject matter knowledge and practical experience in the field of inquiry (Powell, 2002; Skulmoski, Hartman, \& Krahn, 2007), as well as their membership in a relevant professional association (Murray \& Hammons, 1995).

The size of the Delphi panel depends on the purpose of the study, as well as the diversity of the target population (Taylor-Powell, 2002). Delbecq, Van de Ven, \& Gustafson (1975) suggested the panel size can vary from 10 to 30 people, depending upon the background of the experts and the nature of the subject being explored; whereas, Ziglio (1996) contended panel sizes as low as 10 to 15 participants can yield solid results. Although there is no universally agreed criteria for the size of the expert panel, scholars recommend a majority of panel members in a Delphi study that explores a highly specialized discipline: (a) include a minimum of at least 10 members (Adler \& Ziglio, 1996; Delbecq, et al., 1975; Parente \& Anderson-Parente, 1987), (b) come from a homogenous population within the same discipline (Vernon, 2009), and (c) consist of subgroups of participants from different professional or social stratifications (Clayton, 1997).

Anonymous and asynchronous participation. The Delphi method adds a whole new dimension to the group communication process by preserving the power of expert panel 
member’s opinion through anonymous and asynchronous participation (Cyphert \& Gant, 1971).

The anonymous nature of communication eliminates numerous barriers that are inherent in faceto-face meetings, such as dominating personalities, organizational hierarchy, peer pressure, political factors, and presentation skills (Sahakian, 1997). The anonymity of the Delphi process facilitates free expression of opinions without feeling pressured or influenced by other panel members. Asynchronous participation allows panel members the freedom to choose the time of day they contribute to communication process (Turoff \& Hiltz, 1996). Additionally, the panel members may elect to respond only to the specific issues under investigation they feel the best qualified in addressing (Bulger, 2004).

Survey instrument design and mode of communication. Due to the relatively small number of Delphi panel members, the ability to achieve and maintain an ideal response rate can either ensure or jeopardize the validity of the Delphi investigation (Hsu \& Sandford, 2007). The design of the survey instrument (Hsu \& Sanford, 2007; McCampbell \& Stewart, 1992; Umback, 2005) and mode of communication are two important preliminary administrative decisions that can substantially influence the response rate and the validity of the Delphi study (Zhang, 2000).

As a preliminary task, the Delphi researcher must determine whether the issue under investigation should use the traditional Delphi (open ended questions) or a modified Delphi (closed ended questions) in the initial iteration of the survey instrument. Although the purpose of the study should influence the questioning format, the modified Delphi technique is the most popular format for structuring the communication process (McKenna, 1994). It has been suggested that the use of a modified Delphi is the appropriate option if the information concerning the area of investigation is available (Kerlinger, 1973). A modified Delphi enables the researcher to structure the communication process around a predetermined set of 
concepts/principles/statements that serve as a framework for focusing panel members' discussion. According to McCampbell and Stewart (1992), using a pre-established set of statements would (a) assure important statements were included by the researcher that otherwise might have been omitted, and (b) decrease panel member attrition. Additionally, the use of closeended questions in a pilot round of the modified Delphi investigations enables investigators to assess the content validity and comprehensiveness of the survey instrument prior to the first round of the actual Delphi study. According to Umbach (2005), measurement error can be reduced and response rates increased when questions are clear or precise and avoid "double barreling” which refers to asking two questions in one. Thus, separating complex statements into two or more separate questions may be required when designing a survey instrument that contains predetermined criteria.

The mode of communication refers to how the Delphi study is employed, focusing on the means whereby ideas are generation, analyzed, and evaluated. Two existing modes identified from literature are the traditional mailing system (paper-pencil version) and computer mediated (e-Delphi). While both modes of communication have their respective strengths and weakness, the literature suggests the benefits of the e-Delphi outweigh the traditional paper-pencil version (Chou, 2002). Scholars contend the e-Delphi provides a more dynamic and interactive platform for communication which may increase panel member involvement and the validity of the information gathered (Schmidt, 1997; Zhang, 1999). Unlike traditional paper and pencil version which requires relatively long periods of time to construct questionnaires and initiate feedback, internet technology reduces the role of the administrator allowing for the survey results to be created and executed quickly using the survey software and computer mediated communication (Chou, 2002). 
When the technical capabilities of the internet are coupled with the inherent features of the Delphi numerous opportunities are available for the researcher. First, internet technology allows the researcher to reach diverse populations within a short time span (Zhang, 2000) and send survey through electronic mail or post them on a web page. Second, advancements in online survey software have reduced the cost of survey administration for educational research, and the amount of work required in survey distribution, collection and analysis is greatly reduced. For example, specific features of software packages help the researcher manage the Delphi rounds by (a) identifying who has responded and completed or partially completed the survey, (b) sending automatic reminders to non-respondents to propel the timely completion of the online survey, and (c) allowing participants to respond to survey items in multiple sittings without losing partially entered data. Additionally, the responses entered by the participants serve as the data for the researcher, eliminating human error that may result from data entry and scanning (Zhang, 1999). Furthermore, the flexibility in web-based design allows researchers to refine appearance, incorporate easy access navigation features, order questions randomly, offer different questionnaires for Delphi subgroups (Dillman, 2000; Zhang, 1999) and incorporate various communication platforms such as free responses, voting, and threaded discussions.

Delphi rounds and consensus. The Delphi method aims to generate expert consensus on a particular issue through a dispersion of a series of survey questionnaires. The process begins by asking each panel member, referred to as participants, to complete an initial survey questionnaire and return to the researcher. The initial round attempts to uncover issues or contribute ideas related to the topic under investigation, which is often composed of open-ended questions or predetermined survey items. The researcher then summarizes the responses of the initial survey and formulates a second survey based on the ideas provided by the Delphi panel members. The 
second survey is sent to panels members who are typically asked to rank and/or rate edit, modify and comment upon the responses generated during the first round of surveys (Murray \& Hammons, 1995).

The use of rounds in the Delphi allow the researcher to tabulate the results between each round of questioning and provide panel members with feedback in the form of statistical means on each item. This allows panel members the ability to view how their responses on each item compare against the overall opinion of the group. Panel members can then reevaluate and amend their previous viewpoint and provide additional comment in light of the overall group statistical average or collective opinion as the rounds progress (Vernon, 2009). This cyclical process of survey questioning, feedback, and reconsideration is continued until a predetermined level of group consensus is achieved (Beretta, 1996; Green, Jones, Hughes, \& Williams, 1999; Murray \& Hammons, 1995). Although the literature provide little direction concerning the determination of consensus, Linger (1998) suggests that a consensus of agreement is achieved when a seventy percent of participants rate a survey item with a mean rating of five or higher on a seven-point Likert scale. The final stage of the Delphi process concludes with the final results are distributed to panel members.

\section{Advantages of the Delphi Method}

The Delphi method is a beneficial means for aggregating the collective knowledge of individuals in situations where there is incomplete or contradictory information (Hasson, Keeny, \& McKenna, 2000). When conducted properly, the method yields several advantages:

- It provides a structured framework for gather information from a diverse group of experts distributed geographically across time and space (Strauss \& Ziegler, 1975).

- It provides a flexible means for approaching difficult questions and solving complex problems when analytical techniques are not possible. 
- Time and cost make frequent group meetings infeasible.

- Improved accuracy of the decision making process due to controlled feedback and anonymity.

- Asynchronous participations provide maximum flexibility to panel members regarding the time and day they contribute to the problem solving process (Turoff \& Hiltz, 1996).

- Anonymous participation eliminates numerous barriers inherent in face-to-face meetings, such as dominating personalities, organizational hierarchy, political factors, and presentation skills (Sahakian, 1997).

\section{Limitations of the Delphi Method} literature:

Despite the proposed benefits, the following limitations have been articulated in

- High participant motivation is needed since there is an absence of direct communication with other panel members.

- Poor survey instrument design could jeopardize participant response rate and the validity of the results (Hsu \& Sandford, 2007).

- The results of the Delphi method cannot generalize beyond the specific panel of experts that contributed to the study (Clayton, 1997).

- The strength of the findings depends largely on the backgrounds and perceptions of the panel members, as well as their motivation to make a valuable contribution to the topic of investigation (Gordon, 1994).

\section{Executive Summary}

The present success of biomechanics owes much to the emergence of doctoral programs, increase in scholarly writing and research, and the formation of discipline-oriented academies over the past 40 years. Although course work in biomechanics continues to play a major academic role in preparing physical educators, the scope of biomechanics knowledge has 
incrementally become larger in scope to inform a number of other occupational contexts, such as physical therapy, occupational therapy, athletic training, and engineering. Consequently, course work must be organized and applied in a ways to meet the needs of undergraduate majors with a variety occupation goals unrelated to teaching. Although this provides prospective physical educators with a broad educational background, it also widens the gap between what they need to know and what they are expected to apply in teaching school-age children and adolescents. The essential value of biomechanical knowledge becomes diminished when practicing physical educators are unable to integrate critical biomechanical concepts and principles into the professional practice.

Although it is generally assumed that biomechanics course work provides physical educators with the knowledge and skills necessary to analyze movement, evaluate motor performance, and apply the most appropriate intervention (NASPE, 2003), there is ample evidence suggesting physical educators who have completed a basic course in biomechanics are unable to apply the knowledge to solving movement problems (Behets, 1996; Biscan \& Hoffman, 1976; Imwold \& Hoffman, 1983; Knudson, Morrison, \& Reeve, 1991; Siedentop, Doutis, Tsangaridou, et al., 1994; Stroot \& Oslin, 1993; Williams \& Tannehill, 1999). Although recent research is limited, the previous identified studies (Behets, 1996; Biscan \& Hoffman, 1976; Imwold \& Hoffman, 1983; Stroot \& Oslin 1993) combined with findings from Knudson, Morrison, \& Reeve (1991) suggest a standalone undergraduate biomechanics course is insufficient for developing skill analysis competency in physical educators.

As biomechanical knowledge has become more specialized, it is important to identify what content is appropriate for prospective physical educators, and what content should be eliminated when evaluating the effectiveness of the PETE curriculum for future physical 
education teachers. It is equally important to construct a PETE curriculum that will enable prospective physical educators to integrate and use critical knowledge skillfully in the practice context. While many critiques have highlighted the fragmentation of professional preparation programs (Howey \& Zimpher, 1989; Zeichner \& Gore, 1990), there appears to be a clear need to design PETE programs that delineate learning environments and teaching methodologies based on promising assumptions about how practicing physical educators' best learn critical biomechanical subject matter. A challenge for PETE scholars is to seek out an alternative research design that will allow greater collaboration among an interdisciplinary group of professionals to derive consensus about curricular content and teacher preparation issues. A shared level responsibility in the decision making process represents the initial critical step in addressing both the fragmentation of subject matter and misalignment issues. The Delphi method represents an important potential alternative research design for facilitating interdisciplinary communication and achieving consensus on curricular issues that has historically plagued the PETE profession.

The purpose of the present study was to generate consensus among biomechanics specialists, teacher educators, and practicing physical education teachers regarding the most critical biomechanics competencies that prospective physical educators need to learn within the PETE curriculum. A secondary aim of the study was to delineate learning environments and associated instructional methods for delivering core biomechanics content to prospective teachers within the PETE curriculum. The present study is a part of an existing line of Delphi investigations (Bulger \& Housner, 2007; Metcalf, Ross, \& Bulger, in press) systematically looking at subdisciplinary knowledge in relation to the PETE curriculum. This current study seeks to close the gap between what physical educators need to know about movement in the 
area of biomechanics, and what they are expected to apply in promoting skillful movement in the school setting.

The Delphi method represents an important alternative research design for facilitating communication between biomechanics specialist, physical education teacher educators, and practicing physical educators. This type of systemic communication may represent an important first step in bridging the proposed gap that exists between biomechanical knowledge and teaching school-based physical education. The ideas generated as a result of the Delphi process may ultimately help determine future content decisions and instructional practices within the PETE curriculum. As a result, PETE programs may better produce graduates who have the ability to apply core biomechanical content related to skillful movement, physical activity, and fitness in professional practice. 


\section{References: Review of Literature}

Adler, M., \& Ziglio, E. (1996), Gazing into the oracle: The Delphi method and its application to social policy and public health (pp. 3-33). Bristol, PA: Jessica Kingsley Publishers.

American Academy of Pediatrics. (1987). Physical fitness and the schools. Pediatrics, 80, 449450.

American Academy of Pediatrics. (2006). Active healthy living: Prevention of childhood obesity through increased physical activity. Pediatrics, 117, 1834-1841.

American College of Sports Medicine. (1988). Physical fitness in children and youth. Medicine and Science in Sports and Exercise, 20, 422-423.

American Heart Association. (1996). Statement on exercise: Benefits and recommendations for physical activity programs for all Americans. Circulation, 94, 857-862.

Bain, L. L., \& Poindexter, H. B. W. (1981). Applying disciplinary knowledge in professional preparation. Journal of Physical Education and Recreation, 52(2), 40-41.

Balan, C. M., \& Davis, W. E. (1993). Ecological task analysis approach to instruction in physical education. Journal of Physical Education, Recreation, and Dance, 64(9), 54-61.

Bar-Or, O. (2000). Juvenile obesity, physical activity, and lifestyle changes: Cornerstones of prevention and management. The Physician and Sports Medicine, 28(11), 51-58.

Barrett, K. R. (1983). A hypothetical model of observing as a teaching skill. Journal of Teaching in Physical Education, 3(1), 22-31.

Bartlett, R. (2007). Introduction to sport biomechanics: Analysing human movement patterns ( $2^{\text {nd }}$ Ed.). New York, NY: Taylor and Francis e-Library.

Behets, D. (1996). Comparison of visual information processing between preservice students and 
experiences physical education teachers. Journal of Teaching in Physical Education, 16(1), 79-87.

Beretta, R. (1996). A critical view of the Delphi technique. Nurse Researcher, 3(4), 79-89.

Beveridge, S. K., \& Gangstead, S. K. (1988). Teaching experience and training in the sports skill analysis process. Journal of Teaching in Physical Education, 7, 103-114.

Biscan, D. V., \& Hoffman, S. J. (1976). Movement analsyis as a generic ability of physical education teachers and students. Research Quarterly, 47, 161-163.

Bulger, S. M. (2004). Modified Delphi investigation of exercise science in physical education teacher education. Unpublished doctoral dissertation, West Virginia University.

Bulger, S. M., \& Housner, L. D. (2007). Modified Delphi investigation of exercise science in physical education teacher education. Journal of Teaching in Physical Education, 26, 57-80.

Bulger, S. M., Housner, L. D., \& Lee, A. M. (2008). Curriculum alignment: A view from physical education teacher education. Journal of Physical Education, Recreation, and Dance, 79(7), 44-49.

Bulger, S. M., Mohr, D. J., Carson, L. M., Robert, D. L., \& Wiegand, R. L.(2000). Preparing prospective physical educators in exercise physiology. Quest, 52, 166-185.

Chou, C. (2002). Developing the e-Delphi system: a web-based forecasting tool for educational research. British Journal of Educational Technology, 33(2), 233-236.

Clayton, M. J. (1997). Delphi: A technique to harness expert opinion for critical decisionmaking tasks in education. Educational Psychology, 17(4), 373-387. 
Corbin, C. B., \& McKenzie, T. L. (2008). Physical activity promotion: A responsibility for both K-12 physical education and kinesiology. Journal of Physical Education, Recreation, and Dance, 79(6), 47-50.

Cyphert, F. R., \& Gant, W. L. (1971). The Delphi technique: A case study. Phi Delta Kappan, 52(5), 272-274.

Daniels, D. B. (1984). Basic movements and modeling: An approach to teaching skill analysis in the undergraduate biomechanics course. In R. Shapiro \& J.R. Marett (Eds.), Proceedings, $2^{\text {nd }}$ National Symposium on Teaching Kinesiology and Biomechanics in Sports (pp. 243246). Colorado Springs, CO: NASPE.

Darling-Hammond, L. (2006). Constructing 21st-century teacher education. Journal of Teacher Education, 57(3), 300-314.

Delbecq, A. L., Van de Ven, A. H., \& Gustafson, D. H. (1975). Group techniques for program planning: A guide to nominal and Delphi processes. Scott, Foresman and Company: Glenview, IL.

Dillman, D. (2000). Mail and Internet surveys: The tailored design method (2nd ed.). New York: John Wiley \& Sons, Inc.

Dodds, P. (1994). Cognitive and behavioral components of expertise in teaching physical education. Quest, 46(2), 153-163.

Endacott, R., Edwards, B., Crouch, R., Castille, K., Dolan, B., Hamilton, C., et al. (1999). Towards a faculty of emergency nursing. Emergency Nurse 7(5), 10-16.

Gagne, R. M. (1968). Contributions of learning to human development Psychological Review, 75(3) 177-191. 
Gangstead, S. K., \& Beveridge, S. K. (1984). The implementation and evaluation of a methodological approach to qualitative sport skill analysis instruction. Journal of Teaching in Physical Education, 3(2), 60-70.

Gordon, T. J. (1994). The Delphi method: Future research methodology. Washington, DC: Report by American Council for the United Nations University Millennium Project. Retrieved from http://www.futurovenezuela.org/_curso/5-delphi.pdf.

Graber, K. C. (2001). Research on teaching in physical education. In V. Richardson (Ed.), Handbook of research on teaching (4th ed.) (pp. 491-519). Washington, DC: American Educational Research Association.

Green, B., Jones, M., Hughes, D., \& Williams, A. (1999). Applying the Delphi technique in a study of GPs information requirement. Health and Social Care in the Community, 7(3), 198-205.

Hall, S. J., \& Evans, G. G. (2003). Biomechanics. In Concepts and Principles of Physical Education: What Every Student Needs to Know (2nd ed.) B. Mohnsen, ed. Reston, VA: NASPE.

Hamill, J. (2007). Biomechanics Curriculum: Its content and relevance to movement sciences. Quest, 59, 25-33.

Hamill, J., \& Haymes, M. (2005). Biomechanics, exercise physiology, and the 75th anniversary of RQES. Research Quarterly for Exercise and Sport, 76(2), S53-61.

Hasson, F., Keeney, S., \& McKenna, H. (2000). Research guidelines for the Delphi survey technique. Journal of Advanced Nursing, 32(4), 1008-1015.

Hawkins, A. H., \& Wiegand, R. L. (1989). West Virginia University teaching evaluation system and feedback taxonomy. In D. W. Darst, D. B. Zakrajsek, \& V. H. Mancin (Eds.). 
Analyzing Physical Education and Sport Instruction (pp. 277-294). Champaign, IL: Human Kinetics.

Haywood, K. M., \& Getchell, N. (2005). Lifespan Motor Development (4 ${ }^{\text {th }}$ ed.). Champaign, Ill: Human Kinetics.

Henry, F. M. (1964). Physical education-An academic discipline. Journal of Health, Physical Education and Recreation, 35(32), 69-70.

Hoffman, S. J. (1977). Toward a pedagogical kinesiology. Quest, 28, 38-48.

Hoffman, S. J. (1984). Contributions of biomechanics to clinical competence: A view from the gymnasium. In R. Shapiro \& J. R. Marett (Eds.), Proceedings of the second national symposium on teaching kinesiology and biomechanics in sports (pp. 17-20). Colorado Springs: NASPE.

Hoffman, S. J. (2005). Introduction to kinesiology: Studying physical activity $\left(2^{\text {nd }}\right.$ ed.). Champaign, IL: Human Kinetics.

Howey, K. R., \& Zimpher, N. L. (1989). Profiles of preservice teacher education: Inquiry into the nature of programs. Albany, NY: State University of New York Press.

Hsu, C. C., \& Sandford, B. A. (2007). Minimizing non-response in the Delphi process: How to respond to non-response. Practical Assessment, Research \& Evaluation, 12(17). 62-78.

Hudson, J. L. (1995). Core concepts in kinesiology. Journal of Physical Education, Recreation, and Dance, 66(5), 54-55, 59-60.

Imwold, C. H., \& Hoffman, S. J. (1983). Visual recognition of a gymnastic skill by experienced and inexperienced instructors. Research Quarterly for Exercise and Sport, 64, 167-17.

Ives, J. C., \& Knudson, D. (2007). Professional practice in exercise science: The need for greater disciplinary balance. Sports Medicine, 37(2), 103-115. 
Jeffery, G., \& Hache, G. (1995). A group-based Delphi application: Defining rural career counseling needs. Measurement and Evaluation in Counseling and Development, 28(1), 45-61.

Jones, J., \& Hunter, D. (1995). Consensus methods for medical and health services research. British Medical Journal, 311, 376-380.

Kennedy, H. P. (2004). Enhancing Delphi research: methods and results. Journal of Advanced Nursing, 45(5), 504-511.

Kerlinger, E. N. (1973). Foundations of behavioral research (2nd ed.). New York: Holt, Rinehart \& Winston.

Knudson, D. (2003). An integrated approach to the introductory biomechanics course. Physical Educator, 60(3), 122-133.

Knudson, D. (2005). Evidence-Based Practice in Kinesiology: The Theory to Practice Gap Revisited. Physical Educator, 62(4), 212-221.

Knudson, D. V. (2007). Qualitative biomechanical principles for application in coaching. Sports Biomechanics, 6(1), 109-118.

Knudson, D. V., \& Morrison, C. S. (2002). Qualitative analysis of human movement. (2 ${ }^{\text {nd }}$ Ed.). Champaign, IL: Human Kinetics.

Knudson, D. V, Morrison, C. S., \& Reeve, J. (1991). Effects of undergraduate kinesiology courses on qualitative analysis ability. In J. D. Wilkerson, E. Kreighbaum, \& C. L. Tant (Eds.). Teaching kinesiology and biomechanics in sports (pp. 17-20). Ames: Iowa State University.

Lindeman, C. A. (1975). Delphi survey of priorities in clinical nursing research. Nursing Research, 24, 434-441. 
Lindstone, H. A. (1978). The Delphi technique. In J. Fowlers (Ed.), Handbook of futures research (pp. 273-300). West port, CT: Greenwood Press.

Linstone, H., \& Turoff , M. (1975). The Delphi method: Techniques and applications. Reading, MA: Addison-Wesley Publishing Company.

Linger, B. T. (1998). What primary care physicians need to know about attention-deficit hyperactivity disorder: A Delphi of experts and a content analysis. Unpublished doctoral dissertation, West Virginia University, Morgantown, WV.

Locke, L. (1972). Implications for physical education. Research Quarterly, 43, 374-386.

Locke, L. (1990). Why motor learning is ignored: a case of ducks, naughty theories, and unrequited love. Quest, 42(2), 134-142.

Lounsbery, M., \& Coker, C. (2008). Developing skill-analysis competency in physical education teachers. Quest, 60, 255-267.

Magill, R. A. (1994). Influence of augmented feedback on skill learning depends on characteristics of the skill and learner. Quest, 46, 314-327.

Marett, J. R., Pavlacka, J. A., Siler, W. L., \& Shapiro, R. (1984). Kinesiology status update: A national survey. In R. Shapiro \& J. R. Marett (Eds.), Proceedings: Second national symposium on teaching kinesiology and biomechanics in sports (pp. 2-15). Colorado Springs, CO: USOC.

Matthews, M. E., Mahaffey, M. J., Lerner, R. N., \& Bunch, W. L. (1975). Profiles for the future of administrative dieticians via Delphi technique. Journal of the American Dietetic Association, 66(5): 494-9.

McCampbell, W. H., \& Stewart, B. R. (1992). Career ladder programs for vocational education: Desirable characteristics. Journal of Vocational Education Research, 17(1), 53-68. 
McKenna, H. P. (1994). The Delphi technique: A worthwhile approach for nursing? Journal of Advanced Nursing, 19, 1221-1225.

McKenzie, T. L. (1999). School health-related physical activity programs: What do the data say? Journal of Physical Education, Recreation and Dance, 70(1), 16-19.

Miles-Tapping, C., Dyck, A., Brunham, S., Simpson, E., \& Barber, L. (1990). Canadian Therapists priorities for clinical research: A Delphi study. Physical Therapy, 70(7), 44854.

Miller, D. I. (1997). Technology in biomechanics instruction. Quest, 49, 291-295.

Morrison, C. S., \& Harrison, J. M. (1997). Integrating qualitative analysis of movement in the university physical education curriculum. The Physical Educator, 54(2), 64-71.

Morrison, C. S., \& Reeve, E. J. (1986). Effect of instructional units on the analysis of related and unrelated skills. Perceptual and Motor Skills, 62, 563-566.

Murray, J., \& Hammons, J. O. (1995). Delphi: A versatile methodology for conducting qualitative research. The Review of Higher Education, 18(4), 423-436.

National Association for Sport and Physical Education (NASPE) Kinesiology Academy. (1980). Guidelines and standards for undergraduate kinesiology. Journal of Physical Education and Recreation, 51(2), 19-21.

National Association for Sport and Physical Education (NASPE). (2001). Initial physical education program report manual ( $5^{\text {th }}$ ed.). Reston, VA: NASPE Publications.

National Association for Sport and Physical Education (NASPE). (2003). National standards for beginning physical education teachers $\left(2^{\text {nd }}\right.$ ed.). Reston, VA: National Association for Sport and Physical Education. 
National Association for Sport and Physical Education (NASPE). (2004). Moving into the future: National standards for physical education ( $2^{\text {nd }}$ ed.). Reston, VA: National Association for Sport and Physical Education.

National Association for Sport and Physical Education. (2008). National Initial physical education teacher education standards. Retrieved from http://www.aahperd.org/naspe/grants/accreditation/upload/2008-National-Initial-PETEStandards.pdf.

National Association for Sport and Physical Education. (2009a). Active start: A statement of physical activity guidelines for children birth to five year, $\left(2^{\text {nd }}\right.$ ed.). Reston, VA: NASPE Publications.

National Association for Sport and Physical Education. (2009b). Appropriate practice in movement programs for children ages 3-5, $3^{\text {rd }}$ Edition: Position statement. Reston, VA: NASPE Publications.

Nielsen, A. B., \& Beauchamp, L. (1992). The effects of training in conceptual kinesiology on feedback provision patterns. Journal of Teaching in Physical Education, 11(2), 126-138.

Okoli, C., \& Pawlowski, S. (2004). The Delphi method as a research tool: An example, design considerations and applications. Information and Management, 42, 15-29.

Parente, F. J., \& Anderson-Parente, J. (1987). Delphi inquiry systems. In G. Wright \& P. Ayton (Eds.), Judgmental forcasting (pp. 129-156). New York: John Wiley \& Sons.

Pate, R. R., Davis, M. G., Robinson, T. N., Stone, E. J., Thomas, M. L., \& Young, J. C. (2006). Promoting physical activity in children and youth: a leadership role for schools. Journal of the American Heart Association, 114, 1214-1224. 
Payne, G. V., \& Issacs, L. D. (2008). Human motor development: A lifespan approach (7 ${ }^{\text {th }}$ ed). New York, NY: McGraw-Hill.

Phillips, S. J., Clark, J. E. (1984). An integrated approach to teaching kinesiology: A lifespan approach: In R. Shapiro \& J. R. Marett (Eds.), Proceedings: Second national symposium on teaching kinesiology and biomechanics in sports (pp. 19-23). Colorado Springs, CO: USOC.

Pinheiro, V. (1994). Diagnosing motor skills: A practical approach. Journal of Physical Education, Recreation and Dance, 65(2), 49-54.

Pinheiro, V. E. D. (2000). Qualitative analysis for the elementary grades. Journal of Health, Physical Education, Recreation, and Dance, 71(1), 18-21.

Pinheiro, V. E. D., \& Simon, H. A. (1992). An operational model for motor skill diagnosis. Journal of Teaching in Physical Education, 11, 288-302.

Powell, C. (2002). The Delphi technique: Myths and realities. Journal of Advanced Nursing, 41 (4), 376-382.

Reeve, J. (2000). Qualitative analysis: Putting it all together. The Journal of Physical Education, Recreation, and Dance, 71(1), 16-17.

Rikli, R. E. (2006). Kinesiology - A “homeless” field: Addressing organization and leadership needs. Quest, 58, 288-308.

Rink, J. (2007). What knowledge is of most worth? Perspectives on kinesiology from pedagogy. Quest, 59, 100-110.

Robertson, L. D., \& Heyden, S. M. (1985). Integrating the subdisciplines - A culminating experience for undergraduate physical educators. Physical Educator, 42(2), 65-71.

Ross, S. (1981). The epistemic geography of physical education: Addressing the problem 
of theory and practice. Quest, 33, 42-54.

Rowe, G., \& Wright, G. (1999). The Delphi technique as a forecasting tool: Issues and analysis. International Journal of Forecasting 15 (4), 353-375.

Sahakian, C. E. (1997). The Delphi method. Skokie, IL: The Corporate Partnering Institute.

Sallis, J. F., Prochaska, J. J., \& Taylor, W. C. (2000). A review of correlates of physical activity of children and adolescents. Medicine and Science in Sports and Exercise, 32, 963-975.

Satern, M. (1999). Teaching undergraduate biomechanics/kinesiology: A national survey. Paper presented to the Biomechanics Academy at the AAHPERD National Convention, Boston, MA.

Schmidt, W. C. (1997). World-Wide Web Survey Research: Benefits, Potential Problems, and Solutions. Behavior Research Methods, Instruments, \& Computers, 29(2), 274-279.

Siedentop, D. (2009). Introduction to physical education, fitness and sport ( $\left.7^{\text {th }} \mathrm{ed}\right)$. New York, NY: McGraw-Hill.

Siedentop, D., Doutis, P., Tsangaridou, N., Ward, P., \& Rauschenbach, J. (1994). Don't sweat gym! An analysis of curriculum and instruction. Journal of Teaching in Physical Education, 13, 375-394.

Skulmoski, G. J., Hartman, F. T., \& Krahn, J. (2007). The Delphi method for graduate research. Journal of Information Technology Education, 6, 1-21.

Stheeman, S. E., van’t Hof, M. A., Mileman, P. A., \& van der Stelt, P. F. (1995) Use of the Delphi technique to develop standards for quality assessment in diagnostic radiology. Community Dental Health, 12, 194-199. 
Strauss, H., \& Ziegler, H. (1975). The Delphi technique and its uses in social science research. Journal of Creative Behavior, 9(4), 253-259.

Strohmeyer, S. (2007). The biomechanical implications of obesity in K-12 learners: Few studies have targeted the musculoskeletal and mechanical implications of excessive weight. Journal of Physical Education, Recreation and Dance, 78(8), 40-42.

Stroot, S. A., \& Oslin, J. L. (1993). Use of instructional statements by preservice teachers for overhand throwing performance of children. Journal of teaching in physical education, 13, 24-45.

Taylor-Powell, E. (2002). Quick tips collecting group data: Delphi technique. University of Wisconsin, Madison, WI. Retrieved from: http://uwex.edu/ces/pdade/resources/pdf/ Tipsheet4.pdf.

Thomas, K. T., \& Thomas, J. R. (2008). Principles of motor development for elementary school physical education. The Elementary School Journal, 108(3), 181-195.

Turoff, M., \& Hiltz, S. R. (1996). Computer-based Delphi processes. In M. Adler \& E. Ziglio (Eds.), Gazing into the oracle: The Delphi Method and its application to social policy and public health (pp.56-85). Bristol, PA: Jessica Kingsley Publishers.

Ulrich, W. (2001). The quest for competence in systemic research and practice. Systems Research and Behavioral Science, 18(1), 3-28.

Umbach, P. D. (2005). Getting back to the basics of survey research. New Directions for Institutional Research, 127, 91-100.

U. S. Department of Health and Human Services. (1996). Physical activity and health: A report of the Surgeon General. Atlanta, GA: U.S. Department of Health and Human Services, 
Center for Disease Control and Prevention, National Center for Chronic Disease Prevention and Health Promotion.

U. S. Department of Health and Human Services. (1997). Guidelines for school and community programs to promote lifelong physical activity among young people. Morbidity and Mortality Weekly Report, 46(N0. RR-6), 1-35.

U. S. Department of Health and Human Services. (2000). Promoting better health for young people through physical activity and sports. Atlanta, GA: U.S. Department of Health and Human Services and Department of Education.

Vernon, W. (2009). The Delphi technique: A review. International Journal of Therapy and Rehabilitation, 16(2), 69-76.

Vickers, J. N. (1987). The role of subject matter in the preparation of teachers in physical education. Quest, 39, 179-184.

Wiegand, R. L., Bulger, S. M., \& Mohr, D. J. (2004). Curricular issues in physical education teacher education. Journal of Physical Education, Recreation and Dance, 75(8), 47-55.

Wilkinson, S. (1991). A training program for improving undergraduate's analytical skill in volleyball. Journal of Teaching in Physical Education, 11, 177-194.

Wilkinson, S. (1996). Visual analysis of the overarm throw and related sport skills: Training and transfer effects. Journal of Teaching in Physical Education, 16(1), 66-78.

Williams, E., \& Tannehill, D. (1999). Effects of a multimedia performance principle training program on correct analysis and diagnosis of throw-like movements. Physical Educator, 56(3), 143-154.

Wuest, D. A., \& Bucher, C. A. (2009). Foundations of physical education, exercise science, and sport ( $6^{\text {th }}$ ed), New York, NY: McGraw-Hill. 
Zeichner, K. M., \& Gore, J. M. (1990). Teacher socialization. In W. R. Houston (Eds.), Handbook of research on teacher education (pp. 329-348). New York: Macmillan.

Ziglio, E. (1996). The Delphi Method and its contribution to decision-making. In M. Adler \& E. Ziglio (Eds.), Gazing into the oracle: The Delphi Method and its application to social policy and public health (pp. 3-33). Bristol, PA: Jessica Kingsley Publishers.

Zhang, Y. (1999). Using the Internet for survey research. Society for Information Science, 51(1), 57-68.

Zhang, Y. (2000). Using the Internet for survey research: A case study. Journal of the American Society for Information Science, 51(1), 57-68. 


\section{Appendix B}

Biomechanics Recommendations for the Physical Education Teacher Education Curriculum Pilot Study 


\section{E-mail to Identify Participants for Recruitment}

Hello (insert name here):

I am a doctoral student in physical education teacher education at West Virginia University. I am beginning my dissertation research study titled Recommendations for Biomechanics in the Physical Education Teacher Education Curriculum. The purpose of my study is to generate consensus among an interdisciplinary panel of experts (biomechanics specialists, physical education teacher educators, K-12 physical education teachers) regarding the most critical biomechanical competencies that prospective physical educators need to learn within the PETE curriculum. The reason for this e-mail is because I am in need of experts for my study.

I know you are an expert in the field of biomechanics and I am in need of finding other experts such as yourself. Therefore, I was wondering if you would recommend experts who currently teach biomechanics or who teach biomechanics within a physical education teacher education curriculum? I will be randomly selecting from the list of names generated to see if they would like to participate in my study. I greatly appreciate your time and any information you could send me!

Also, please let me know if you would be willing to serve as a potential expert in this study. Your knowledge and perspective regarding the role of biomechanics in preparing physical educators would certainly make a valuable contribution to this study.

Thank you for your assistance,

Susan Ross

Susan Ross

West Virginia University

College of Physical Activity \& Sport Sciences

P.O. Box 6116

Morgantown, WV 26506

(304) 293-0848 


\section{E-mail for Pilot Study Participant Recruitment}

Hello (insert name here):

I am writing to request your participation as an expert judge for the instrument design phase of a research project being conducted at West Virginia University, titled Recommendations for Biomechanics in the Physical Education Teacher Education Curriculum. You were selected to participate because of your high degree of expert knowledge in (a) biomechanics, (b) physical education teacher education, and/or (c) K-12 physical education. If you choose to contribute, your specific role in this project will be to critique an online survey instrument containing 20 concepts followed by 108 key competencies in the area of biomechanics.

The ultimate goal of this preliminary phase of the research project is to produce a valid list of theoretical and applied competencies that will be judged for inclusion the physical education teacher education undergraduate curriculum in a follow-up Delphi investigation. There is no known research to date that has employed an interdisciplinary team to examine a list of theoretical and applied biomechanics competencies as they specifically apply to the preparation of prospective physical education teachers. Expert validation of a complete list of competencies is necessary prior to implementation in the Delphi study that will follow.

You will receive an e-mail message containing a link to the survey questionnaire and instructions. You will remain anonymous to other expert participants, and only I (the researcher) will be able to identify your specific answers. Your name will be used only in the list of contributors to the study. All other information provided by you will remain confidential.

The amount of time necessary to evaluate and critique the survey instrument will vary with each participant, but will range from 1 to 1.5 hours. The tentative time line for the pilot phase will begin December 11, 2009 and end on January 8, 2010. You are free to contribute within that time frame at your convenience. There are no right or wrong answers in evaluating survey items; the study is seeking your expert opinion. In a follow-up study, the Delphi panel members will use the questionnaire you help design to rate a series of biomechanics competencies in terms of their importance and pedagogical relevance for prospective P-12 physical education teachers. You will be sent the complete results of the final study.

Please reply to this email (sross11@mix.wvu.edu) and let me know you willingness to participate in this study. Should you have any immediate questions, please feel free to call me at (304) 293-0848.

Thank you for your consideration, Susan Ross West Virginia University, College of Physical Activity \& Sport Sciences sross11@mix.wvu.edu, (304) 293-0848

This study is being conducted by Susan Ross and Andrew Hawkins, Ph.D., both are with the College of Physical Activity and Sport Sciences at West Virginia University. 


\section{Phone Script for Pilot Study Participant Recruitment}

"Hello, my name is Susan Ross and I am calling to request your participation as an expert panel member for the pilot test of my dissertation titled Recommendations for Biomechanics in the Physical Education Teacher Education Curriculum. This research study will involve the administration of a Delphi procedure to determine the essential biomechanics competencies that should be included in the physical education teacher education curriculum. For your contribution to this research study, I simply need you to critique the survey items using a rating scale that will eventually be employed to justify the validity and completeness

of each competency for its future use in the physical education teacher education curriculum.

- You must be 18 years of age or older to participate.

- Your participation is entirely voluntary, you can choose to stop participation at any time and you do not have to answer any questions you do not want to answer.

- Your responses will be kept as confidential as legally possible. All data will be erased once my dissertation is complete. At no time will your name be revealed during reporting.

- Your job status will not be affected if you decide either not to participate or to withdraw.

- West Virginia's University's Institutional Review Board acknowledgement of this project is on file.

Would you be interested in participating as an expert for this pilot study?”

\section{YES/NO (IF “NO” GO TO 1 / IF “YES” GO TO 2)}

1. “Thank you for your time and consideration.”

2. “Thank you for agreeing to participate; your time and efforts are greatly appreciated. I will email more information regarding your participation in this research study, as well as a link to the online survey instrument. Thank you for agreeing to participate. Your expert contribution is vital to the success of this research project.” 


\section{E-mail to Provide Pilot Study Detailed Information}

Hello (insert name here),

Thank you for agreeing to participate as an expert panel member! The expert panel members for this study will consist of three biomechanics experts, three physical education teacher educators, and three K-12 physical education teachers.

Before taking part in this study I want to make sure you understand the following: You must be 18 years of age or older to participate; Your participation is entirely voluntary, you can choose to stop participation at any time and you do not have to answer any questions you do not want to answer; Your responses will be kept as confidential as legally possible; All data will be erased once all research interests are exhausted; At no time will your name be revealed during reporting; Your job status will not be affected if you decide to either not participate or withdraw; and West Virginia's University's Institutional Review Board (IRB) acknowledgement of this project is on file.

If possible, I would greatly appreciate if you would please complete the online survey by January 8th. Instructions on completing the online survey will appear once you access the survey hyperlink below. You must commit to the completion of the survey prior to clicking on the hyperlink above. You will not be allowed to access the survey more than once.

The following hyperlink will direct you to the online survey: http://www.surveymonkey.com/s/CK6BL3R

Thank you again for agreeing to participate in this study. If you have any questions, please feel free to contact me at sross11@mix.wvu.edu or (304) 293-0848.

Sincerely,

Susan

Susan Ross

West Virginia University

College of Physical Activity \& Sport Sciences

P.O. Box 6116

Morgantown, WV 26506

(304) 293-0848 


\section{Biomechanics Modified Delphi Pilot Study}

\section{Survey I ntroduction}

Welcome and thank you for agreeing to participate in the instrument development phase of this Delphi investigation!

Your input regarding these competencies will have the potential to influence future curricular decision making in physical education teacher education. Your practical experience, insight, and judgment are vital to the success of this project. The survey items you have agreed to review will be used in a subsequent research project to generate consensus of expert opinion regarding the critical theoretical and applied biomechanics competencies that prospective physical educators need to learn within the physical education teacher education curriculum.

The Delphi method will be used to address this research inquiry in a follow-up study with a different panel of experts. The Delphi method is a research protocol that involves (a) the identification and selection of a small panel of experts, (b) the use of multiple rounds of surveying as a means to collect expert opinion on a topic, and (c) the attainment of group consensus through regular feedback.

Please remember the final date for survey completion is January 8th. You will be sent the results of this pilot study as well as the final results from the research project. The final results will reveal expert recommendations for undergraduate biomechanics competencies in the physical education teacher education curriculum.

Thank you for your time and input! I greatly appreciate your assistance in the timely completion of this project. Please feel free to call or e-mail me with any questions you may have.

Susan Ross

West Virginia University

College of Physical Activity \& Sport Sciences

sross11@mix.wvu.edu

(304) 293-0848

Due to the nature of study, the list of potential survey items you are asked to evaluate is rather extensive. The items that you are evaluating were adapted from a variety of sources, including:

* National Assocation for Sport and Physical Education Kinesiology Academy. (1980). Guidelines and standards for undergraduate kinesiology. J ournal of Physical Education and Recreation, 51(2), 19- 21.

* National Association for Sport and Physical Education. (2003). Guidelines for Undergraduate Biomechanics. Reston, VA: NASPE Publications.

*Hall, S.J. (1999). Basic Biomechanics. New York, NY: McGraw-Hill.

*Knudson, D.V., \& Morrison, C.S. (2002). 2nd Ed. Qualitative Analysis of Human Movement. Champaign, IL: Human Kinetics.

*Hamilton, N., Weimar, W., \& Luttgens, K. (2008). 11th Ed. Kinesiology: Scientific Basis of Human Motion. New York, NY: McGraw- Hill.

All are reproduced with the permission of the Motor Development Academy within NASPE; as well as McGraw- Hill and Human Kinetics. 


\section{Biomechanics Modified Delphi Pilot Study}

\section{Survey I nstructions}

The survey instrument you are helping to design will ultimately include a comprehensive list of undergraduate biomechanics competencies that will judged in regards to their importance and relevance in the physical education teacher education curriculum.

The goal of this pilot phase of the research project is to produce a valid list of biomechanics competencies that comprehensively represent the available body of knowledge in the area of biomechanics. Your role as an expert is to evaluate the content validity and completeness of the survey items and instrument.

The survey contains 20 concepts followed by key competencies.

Please do the following:

1) DETERMINE CONTENT VALIDITY. Is the item a valid biomechanical competency that could potentially be incorporated in the physical education teacher education curriculum?

Rate each competency individually using the following scale contained within the survey:

- Rating of (5) means DEFINITELY KEEP the item;

- Rating of (4) means PROBABLY KEEP the item;

- Rating of (3) means you are NEUTRAL or undecided;

- Rating of (2) means PROBABLY DROP the item;

- Rating of (1) means DEFINITELY DROP the item from the study because it is not a valid biomechanics competency for physical education teacher education.

2) DETERMI NE COMPLETENESS. In the space provided within each concept area:

- Suggest revisions for competencies (e.g. changes in terminology) that are not an adequate

representation of the content or are unclear. Please be as specific as possible and refer to each item by their corresponding letter ( $a, b, c$, etc).

- Add any new competencies you feel are needed.

Your critique of survey items will serve to improve the quality of this survey instrument for subsequent rounds.

3) At the conclusion of the survey a space has been provided for you to write any additional concepts and/or competencies that you would like added to the survey instrument.

REMINDERS:

1-You must enter your name on the first page of the survey in order to continue with the survey. This is the only question you must answer.

2-You may return to the instructions page at any time by using the "Prev" buttons at the bottom of the survey pages.

3- There is complete freedom (once you have entered your name) to go to any page within the survey and change your responses if necessary.

4- Once you have accessed the website link, you WILL BE allowed to go back into the survey at another day/time at your convenience. However, the survey will end on January 8, 2010.

5- A survey completion bar will be located at the top of each page in order to show your progress through the survey.

Thank you very much for your assistance in completing the instrument design phase of this research project. 


\section{Biomechanics Modified Delphi Pilot Study}

\section{Table of Contents}

Section 1: Participant Information

Section 2: Introduction to Biomechanics (Question 2)

Section 3: Application of Biomechanics Competencies to Human Movement (Question 3)

Section 4: Qualitative Analysis of Human Movement (Questions 4- 7)

Section 5: Quantitative Analysis of Human Movement (Question 8)

Section 6: Anatomical Bases (Questions 9-11)

Section 7: Mechanical Bases (Questions 12-14)

Section 8: Motor Skills: Principles and Applications (Questions 15-21)

Section 9: Open Ended Question (Question 22)

Section 10: Survey Instrument's Overall Quality (Questions 23-24) 


\section{Biomechanics Modified Delphi Pilot Study}

\section{Section 1: Participant I nformation}

* 1. Please enter your name:

Name: 


\section{Biomechanics Modified Delphi Pilot Study}

\section{Section 2: I ntroduction to Biomechanics}

\section{The student will be able to:}

a) define the terms biomechanics, statics, dynamics, kinematics, and kinetics and explain the ways in which they are related.

b) describe the scope of scientific inquiry addressed by biomechanists.

c) distinguish between qualitative and quantitative approaches for analyzing human movement.

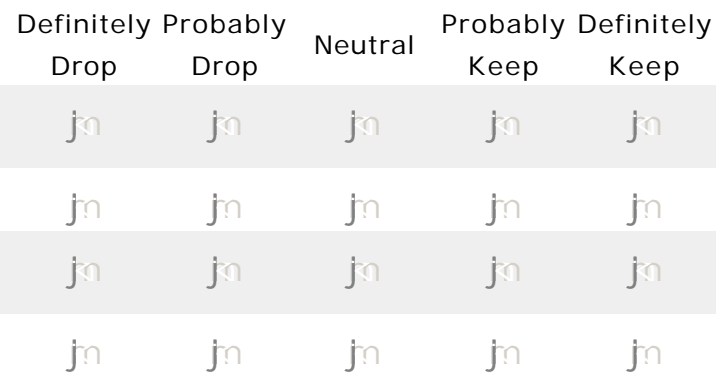

d) explain how to formulate questions for qualitative analysis of human movement.

Please list below any suggestions for improvement and/or any additional competencies for this section.

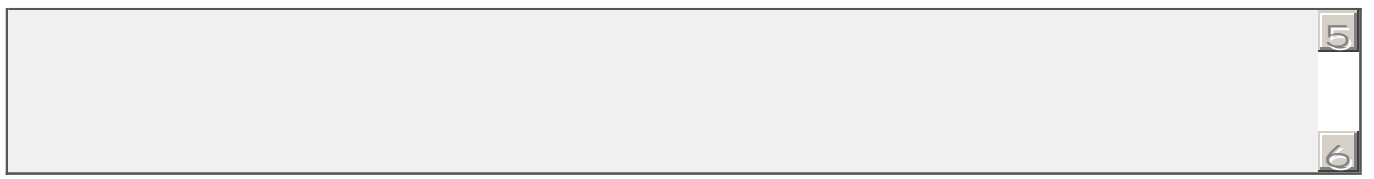




\section{Biomechanics Modified Delphi Pilot Study}

\section{Section 3: Application of Biomechanics Competencies to Human}

\section{Movement}

\section{The student will be able to:}

a) observe and describe a movement technique accurately

b) determine the anatomical and mechanical factors basic to the performance of an observed movement

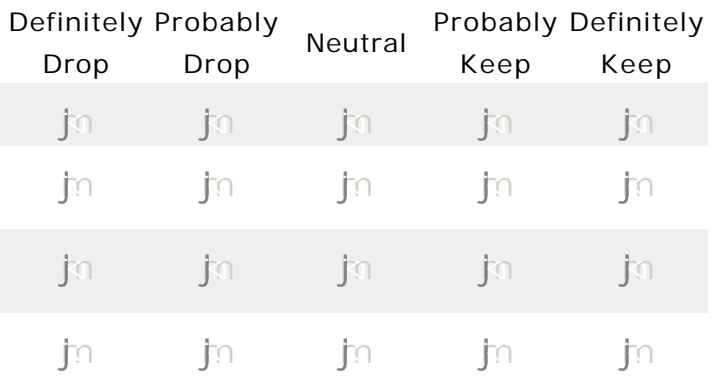
the task at hand

d) identify those factors that limit performance and establish a priority for change in those factors most likely to lead to improvement in performance.

Please list below any suggestions for improvement and/or additional competencies for this section.

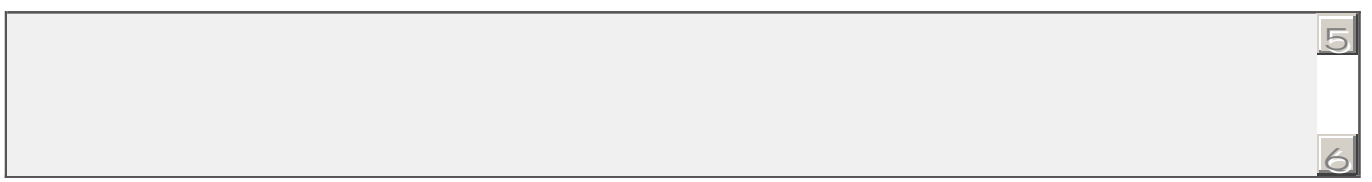




\section{Biomechanics Modified Delphi Pilot Study}

\section{Section 4 : Qualitative Analysis of Human Movement}

\section{Preparation: Gathering Relevant Knowledge}

\section{The student will be able to:}

a) define the critical features of various skills and explain how they are identified in the preparation task of qualitative analysis.

b) explain how preparation in qualitative analysis is related to effective teaching and systematic observation.

c) explain how preparing for qualitative analysis can be integrated with planning for teaching.

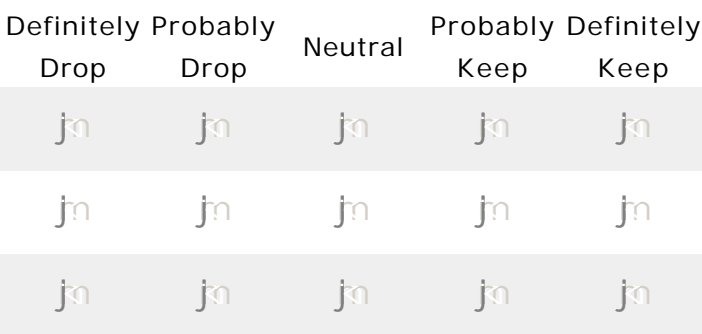

Please list below any suggestions for improvement and/or any additional competencies for this section.

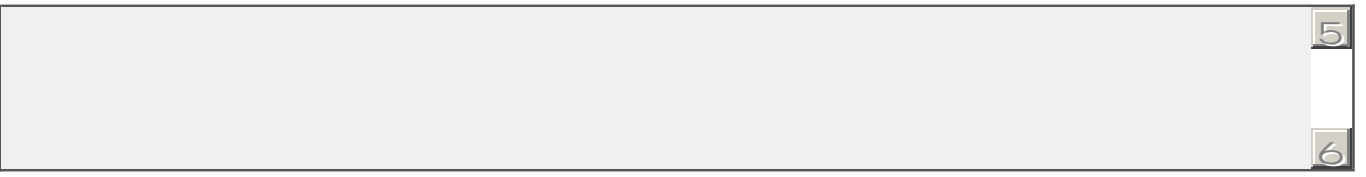

\section{Observation: Developing a Systematic Observation Strategy}

\section{The student will be able to:}

a) explain how to compensate for perceptual limitations by planning a

systematic observational strategy.

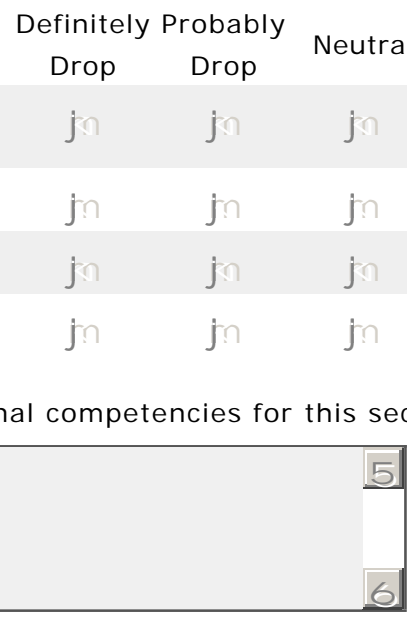

b) identify key elements of a systematic observational strategy.

c) identify several effective systematic observational strategies.

d) explain how all the senses can be integrated to improve observation.

Please list below any suggestions for improvement and/or any additional competencies for this section.

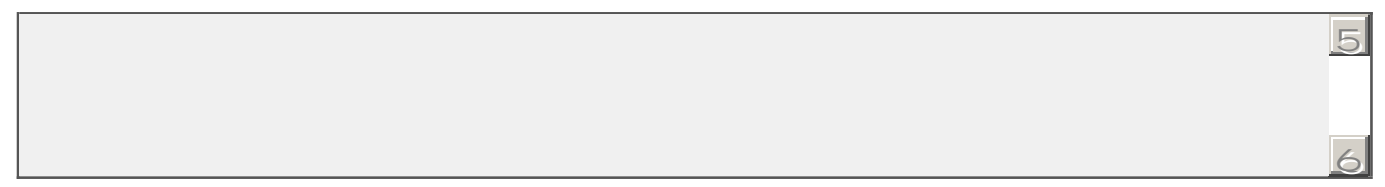

\section{Evaluation and Diagnosis: Critical Thinking Within Qualitative Analysis}

a) explain why evaluation of performance errors is necessary for qualitative analysis

Definitely Probably
Drop Drop Neutral Probably Definitely

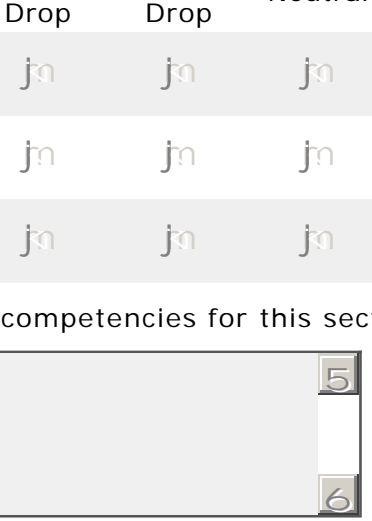

b) discuss major difficulties in evaluating strengths and weaknesses of performance.

c) discuss strategies for prioritizing weaknesses that serve as performance diagnosis.

Keep Keep

Please list below any suggestions for improvement and/or any additional competencies for this section.

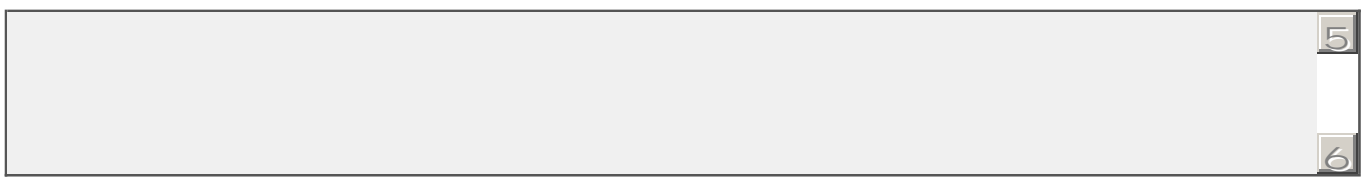




\section{Biomechanics Modified Delphi Pilot Study}

\section{I ntervention: Strategies for I mproving Performance}

\section{The student will be able to:}

a) identify a variety of intervention strategies (e.g., feedback, task modification, mechanical guidance) used in qualitative analysis to improve performance.

b) identify research supported guidelines for the provision of augmented verbal feedback.

c) list the functions of feedback as intervention in qualitative analysis.

d) describe how to develop appropriate cue words and phrases.

e) identify situations where the intervention of exaggeration, modification of practice, manual or mechanical guidance, conditioning,

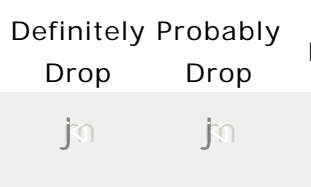
Neutral Probably Definitely or ecological intervention would be appropriate to improve performance.
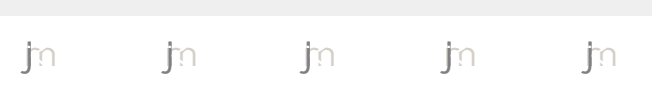

Please list below any suggestions for improvement and/or any additional competencies for this section.

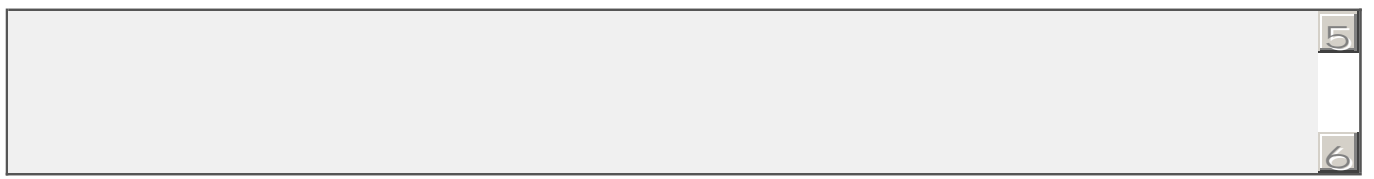




\section{Biomechanics Modified Delphi Pilot Study}

\section{Section 5: Quantitative Analysis of Human Movement}

\section{Quantitative Reasoning and Problem Solving}

\section{The student will be able to:}

a) categorize classes of quantitative problems and select appropriate techniques for analysis and problem solving.

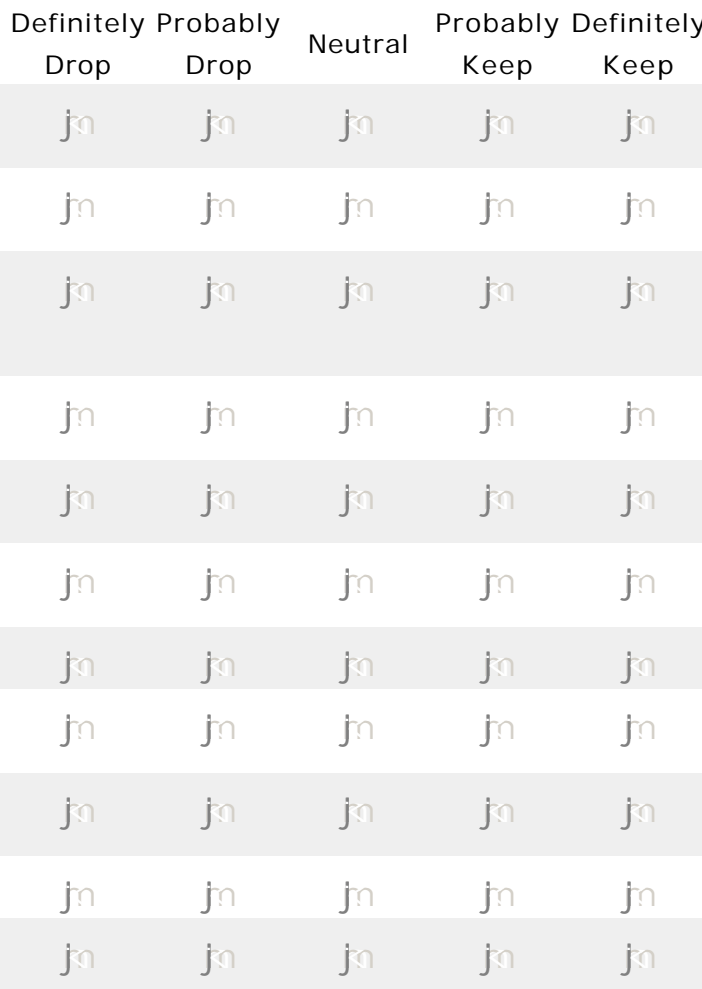

b) interpret graphs and simple models which are used to explain human movement.

c) demonstrate an awareness of and proficiency with various computational skills to effectively interpret and use quantitative information.

d) understand the tools which are used to acquire human movement data.

e) solve quantitative problems involving vector quantities using both graphic and trigonometric procedures.

f) solve quantitative problems involving angular kinematic quantities and the relationship between angular and linear kinematic quantities.

g) solve quantitative problems related to kinetic concepts.

h) solve basic quantitative problems using the equations of static equilibrium.

i) solve quantitative problems relating to the factors that cause or modify angular motion.

j) list possible sources of error in recorded movement data.

k) develop the ability to think critically about information and then develop effective strategies to problems relating to human movement and performance.

Please list below any suggestions for improvement and/or any additional competencies for this section.

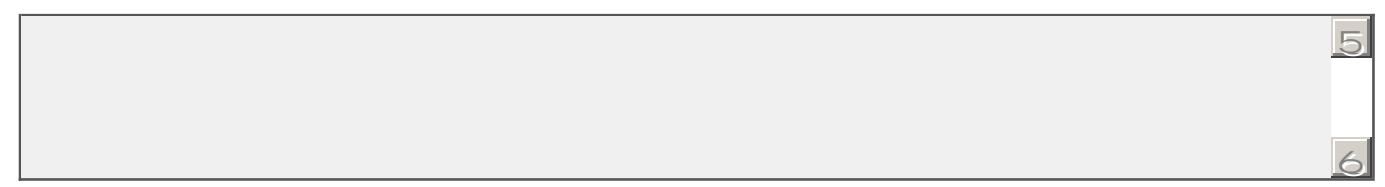




\section{Biomechanics Modified Delphi Pilot Study}

\section{Section 6: Anatomical Bases}

\section{J oint Structure and Function}

\section{The student will be able to:}

a) name and define the fundamental planes and axes.

b) describe and demonstrate joint movement with respect to plane and axis of motion.

c) explain the relationship between joint structure and function.

d) name and demonstrate the actions possible in each joint in other than the anatomical starting position.

e) state the factors contributing to joint range of motion and stability.

f) classify joints according to structure and explain the relationship between joint structure and its capacity for movement.

g) measure a joint's range of motion and state appropriate procedures for improving that range.

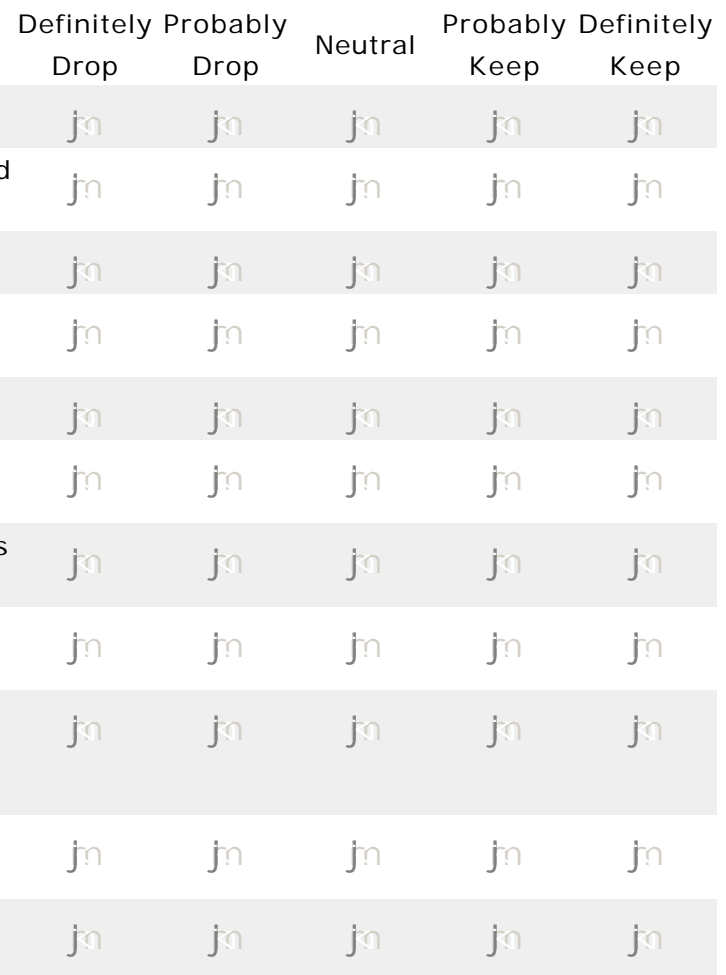

h) explain how the schedule of ossification of epiphyseal cartilage is related to the nature of activities suitable for different age groups. i) observe human movement and explain the reasons for different joint actions and ranges of motion using knowledge of joint structure, stability, and mobility.

j) assess flexibility and create safe and effective stretches for the major muscle groups surrounding each joint.

k) perform an anatomical analysis of the joint actions and planes of motion for a selected motor skill.

Please list below any suggestions for improvement and/or additional competencies for this section.

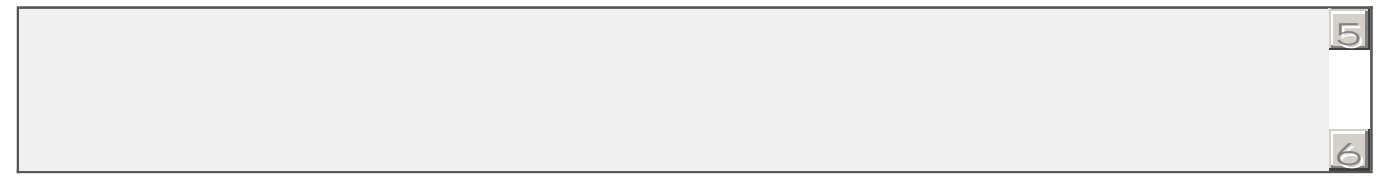




\section{Biomechanics Modified Delphi Pilot Study}

\section{Section 6: Anatomical Basis (continued)}

\section{Muscle Mechanics}

\section{The student will be able to:}

a) name the major muscles or muscle groups active in any given joint action.

b) identify the type(s) of muscular contraction (static, concentric, eccentric) occurring in any given joint action.

c) explain the cooperative action of muscles in controlling joint actions and identify the role (agonist, antagonist, stabilizer, neutralizer) played by the muscle(s) in a given movement.

d) explain the force-velocity and length-tension relationships of muscle and recognize their application in static positions and dynamic movements.

e) recognize the use of the stretch-shortening cycle of muscle in human movement and create effective training exercises that utilize this phenomenon.

f) describe the mechanical response of different muscle fiber types, the influence of training upon them, and the potential for muscle fiber

Definitely Probably Drop

$\bigcirc$ Drop

$\bigcirc$

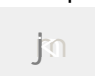

Neutral

Probably Definitely

Keep Keep

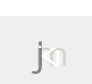

$\bigcirc$
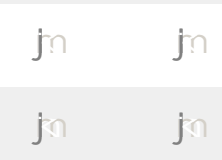

0

$\bigcirc$
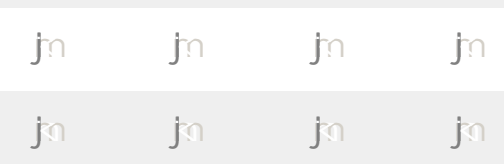

$\bigcirc$
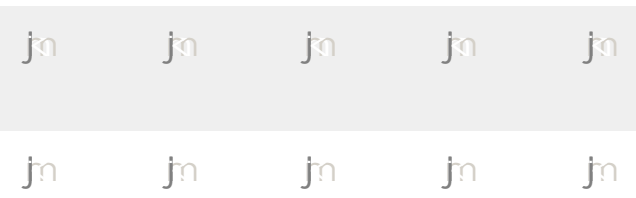

$\bigcirc$
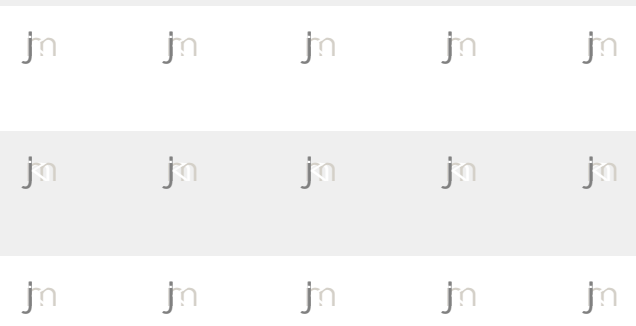
type to influence performance.

Please list below any suggestions for improvement and/or additional competencies for this section.

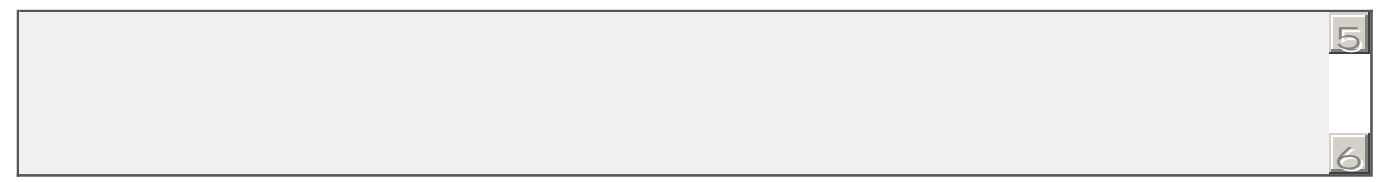




\section{Biomechanics Modified Delphi Pilot Study}

\section{Section 6: Anatomical Basis (continued)}

\section{Neuromuscular Function}

\section{The student will be able to:}

a) name and define the basic structures (e.g., motor unit, muscle spindle and proprioceptors) of the neuromuscular system.

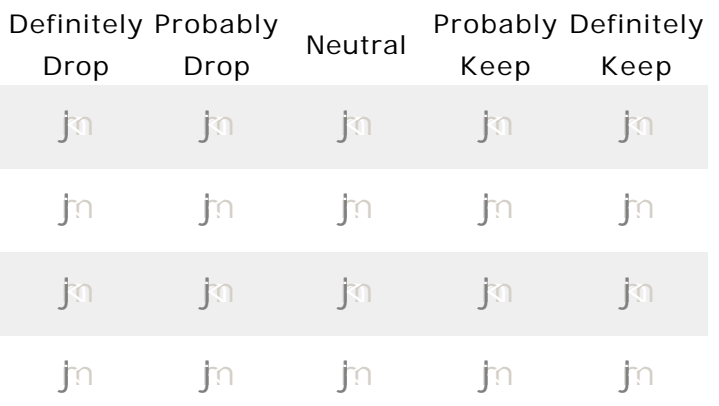

b) explain how gradations in strength of muscle contraction and precision of movements occur.

c) explain how the various receptors function, and describe the effect each has on musculoskeletal movement.

d) describe the anatomical bases for reflex acts and name and define examples of reflexes (e.g., stretch reflex, righting and supporting reflexes, reciprocal inhibition or co-contraction) affect human movement.

e) describe how recruitment and rate coding of motor units regulate muscle force production.

f) perform an analysis of the neuromuscular factors influencing the performance of a variety of motor skills.

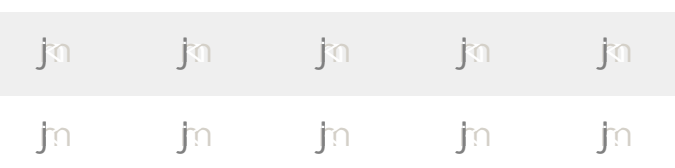

Please list below any suggestions for improvement and/or additional competencies for this section.

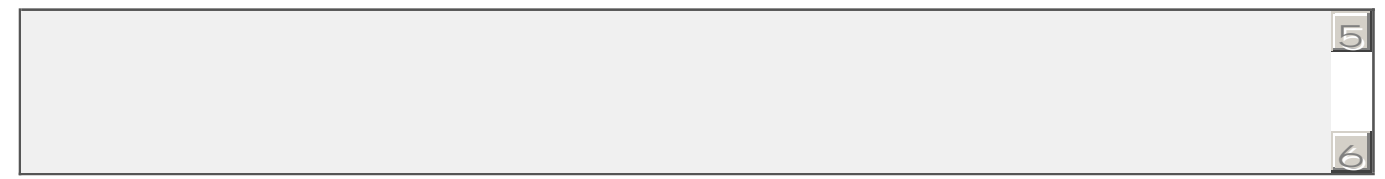




\section{Biomechanics Modified Delphi Pilot Study}

\section{Section 7: Mechanical Bases}

\section{Basic Considerations}

\section{The student will be able to:}

a) define a movement system and determine the nature of the system's movement (i.e., linear, angular, general motion).

b) appropriately represent kinematic and kinetic quantities as vectors and use vectors, vector addition, and vector resolution to enhance the

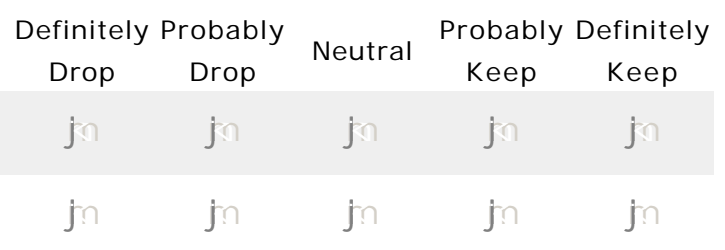
understanding of basic mechanical concepts (e.g., impact of the direction of resultant force application (external forces), the effect of changes in line of muscle pull upon the amount of force used to rotate a segment (internal forces).

Please list below any suggestions for improvement and/or additional competencies for this section.

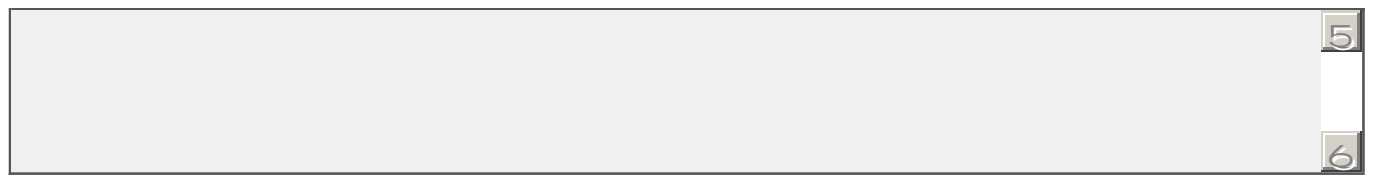




\section{Biomechanics Modified Delphi Pilot Study}

\section{Section 7: Mechanical Basis (continued)}

\section{Movement Kinematics}

\section{The student will be able to:}

a) define the basic terms of distance, displacement, speed, velocity, and acceleration as they relate to linear and angular motion in human

Definitely Probably

Drop

$\bigcirc$

Drop

Neutral

Probably Definitely

Keep Keep movements.

b) use kinematic variables to compare the quality of various motor performances (e.g., across skill level, fitness level, gender, age, body size and type, etc.).

c) explain the kinematic relationships between linear and angular motion and apply this relationship to improve motor skill performance

(e.g., striking, throwing, kicking) and equipment design (e.g., sport, rehabilitation, work environment).

d) describe how the variables of release height, angle, and velocity affect projectile motion and apply these variables to a projectile activity to optimize performance.

e) explain how to plan and conduct an effective qualitative human movement analysis.

f) use simple concepts of motion description (kinematics) to analyze human motion in qualitative terms.

g) identify and describe the uses of available instrumentation for measuring kinematic quantities.
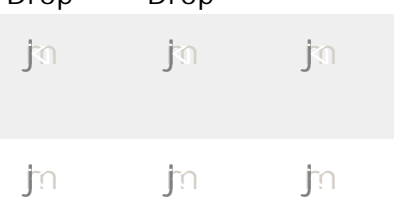

$\bigcirc$
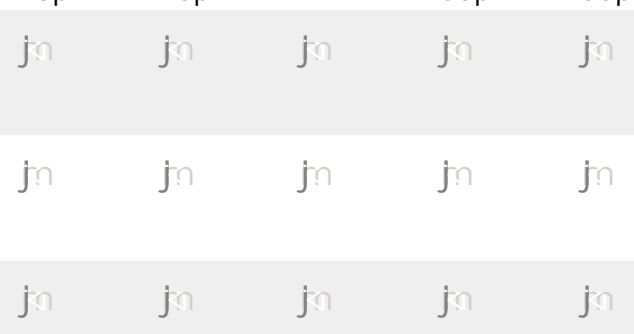

O
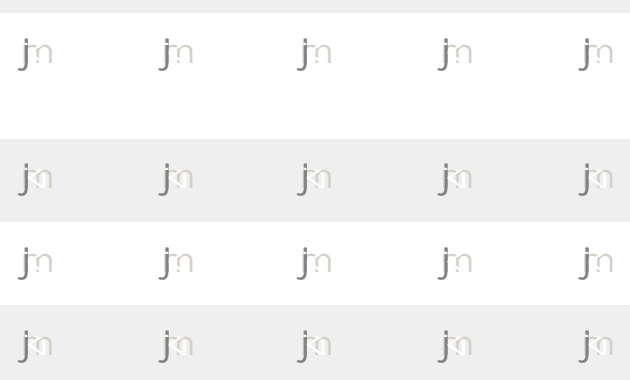

$\bigcirc$

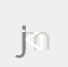

Please list below any suggestions for improvement and/or additional competencies for this section.

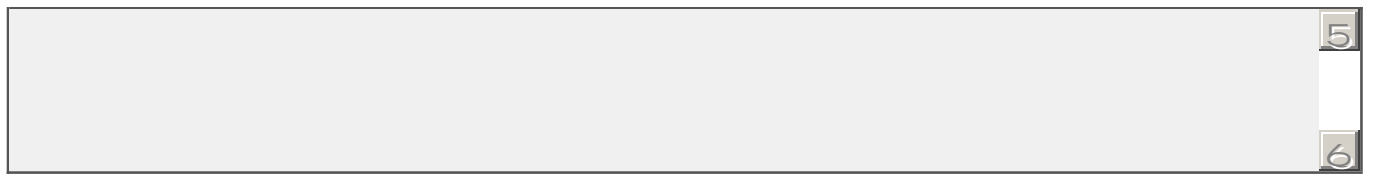




\section{Biomechanics Modified Delphi Pilot Study}

\section{Section 7: Mechanical Basis (continued)}

\section{Movement Kinetics}

\section{The student will be able to:}

a) define basic terms (e.g., force, inertia, mass, and weight) as they relate to linear motion in human movement.

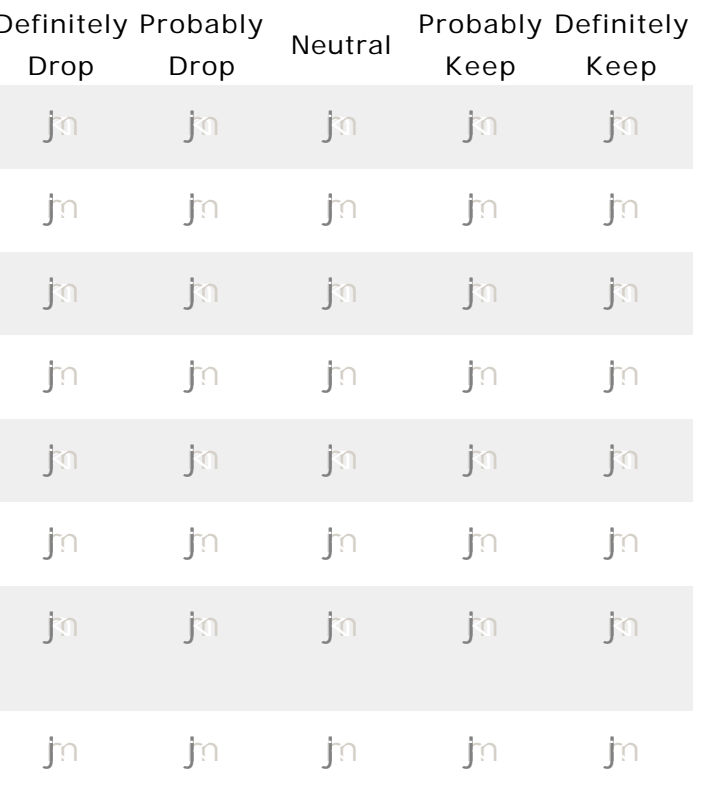

b) define basic terms (e.g., torque, moment, moment of inertia, moment arm, radius) as they relate to angular motion.

c) identify Newton's laws of motion and gravitation and describe practical illustrations of the laws.

d) identify and provide examples of the angular analogues of Newton's laws of motion.

e) explain what factors affect friction and discuss the role of friction in daily activities and sports.

f) explain the effects of weight, normal reaction, friction, buoyancy, drag, and lift upon motor performance.

g) estimate the location of the center of gravity of persons in any position and describe how changes in location of the center of gravity and other mechanical factors that influence stability.

h) identify and explain the importance of impulse-momentum, workenergy, and the conservation of momentum to the production of effective human movements.

Please list below any suggestions for improvement and/or additional competencies for this section.

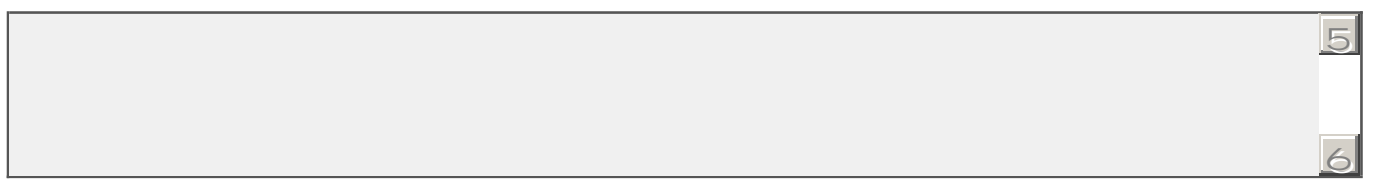




\section{Biomechanics Modified Delphi Pilot Study}

\section{Section 8: Motor Skills: Principles and Applications}

\section{Standing Posture}

\section{The student will be able to:}

a) identify and describe the skeletomuscular and neuromuscular antigravity mechanisms involved in volitional standing positions.

b) summarize the similarities and differences that occur in the relation of the line of gravity to various body landmarks with good and poor anteroposterior segmental alignment.

c) discuss the factors that affect the stability and energy cost of erect posture.

d) explain the effects that the variables of age, body build, strength, and flexibility have on the alignment of body segments in the standing posture.

e) name the values, if any, of good posture.

f) perform biomechanical analyses on the posture of individuals of different ages and body builds.

Please list below any suggestions for improvement and/or additional competencies for this section.

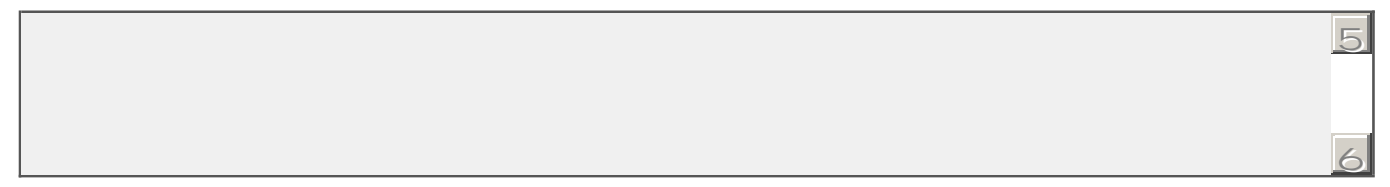




\section{Biomechanics Modified Delphi Pilot Study}

\section{Section 8: Motor Skills: Principles and Applications (continued)}

\section{Moving Objects: Pushing and Pulling}

a) classify activities involving push or pull patterns according to the nature of the force applications.

b) name and discuss anatomical and mechanical factors and principles that apply to representative push or pull activities.

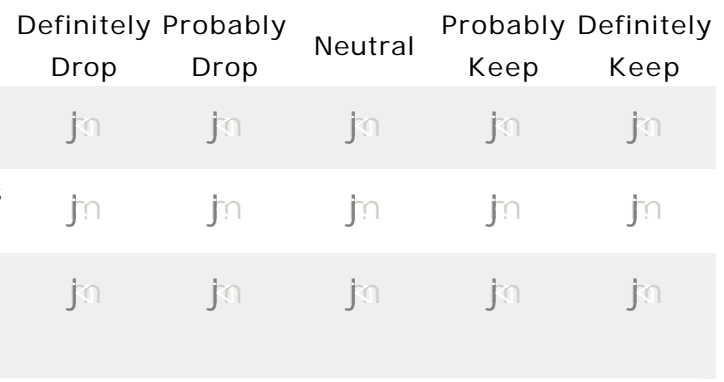

c) analyze the performance of someone performing a push-pull skil under each of these force application conditions: momentary contact, projection, or continuous application.

Please list below any suggestions for improvement and/or additional competencies for this section. 


\section{Biomechanics Modified Delphi Pilot Study}

\section{Section 8: Motor Skills: Principles and Applications (continued)}

\section{Moving Objects: Throwing, Striking, and Kicking}

\section{The student will be able to:}

a) classify activities involving sequential throwing, kicking, or striking patterns according to the nature of force applied.

b) name and discuss anatomical and mechanical factors that apply to representative throwing, kicking, or striking activities.

c) perform an analysis of someone engaging in a sequential throwing, kicking, or striking skill under each of these force application conditions: momentary contact, projection, continuous application.

d) plan and conduct a qualitative analysis of common object control skills.

e) plan and conduct a quantitative analysis of common object control skills.

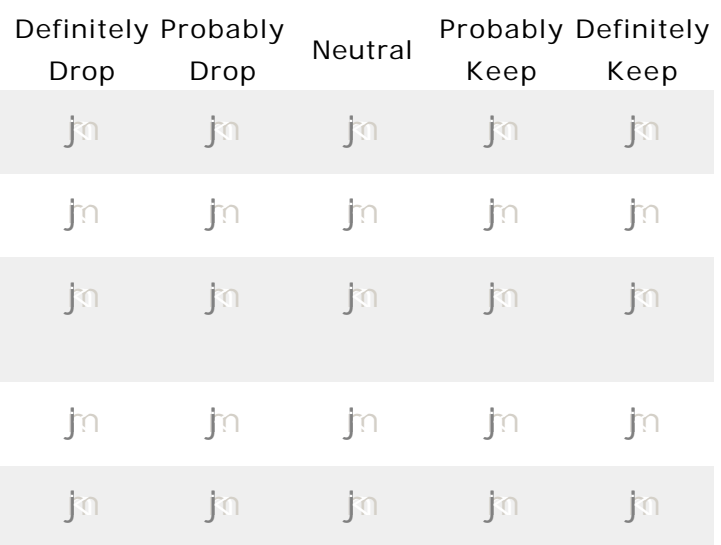

Please list below any suggestions for improvement and/or additional competencies for this section.

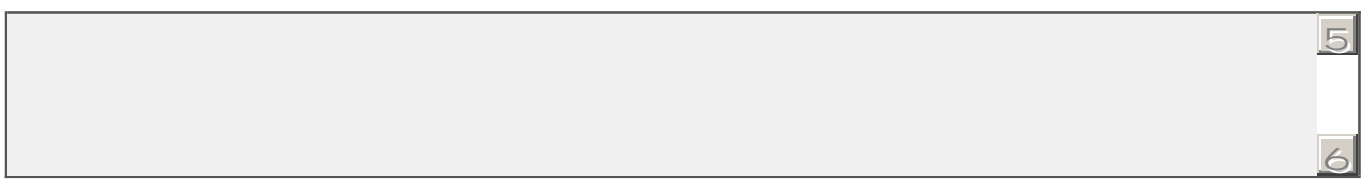

\section{Locomotion: Solid Surface}

\section{The student will be able to:}

a) identify and classify motor skills belonging in the categories that fall under the heading of moving one's body on the ground or on another

\section{Definitely \\ Drop} resistant surface.

b) describe the anatomical and mechanical nature of motor skills representative of the major types of locomotor patterns.

c) name and state anatomical and mechanical principles that apply to the locomotion patterns of walking, running, and jumping.

d) evaluate performance of motor skills representative of the major locomotor patterns in terms of application of the related biomechanical principles.

e) plan and conduct a qualitative analysis of someone performing a locomotor skill.

f) plan and conduct a quantitative analysis of someone performing a locomotor skill.

O Drop Neutral

Probably Definitely

Keep Keep

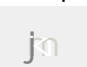

$\bigcirc$

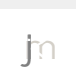

0

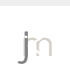

$\bigcirc$
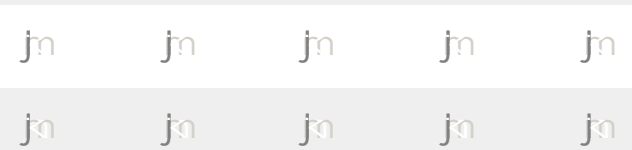

0

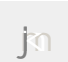

0

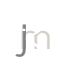

0

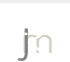

$\bigcirc$
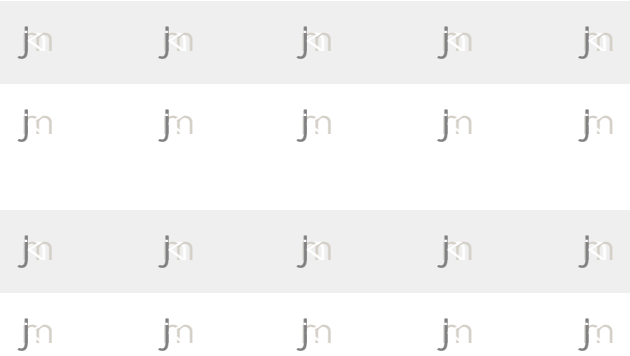


\section{Biomechanics Modified Delphi Pilot Study}

\section{Section 8: Motor Skills: Principles and Applications (continued)}

\section{Locomotion: The Aquatic Environment}

\section{The student will be able to:}

a) name those factors that contribute to the propulsion of a swimmer.

b) name those factors that impede the progress of a swimmer.

c) explain how the propulsive and resistive factors named affect the length or frequency of a swimming stroke.

d) complete a biomechanical analysis of a swimming stroke by identifying the anatomical and mechanical factors important to success

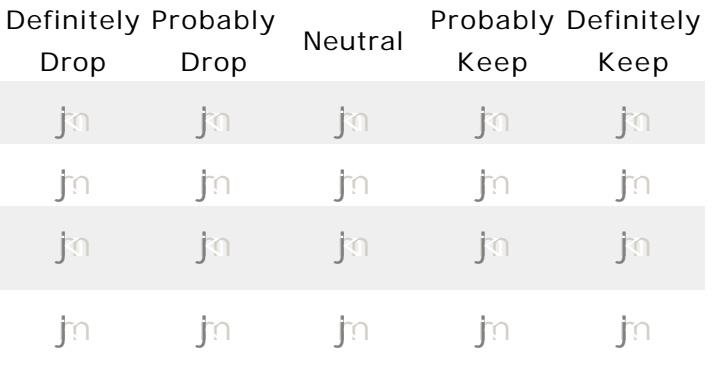
in the selected stroke, as well as those factors that appear to limit the particular performance.

Please list below any suggestions for improvement and/or additional competencies for this section.

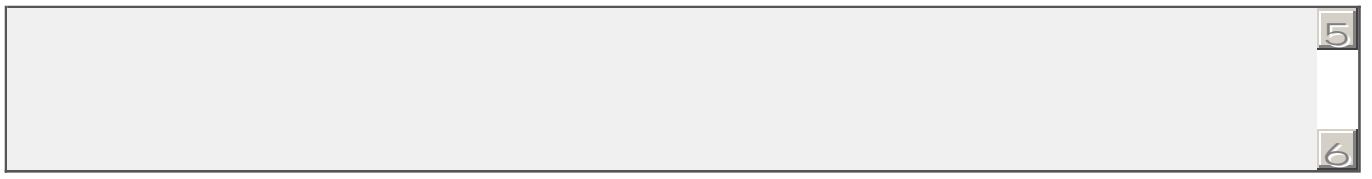

\section{Locomotion: When Suspended and Free of Support}

\section{The student will be able to:}

a) explain how each of the following influences the action of swinging bodies: weight of the body, length of the pendulum, angular momentum, potential-kinetic energy, centripetal-centrifugal force, and friction.

b) describe how to initiate pendular action, increase the height of a swing, alter the period, change grips, and dismount safely.

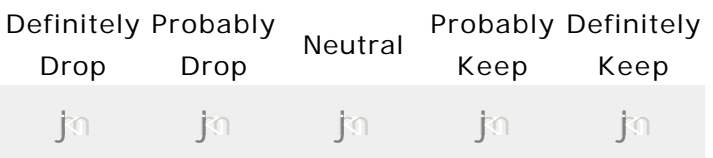

c) explain how each of the following influences the flight path of unsupported bodies: angle of projection, vertical velocity, gravity, and angular momentum.

d) describe how to initiate and control rotation of unsupported bodies.

e) analyze the performance of a suspension and a nonsupport movement.

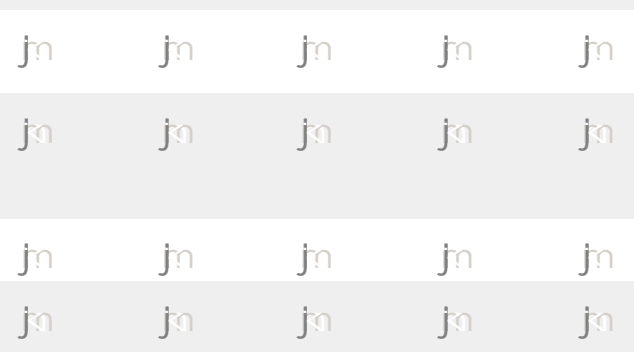

Please list below any suggestions for improvement and/or additional competencies for this section.

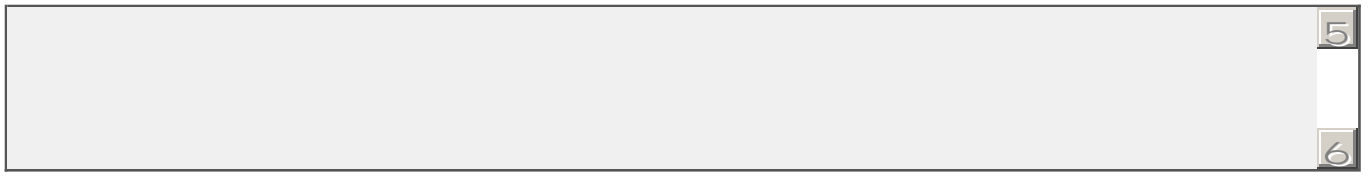




\section{Biomechanics Modified Delphi Pilot Study}

\section{Section 8: Motor Skills: Principles and Applications (continued)}

\section{I mpact}

a) name the common problems associated with the diverse forms of receiving impact

b) explain how the work-energy, impulse-momentum, and pressurearea relationships apply to receiving the impact either of one's own body or of external objects.

c) state the principles related to avoiding injury while receiving impact and furnish an application for each.

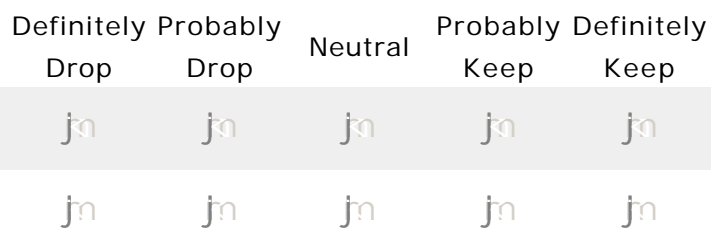

d) state the principles related to maintaining and regaining equilibrium while receiving impact and furnish an application for each.

e) state the principles related to accuracy and control while receiving impact and furnish an application for each.

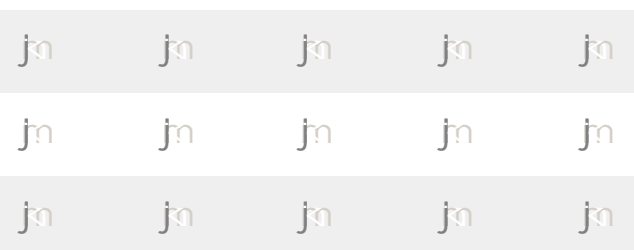

Please list below any suggestions for improvement and/or additional competencies for this section.

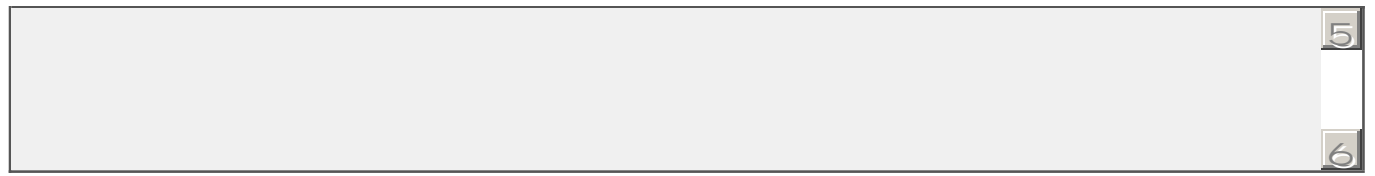




\section{Biomechanics Modified Delphi Pilot Study}

\section{Section 9: Open Ended Question}

22. The ultimate goal of this survey is to generate a comprehensive list of theoretical and applied competencies in the area of biomechanics that could potentially be incorporated into the physical education teacher education curriculum. Your expert opinion is valued!

Please list any additional biomechanics concepts and/ or competencies that you would like added to the survey.

Also, please provide any suggestions that would enhance the organization and clarity of the overall survey design.

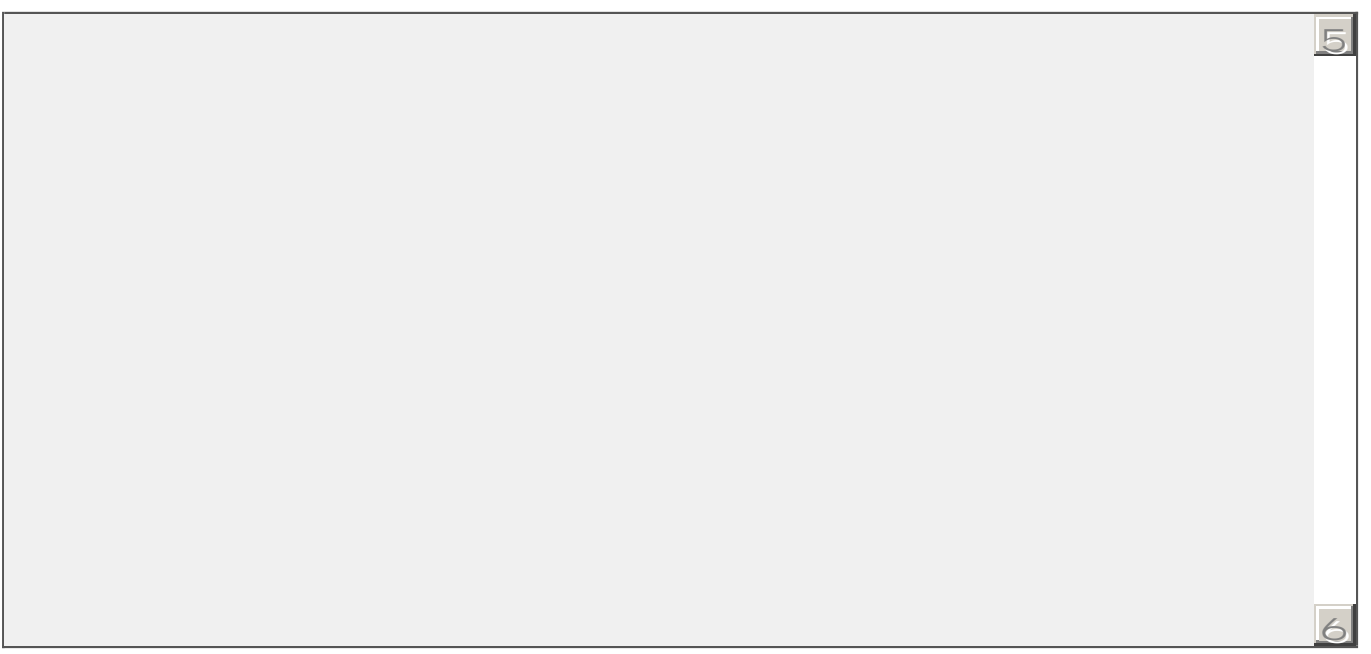




\section{Biomechanics Modified Delphi Pilot Study}

\section{Section 10: Survey I nstrument's Overall Quality}

23. In your opinion, does the instrument (after amended) represent valid competencies for use in the physical education teacher education curriculum?

Yes

$\bigcirc$ no

If no, please explain:

\begin{tabular}{|l|l|}
\hline & 5 \\
\hline
\end{tabular}

24. In your opinion, does the instrument (after amended) represent a comprehensive overview of the biomechanics competencies that should be included in the physical education teacher education undergraduate program?

Yres

No

If no, please explain:

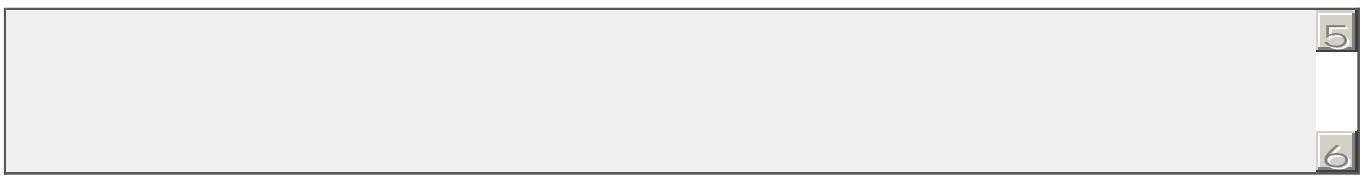




\section{Biomechanics Modified Delphi Pilot Study}

\section{Thank you!}

Thank you for your time and participation in this pilot study! Your input is greatly appreciated!

\section{Susan Ross}

West Virginia University

College of Physical Activity \& Sport Science

sross11@mix.wvu.edu

(304) 293-0848 


\section{Appendix C}

Recommendations for Biomechanics in the Physical Education Teacher Education Curriculum

Round I 


\section{E-mail for Round I Participant Recruitment}

Hello (insert name here):

I am writing to request your participation as an expert judge in a biomechanics research project being conducted at West Virginia University, titled Recommendations for Biomechanics in the Physical Education Teacher Education Curriculum. The ultimate purpose of this research project is to determine a list of essential biomechanics competencies for inclusion in the undergraduate physical education teacher education curriculum. You were selected to participate because of your high degree in the area of biomechanics and/or its practical application within school-based physical education programs.

The research will involve a two-round Modified Delphi investigation using an online survey tool to generate knowledge from a group of experts by means of a series of survey questionnaires, referred to as rounds. As a participant, you will be asked to rate a series of biomechanics competencies in terms of their importance and relevance for prospective K-12 physical educators. Additionally, in the second Delphi round you will be asked to recommend learning environments and instructional method for delivering core biomechanics content within the physical education teacher education curriculum.

Below is the tentative time line in order for you to determine if this study will fit into your schedule:

-February 22, 2010 - Round 1 survey sent to participants (you will have three weeks to complete at your convenience)

-March 22, 2010 - Round 2 survey sent to participants (you will have three weeks to complete at your convenience)

\section{* Please refer to the email attachment for a brief description of the study, participation criteria, the nature of your role, and time involved.}

Upon completion, a copy of the completed survey and results will be sent to you. Also, your name will be acknowledged as an expert panel member in this study.

Would you be willing to participate in this research investigation? Please feel free to contact me at (304) 293-0848 if you have any immediate questions regarding this e-mail. Please reply by Friday, February 19, 2010.

Thank you for your consideration, I look forward to hearing from you soon!

\section{Susan Ross}

West Virginia University

College of Physical Activity \& Sport Sciences

(304) 293-0848

This study is being conducted by Susan Ross and Andrew Hawkins; both are with the College of Physical Activity and Sport Sciences at West Virginia University. 


\section{Attachment Sent in Round I Participant Recruitment E-mail}

\section{Recommendations for Biomechanics in Physical Education Teacher Education}

\section{Why is this study being conducted?}

The primary purpose of this study is to identify a list of theoretical and applied biomechanics competencies for inclusion in the physical education teacher education curriculum. A secondary aim is to identify specific learning environments (e.g., teaching methods course, activity courses, clinical/field experience, biomechanics course) and instructional methods for delivering biomechanics content within the undergraduate physical education teacher education curriculum.

Although Guidelines and Standards for Undergraduate Biomechanics have been endorsed by NASPE (2004), I am proposing that a panel of experts take a critical look at these guidelines and standards and other textbook competencies as they specifically relate to the preparation of K-12 physical education teachers.

Upon completion, the study may actually help validate the current Guidelines and Standards for teaching undergraduate biomechanics. The study may also bring to light "what" content in the area of biomechanics are most important and relevant in the preparation of physical educators, and "where" the content should be delivered within PETE curriculum.

\section{How will the study be conducted?}

A two-round Delphi method using an online survey tool will be used to generate knowledge from the group of experts by means of a series of questionnaire, referred to as rounds.

\section{What are the Criteria for Participation?}

The Delphi panel will include eight participants from each of subgroup: biomechanics, PETE, K12 physical educators. In order to participate, you must meet ONE of the following qualifications:

Biomechanics Specialist: Experience teaching an undergraduate biomechanics course and serve as a member of the Biomechanics Academy of NASPE or the American Society for Biomechanics.

PETE: Physical education teacher education faculty who serve as a member of the Curriculum and Instruction Academy of NASPE.

K-12 Physical Education Teacher: District physical education teacher of the year award recipient through NASPE.

\section{What is your role if you choose to participate?}

Round I: Simply rate 107 biomechanics competencies in terms of their theoretical importance and pedagogical relevance for prospective K-12 physical education teachers. 
Round II: Unlike the first round, the individual and group mean ratings for each competency will be provided allowing you to see how your responses compared with the overall group (all names and individual ratings are anonymous). You will then be asked to re-evaluate your previous viewpoint/response in light of the overall group opinion and rate the competencies a second time. At the conclusion of the survey, you will be asked to answer one open ended question.

\section{Time Involved}

Below is the tentative time line in order for you to determine if this study will fit into your schedule:

Round 1 survey will be sent to participants on February 22, 2010 in which you will have three weeks to judge the competencies at your convenience. Approximate Time: 50-minutes - 1:20 minutes. You are free to enter and exit survey within the time provided.

Round II survey will be sent to participants on March 22, 2010 in which you will have three weeks to complete at your convenience. Approximate Time: 1-hour to 1:30 minutes.

Upon completion, a copy of the completed survey and results will be sent to you. Also, your name will be acknowledged as an expert panel member in this study. However, it is very important for you to be able to participate in both rounds of the survey. 


\section{Phone Script for Round I Participant Recruitment}

"Hello, my name is Susan Ross and I am calling to request your participation as an expert panel member for my dissertation titled Recommendations for Biomechanics in the Physical Education Teacher Education Curriculum. This research study will involve the administration of a Delphi procedure to determine the biomechanics competencies that should be included in the physical education teacher education curriculum. For your contribution to this research study, I simply need you to critique the survey items using a rating scale that will determine the validity and completeness of each competency for future

use in the physical education teacher education curriculum.

- You must be 18 years of age or older to participate.

- Your participation is entirely voluntary, you can choose to stop participation at any time and you do not have to answer any questions you do not want to answer.

- Your responses will be kept as confidential as legally possible. All data will be erased once my dissertation is complete. At no time will your name be revealed during reporting.

- Your job status will not be affected if you decide either not to participate or to withdraw.

- West Virginia's University's Institutional Review Board acknowledgement of this project is on file.

Would you be interested in participating as an expert for this study?”

\section{YES/NO (IF “NO” GO TO 1 / IF “YES” GO TO 2)}

1. “Thank you for your time and consideration.”

2. "Thank you for agreeing to participate; your time and efforts are greatly appreciated. I will email more information regarding your participation in this research study, as well as a link to the online survey instrument. Thank you for agreeing to participate. Your expert contribution is vital to the success of this research project.” 


\section{Attachment in E-mail Sent to Round I Participants \\ Biomechanics Index of Terms}

\section{Anatomical Bases of Movement Terms}

Agonist: an anatomical term referring to the concentric action of a muscle or muscle group for presumed to create a specific movement.

Antagonist: an anatomical term referring to a muscle or muscle group that is presumed to oppose (eccentric action) a specific movement.

Concentric: contractions that permit a muscle to shorten (e.g., raising a weight during a bicep curl).

Eccentric: muscle activation involving the lengthening of a muscle.

Force-Velocity: skeletal muscle mechanical property that shows how muscle force potentially depends on muscle velocity.

Isometric: describes the contraction of muscles when the fibers increase in tension, but do not shorten in length. For example, isometric exercises can be induced in muscles that are used when a limb is made to pull or push against something that does not move.

Joint actions: flexion, extension, and hyperextension (in sagittal plane); abduction and adduction (in frontal plane); left rotation, right rotation, medial rotation, and lateral rotation (in transverse plane).

Muscle Spindle: an intramuscular receptor that senses changes in muscle length.

Motor Unit: a motor neuron and the muscle fibers it innervates.

Neuromuscular Recruitment: activation of motor units of muscles by the central nervous system.

Planes of movement: sagittal plane, frontal plane, and transverse plane.

\section{Mechanical Bases of Movement Terms}

Acceleration: change in velocity involving speed and direction.

Displacement: linear change in position in a particular direction (vector).

Dynamics: study of objects (bodies) being accelerated by the actions of forces. 
Force: any action that changes or tends to change the motion of an object (e.g., push, pull).

Impulse-Momentum: principle which states that the change in momentum of an object is equal to the net impulse applied; the original language of Newton's second law.

Impulse-Momentum Relationships: studying movements over intervals of time.

Inertia: the resistance to acceleration - reluctance of body to change what it is doing.

Kinematics: description of motion, including considerations of space and time without reference to the forces causing it. Examines how, when and where a body moves. Motion of objects is usually measured in linear (meters, feet, etc) or angular (radians, degrees, etc) terms. For example, measuring the speed of the athlete, length of the stride, or the angular velocity of hip extension.

Linear: movement of the body in a straight line or pathway. Also when external forces are applied directly through the center of body mass.

Curvilinear: motion along a curved pathway.

Angular: combination of linear and curvilinear. Body moves along a circular path about some AXIS in space.

Kinetics: concerned with what causes a body to move the way it does by studying the action of forces.

Linear: precise ways to document the causes of the linear motion of all objects. Approaches to studying the causes of motion include Newton's Laws of Motion, impulse-momentum relationships, and work-energy relationships.

Angular: explains causes of rotary motion and employs many variables similar to linear kinetics (e.g., Newton's Laws of Motion)

Mass: amount of matter that is possessed by an object.

Mechanics: a branch of physics that deals with forces and the motion they create.

Moment Arm: shortest distance between a force's line of action and an axis of rotation.

Moment of Inertia: body's tendency to resist acceleration - based on both mass and the distance the mass is distributed from the axis of rotation.

Momentum: mass x speed

Statics: study of objects (bodies) at rest or moving at a constant rate. 
Torque (moment of force): twisting, turning, or rotary force related to the production of angular acceleration. When force is applied to an object that is not on line with the center of the object, the force will create a torque that tends to rotate the object. For example, kicking a soccer ball below the center will create a torque that causes a backspin.

Vectors: Algebraic representations of mechanical variables to enhance the understanding of the science of mechanics. A vector quantity has both magnitude and direction. The magnitude of a vector is its size. Graphically, vectors are represented by arrow-shaped symbols indicating the line of action. The arrowhead denotes the direction and sense of the vector.

Velocity: speed and direction of the body.

Work-Energy: principle in physics which states that the work done on a body is equal to the net change in energy in the body.

Work-Energy Relationships: focuses on the distance covered in the movement.

\section{Analytic methods for solving movement problems}

Quantitative Analysis of Movement: requires a numerical evaluation of an individual's movement. Involves measurements of biomechanical variables (e.g., joint angles, force, speed) using sophisticated instruments, such as videography to record movement performance.

Qualitative Analysis of Movement: a systematic observation and judgment of the quality of movement for the purpose of providing the most appropriate intervention (Knudson \& Morrison, 2002). 


\section{Biomechanics Study Round I}

\section{Survey I ntroduction}

Welcome and thank you for agreeing to participate as an expert panel member in this Modified Delphi investigation!

As a panel member, you are asked to rate a list of biomechanics competencies in terms of their theoretical IMPORTANCE and pedagogical RELEVANCE for prospective physical education teachers. The survey will be used to generate expert consensus regarding the core biomechanics competencies physical educators should "know" and be able to "apply" as a result of their course work and training throughout the physical education teacher education curriculum. Your input regarding these competencies will have the potential to influence future curricular decision making in physical education teacher education. Your practical experience, insight, and judgment are vital to the success of this project.

Clarification of Definitions:

Theoretical Importance: Biomechanics competency that should be understood by the physical educator. Pedagogical Relevance: Biomechanics competency that is directly related to teaching physical education K- 12 school setting.

The Delphi method will be used to address this research inquiry, allowing you the opportunity to share your feedback and provide recommendations. The Delphi method is a research protocol that involves (a) the identification and selection of a small panel of experts, (b) the use of multiple rounds of surveying as a means to collect expert opinion on a topic, and (c) the attainment of group consensus through regular feedback.

Please remember the final date for Round I survey completion is March 15th. You will be sent the Round II survey approximately one week after the results are tabulated. I greatly appreciate your assistance in the timely completion of this project.

Thank you for your time and input! I greatly appreciate your assistance in the timely completion of this project. Please feel free to call or email me with any questions.

\section{Susan Ross}

West Virginia University

College of Physical Activity \& Sport Sciences

sross11@mix.wvu.edu

(304) 293-0848

Due to the nature of study, the list of competencies you are asked to evaluate is rather extensive. The items that you are evaluating were adapted from a variety of sources, including:

* National Assocation for Sport and Physical Education Kinesiology Academy. (1980). Guidelines and standards for undergraduate kinesiology. Journal of Physical Education and Recreation, 51(2), 19- 21.

* National Association for Sport and Physical Education. (2003). Guidelines for Undergraduate Biomechanics. Reston, VA: NASPE Publications.

*Hall, S.J . (1999). Basic Biomechanics. New York, NY: McGraw-Hill.

*Knudson, D.V., \& Morrison, C.S. (2002). 2nd Ed. Qualitative Analysis of Human Movement. Champaign, IL: Human Kinetics.

*Hamilton, N., Weimar, W., \& Luttgens, K. (2008). 11th Ed. Kinesiology: Scientific Basis of Human Motion. New York, NY: McGraw- Hill.

All are reproduced with the permission of the National Association for Sport and Physical Education, the lournal of Physical Education, Recreation, and Dance; as well as McGraw-Hill and Human Kinetics. 


\section{Biomechanics Study Round I}

\section{Survey I nstructions}

The following survey contains 107 competencies you will need to judge in regard to their theoretical importance and pedagogical relevance in the physical education teacher education curriculum. Due to the nature of study, the list of competencies you are asked to evaluate is rather extensive.

Please do the following:

Rate each of the questionnaire items separately in the areas of IMPORTANCE and RELEVANCE. For the purpose of this study, IMPORTANCE will refer to the item's value as a theoretical underpinning of the physical education profession (should be understood by the physical educator). RELEVANCE will refer to the item's practical or applied value to the K-12 physical educator (directly related to teaching physical education in the school setting).

\section{RATING SCALE:}

A rating of (5) or (4) in BOTH IMPORTANCE and RELEVANCE means that you consider the item to be essential in the preparation of prospective K- 12 physical education teachers.

A rating of (3) means you have no opinion or are undecided regarding the IMPORTANCE and RELEVANCE of the item.

A rating of (2) or (1) on EITHER IMPORTANCE or RELEVANCE means the item is not essential for the preparation of prospective P- 12 physical education teachers.

If you choose not to respond to a particular item, please leave it blank.

A few reminders:

1-You must enter your name on the first page of the survey in order to continue. This is the only question you must answer.

2-You may return to the instructions page at any time by using the "Prev" buttons at the bottom of the survey pages. There is complete freedom (once you have entered your name) to go to any page within the survey and change your responses if necessary.

3- A survey completion bar will be at the top of each page in order to show your progress through the survey.

4- You can leave and return to the survey at any time. 


\section{Biomechanics Study Round I}

\section{Table of Contents}

Section 1: Participant Information

Section 2: Introduction to Biomechanics (Question 2)

Section 3: Application of Biomechanics Competencies to Human Movement (Question 3)

Section 4: Qualitative Analysis of Human Movement (Questions 4-7)

Section 5: Quantitative Analysis of Human Movement (Question 8)

Section 6: Anatomical Bases (Questions 9-11)

Section 7: Mechanical Bases (Questions 12-14)

Section 8: Motor Skills: Principles and Applications (Questions 15-21) 


\section{Biomechanics Study Round I}

\section{Section 1: Participant I nformation}

* 1. Please enter your name:

Name: 


\section{Biomechanics Study Round I}

\section{Section 2: I ntroduction to Biomechanics}

\section{The student will be able to:}

a) define and explain the terms biomechanics, statics, dynamics, kinematics, and kinetics in relation to human movement.

b) describe the scope of scientific inquiry addressed by biomechanists.

c) distinguish between qualitative and quantitative approaches for analyzing human movement.

d) explain how to formulate questions for qualitative analysis of human movement.
Importance

Relevance
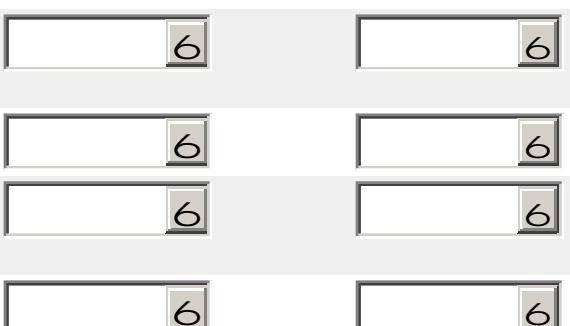


\section{Biomechanics Study Round I}

\section{Section 3: Application of Biomechanics Competencies to Human}

\section{Movement}

\section{The student will be able to:}

a) observe and describe a movement technique accurately

b) determine the anatomical and mechanical factors basic to the performance of an observed movement

c) evaluate the appropriateness of a performer's technique with reference to the movement task

d) identify factors that limit skillful performance and establish a priority for change in those factors most likely to lead to improvement in performance.
Importance

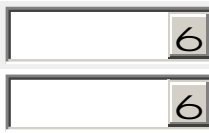

Relevance
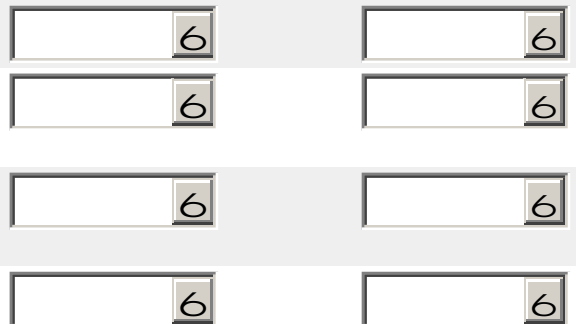


\section{Biomechanics Study Round I}

\section{Section 4 : Qualitative Analysis of Human Movement}

\section{Preparation: Gathering Relevant Knowledge}

\section{The student will be able to:}

a) define the critical features of various motor skills and explain how they are identified in the preparation task of qualitative analysis of

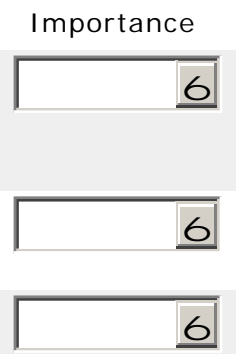
movement.
b) explain how preparation in qualitative analysis of movement is related to effective teaching and observation.
c) explain how preparing for qualitative analysis can be integrated with planning for teaching.

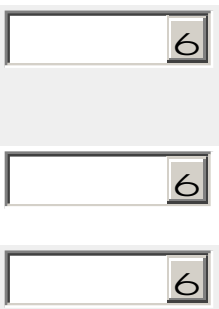

\section{Observation: Developing a Systematic Observation Strategy}

\section{The student will be able to:}

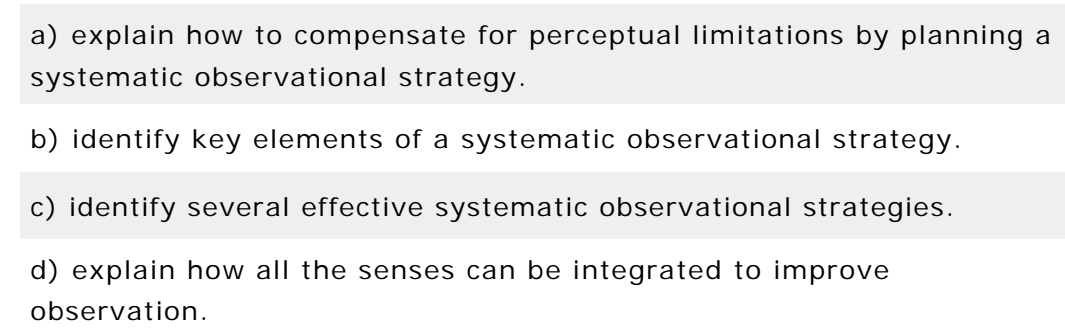

Importance

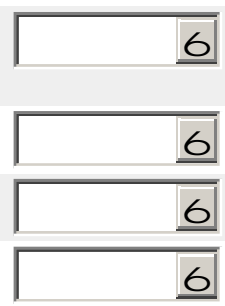

Relevance

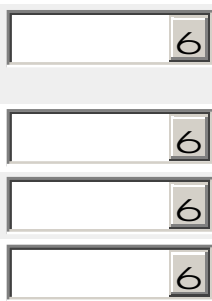

\section{Evaluation and Diagnosis: Critical Thinking Within Qualitative Analysis}
a) explain why evaluation of performance errors is necessary for qualitative analysis.
b) discuss major difficulties in evaluating strengths and weaknesses of performance.
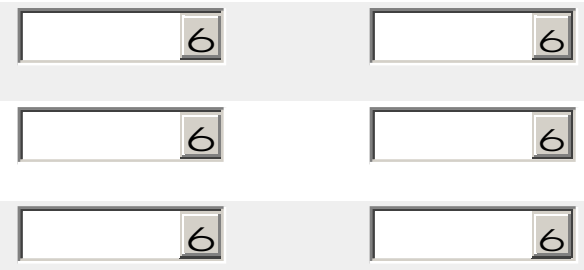


\section{Biomechanics Study Round I}

\section{I ntervention: Strategies for I mproving Performance}

\section{The student will be able to:}

a) identify a variety of intervention strategies (e.g., feedback, task modification, mechanical guidance) used in qualitative analysis to
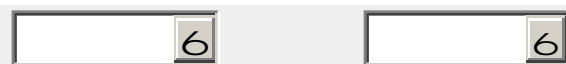
improve performance.

b) identify research supported guidelines for the provision of augmented verbal feedback.

c) list the functions of feedback as intervention in qualitative analysis.

d) describe how to develop appropriate cue words and phrases for improving skill performance.

e) identify the most appropriate intervention strategy (e.g., feedback, task modification, mechanical guidance) for improving skill performance across novice, intermediate, and expert performers. 


\section{Biomechanics Study Round I}

\section{Section 5: Quantitative Analysis of Human Movement}

\section{Quantitative Reasoning and Problem Solving}

\section{The student will be able to:}

a) categorize classes of quantitative problems and select appropriate techniques for analysis and problem solving.

b) interpret graphs and simple models which are used to explain human movement.

c) demonstrate an awareness of and proficiency with various computational skills to effectively interpret and use quantitative information.

d) identify current technology used to quantify biomechanical variables in human movement.

e) solve quantitative problems involving vector quantities using both graphic and trigonometric procedures.

f) solve quantitative problems involving angular kinematic quantities and the relationship between angular and linear kinematic quantities.

g) solve quantitative problems related to kinetic concepts.

h) solve basic quantitative problems using the equations of static equilibrium.

i) solve quantitative problems relating to the factors that cause or modify angular motion.

j) list possible sources of error in recorded movement data.

k) develop the ability to think critically about information and then develop effective strategies to problems relating to human movement

Importance
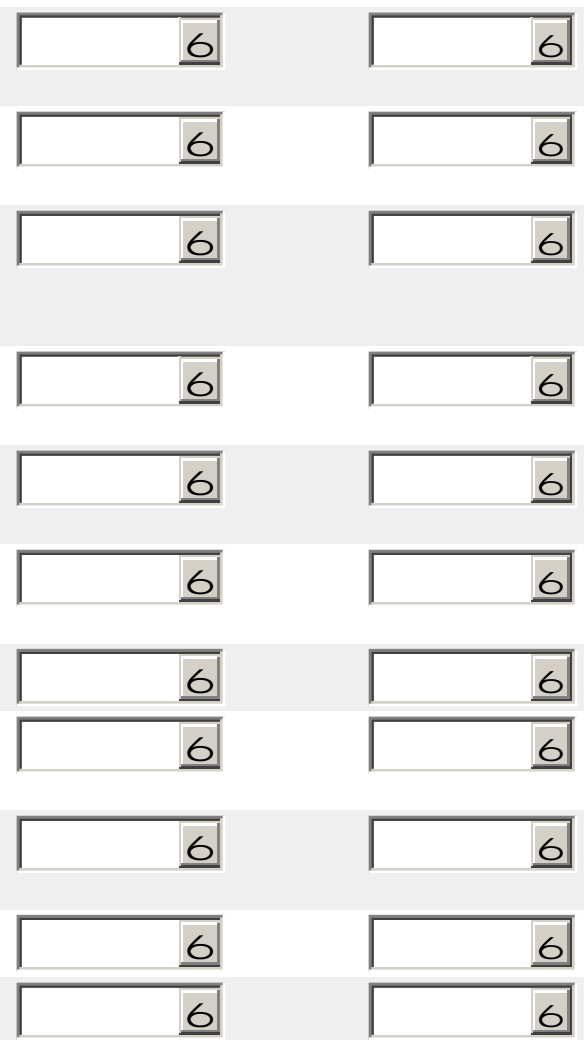


\section{Biomechanics Study Round I}

\section{Section 6: Anatomical Bases}

\section{J oint Structure and Function}

\section{The student will be able to:}

a) name and define the fundamental planes and axes.

b) describe and demonstrate joint movement with respect to plane and axis of motion.

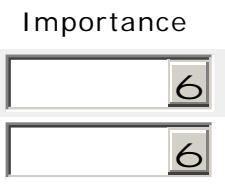

c) explain the relationship between joint structure and function.

d) name and demonstrate the actions possible in each joint in other than the anatomical starting position.

e) state the factors contributing to joint range of motion and stability.

f) classify joints according to structure and explain the relationship between joint structure and its capacity for movement.

g) observe a joints range of motion qualitatively and state appropriate procedures for improving that range.

h) explain how the schedule of ossification of epiphyseal cartilage is related to the nature of activities suitable for different age groups.
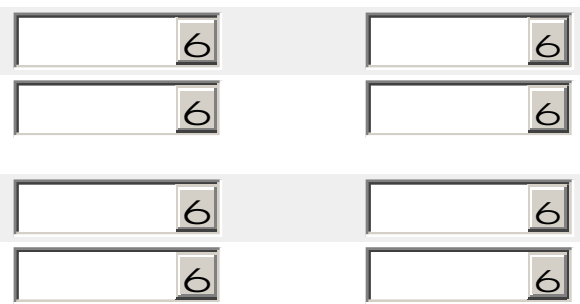

i) observe human movement and explain the reasons for different joint actions and ranges of motion using knowledge of joint structure, stability, and mobility.

j) assess flexibility and create safe and effective stretches for the major muscle groups surrounding each joint.
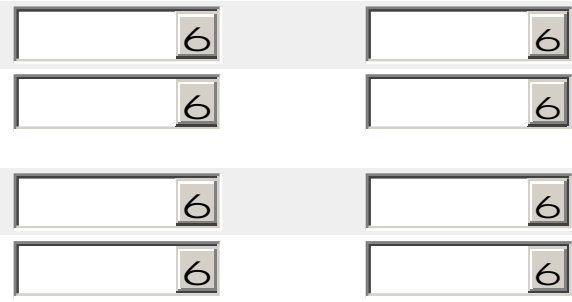

k) perform an anatomical analysis of the joint actions and planes of motion for a selected motor skill.
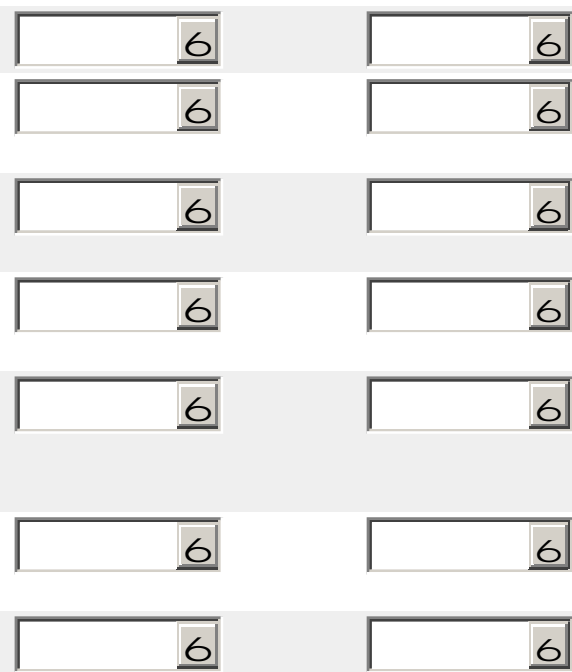


\section{Biomechanics Study Round I}

\section{Section 6: Anatomical Basis (continued)}

\section{Muscle Mechanics}

\section{The student will be able to:}

a) name the major muscles or muscle groups active in any given joint action.

b) identify the type(s) of muscular contraction (static, concentric, eccentric) occurring in any given joint action.

c) explain the cooperative action of muscles in controlling joint actions and identify the role (agonist, antagonist, stabilizer, neutralizer) played by the muscle(s) in a given movement.

d) explain the force-velocity and length-tension relationships of muscle and recognize their application in static positions and dynamic movements.

e) recognize the use of the stretch-shortening cycle of muscle in human movement and create effective training exercises that utilize this phenomenon.

f) describe the mechanical response of different muscle fiber types, the influence of training upon them, and the potential for muscle fiber
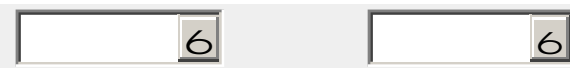
type to influence performance. 


\section{Biomechanics Study Round I}

\section{Section 6: Anatomical Basis (continued)}

\section{Neuromuscular Function}

\section{The student will be able to:}

a) name and define the basic structures (e.g., motor unit, muscle spindle and proprioceptors) of the neuromuscular system.

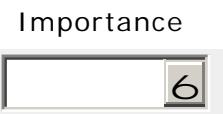

Relevance

b) explain how the various receptors function, and describe the effect each has on musculoskeletal movement.

c) describe the anatomical bases for reflex acts and name and define examples of reflexes (e.g., stretch reflex, righting and supporting reflexes, reciprocal inhibition or co-contraction) affect human movement.

d) describe how recruitment and rate coding of motor units regulate muscle force production.

e) perform an analysis of the neuromuscular factors influencing the performance of a variety of motor skills.
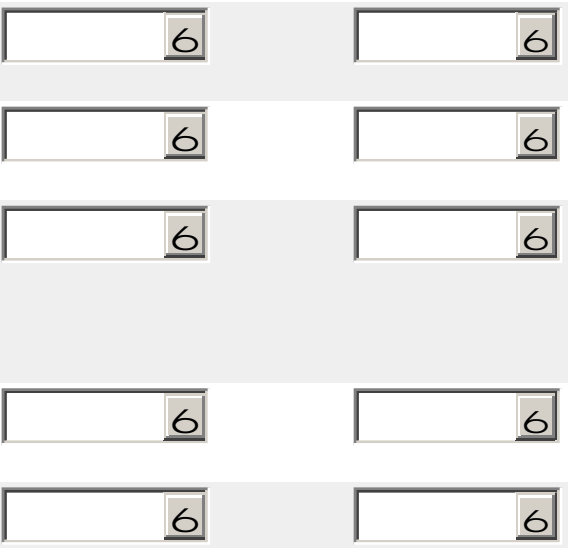


\section{Biomechanics Study Round I}

\section{Section 7: Mechanical Bases}

\section{Basic Considerations}

\section{The student will be able to:}

a) define a movement system and determine the nature of the system's movement (i.e., linear, angular, general motion).

b) appropriately represent kinematic and kinetic quantities as vectors and use vectors, vector addition, and vector resolution to enhance the understanding of basic mechanical concepts (e.g., impact of the direction of resultant force application (external forces), the effect of changes in line of muscle pull upon the amount of force used to rotate a segment (internal forces). 


\section{Biomechanics Study Round I}

\section{Section 7: Mechanical Basis (continued)}

\section{Movement Kinematics}

\section{The student will be able to:}

a) define the basic terms of distance, displacement, speed, velocity, and acceleration as they relate to linear and angular motion in human movements.

b) use kinematic variables to compare the quality of various motor performances (e.g., across skill level, fitness level, gender, age, body size and type, etc.).

c) explain the kinematic relationships between linear and angular motion and apply this relationship to improve motor skill performance
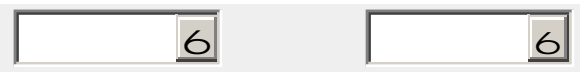
(e.g., striking, throwing, kicking) and equipment design (e.g., sport, rehabilitation, work environment).

d) describe how the variables of release height, angle, and velocity affect projectile motion and apply these variables to a projectile activity to optimize performance.

e) explain how to plan and conduct an effective qualitative human movement analysis.

f) use simple concepts of motion description (kinematics) to analyze human motion in qualitative terms.

g) identify and describe the uses of available instrumentation for measuring kinematic quantities.
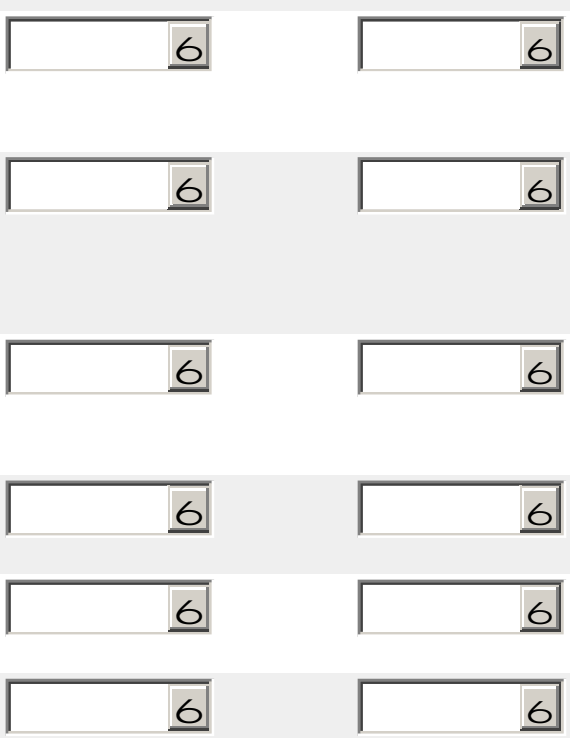


\section{Biomechanics Study Round I}

\section{Section 7: Mechanical Basis (continued)}

\section{Movement Kinetics}

\section{The student will be able to:}

a) define basic terms (e.g., force, inertia, mass, and weight) as they relate to linear motion in human movement.

b) define basic terms (e.g., torque, moment, moment of inertia, moment arm, radius) as they relate to angular motion.

c) identify Newton's laws of motion and gravitation and describe practical illustrations of the laws.

d) identify and provide examples of the angular analogues of Newton's laws of motion.

e) explain what factors affect friction and discuss the role of friction in daily activities and sports.

f) explain the effects of weight, normal reaction, friction, buoyancy, drag, and lift upon motor performance.

g) estimate the location of the center of gravity of persons in any position and describe how changes in location of the center of gravity and other mechanical factors that influence stability.

h) identify and explain the importance of impulse-momentum, workenergy, and the conservation of momentum to the production of
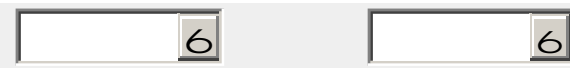

effective human movements. 


\section{Biomechanics Study Round I}

\section{Section 8: Motor Skills: Principles and Applications}

\section{Standing Posture}

\section{The student will be able to:}

a) identify and describe the skeletomuscular and neuromuscular antigravity mechanisms involved in volitional standing positions.

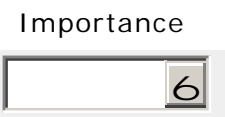

Relevance

b) summarize the similarities and differences that occur in the relation of the line of gravity to various body landmarks with good and poor
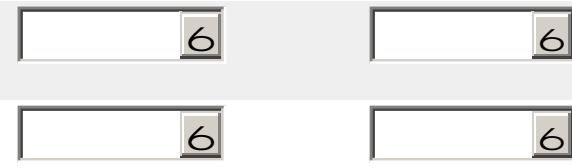
anteroposterior segmental alignment.

c) discuss the factors that affect the stability and energy cost of erect posture.

d) explain the effects that the variables of age, body build, strength, and flexibility have on the alignment of body segments in the standing posture.

e) name the values, if any, of good posture.

f) perform biomechanical analyses on the posture of individuals of different ages and body builds.
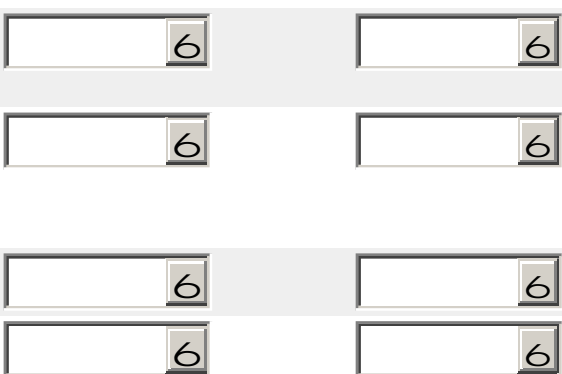


\section{Biomechanics Study Round I}

\section{Section 8: Motor Skills: Principles and Applications (continued)}

\section{Moving Objects: Pushing and Pulling}

Importance

a) classify activities involving push or pull patterns according to the nature of the force applications.

b) name and discuss anatomical and mechanical factors and principles that apply to representative push or pull activities.

c) analyze the performance of someone performing a push-pull skill under each of these force application conditions: momentary contact, projection, or continuous application.

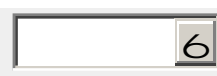

Relevance
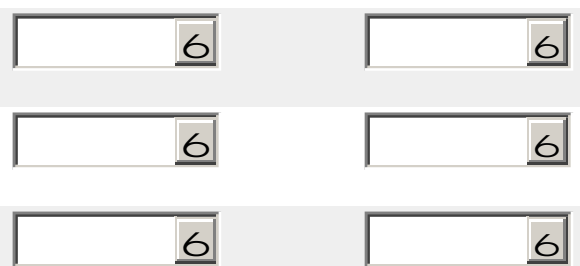


\section{Biomechanics Study Round I}

\section{Section 8: Motor Skills: Principles and Applications (continued)}

\section{Moving Objects: Throwing, Striking, and Kicking}

\section{The student will be able to:}

a) classify activities involving sequential throwing, kicking, or striking patterns according to the nature of force applied.

b) name and discuss anatomical and mechanical factors that apply to representative throwing, kicking, or striking activities.

C) perform an analysis of someone engaging in a sequential throwing, kicking, or striking skill under each of these force application

conditions: momentary contact, projection, continuous application.

d) plan and conduct a qualitative analysis of common object control skills.

e) plan and conduct a quantitative analysis of common object control skills.
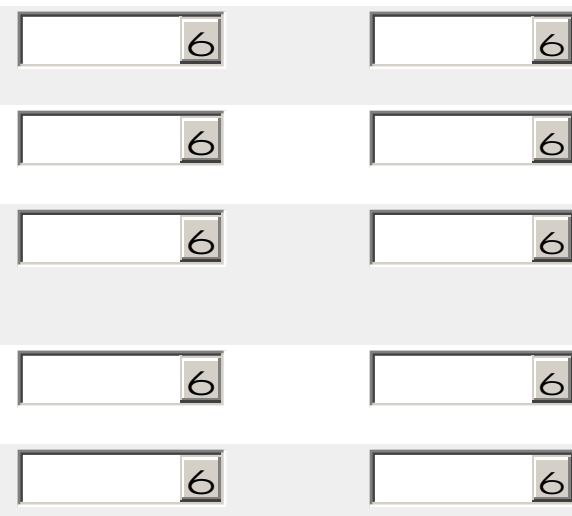

18. Locomotion: Solid Surface

\section{The student will be able to:}

a) identify and classify motor skills belonging in the categories that fall under the heading of moving one's body on the ground or on another resistant surface.

b) describe the anatomical and mechanical nature of motor skills representative of the major types of locomotor patterns.
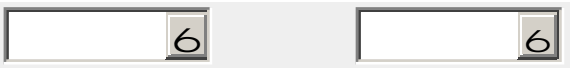

c) name and state anatomical and mechanical principles that apply to the locomotion patterns of walking, running, and jumping.

d) evaluate performance of motor skills representative of the major locomotor patterns in terms of application of the related
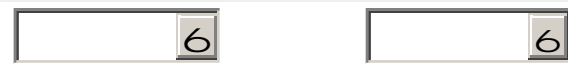
biomechanical principles.

e) plan and conduct a qualitative analysis of someone performing a locomotor skill.
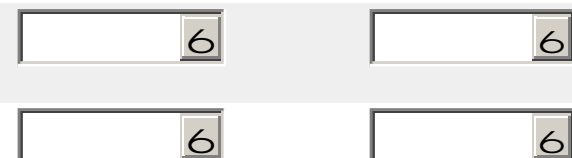

f) plan and conduct a quantitative analysis of someone performing a locomotor skill.
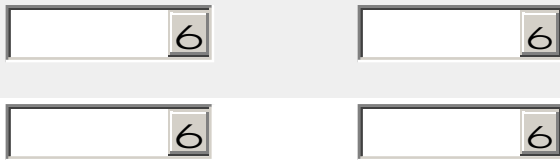


\section{Biomechanics Study Round I}

\section{Section 8: Motor Skills: Principles and Applications (continued)}

\section{Locomotion: The Aquatic Environment}

\section{The student will be able to:}

a) identify factors that contribute to the propulsion of a swimmer.

b) identify factors that impede the progress of a swimmer.

c) explain how the propulsive and resistive factors identified affect the length or frequency of a swimming stroke.

d) complete a biomechanical analysis of a swimming stroke by identifying the anatomical and mechanical factors important to success
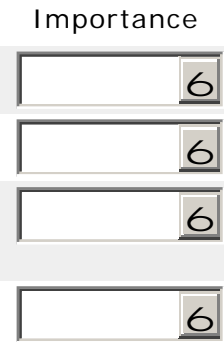

Relevance

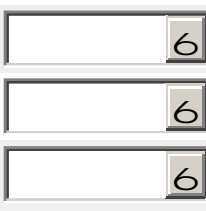
in the selected stroke, as well as those factors that appear to limit the particular performance.

\section{Locomotion: When Suspended and Free of Support}

\section{The student will be able to:}

a) explain how each of the following influences the action of swinging bodies: weight of the body, length of the pendulum, angular

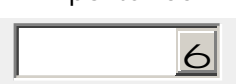
momentum, potential-kinetic energy, centripetal-centrifugal force, and friction.

b) describe how to initiate pendular action, increase the height of a swing, alter the period, change grips, and dismount safely.

c) explain how each of the following influences the flight path of unsupported bodies: angle of projection, vertical velocity, gravity, and angular momentum.

d) describe how to initiate and control rotation of unsupported bodies.

e) analyze the performance of a suspension and a nonsupport movement.

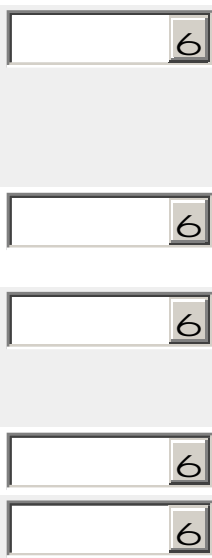




\section{Biomechanics Study Round I}

\section{Section 8: Motor Skills: Principles and Applications (continued)}

\section{I mpact}

a) name the common problems associated with the diverse forms of receiving impact

b) explain how the work-energy, impulse-momentum, and pressurearea relationships apply to receiving the impact either of one's own body or of external objects.

c) state the principles related to avoiding injury while receiving impact and furnish an application for each.

d) state the principles related to maintaining and regaining equilibrium while receiving impact and furnish an application for each.

e) state the principles related to accuracy and control while receiving impact and furnish an application for each.
Importance

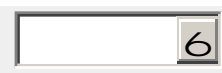

Relevance
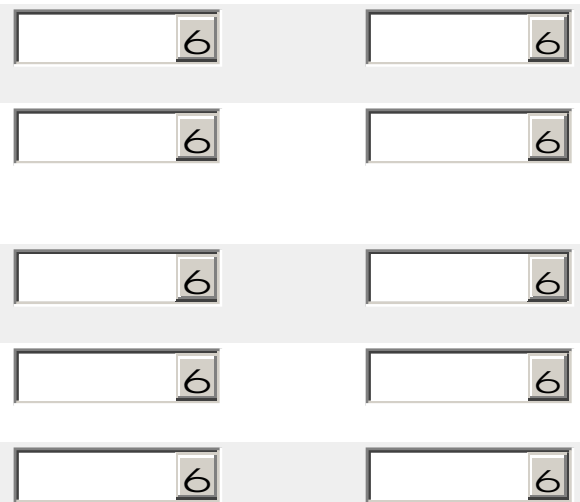


\section{Biomechanics Study Round I}

\section{Thank you!}

Thank you for your time and participation in this research study! Your input is greatly appreciated! You will be sent the results from Round I once the data for all participants has been analyzed.

\section{Susan Ross}

West Virginia University

College of Physical Activity \& Sport Sciences

sross11@mix.wvu.edu

(304) 293-0848 


\section{Appendix D}

Biomechanics Recommendations for the Physical Education Teacher Education Curriculum

Round II 


\section{Round II E-mail}

Hello (insert name here),

Thank you again for agreeing to participate in my study titled Recommendations for Biomechanics in the Physical Education Teacher Education Curriculum. In this second and final round, your task will be to rate each survey item a second time. As additional information, I have attached a document containing both your individual rating (IR) and group mean ratings (GR) of each survey item from the first round. The document will allow you to view how your responses on each item compared against the overall opinion of the group.

At the end of the survey, you will find an additional set of questions asking you to recommend possible learning environments and instructional methods for delivering biomechanics content to prospective physical educators within the PETE curriculum. Please use the attached email document titled Biomechanics Round II Survey Reference for clarification on how the terms learning environment and instructions methods are defined for the purpose of this study. Additional reference material is also included.

Your valuable contribution is essential for the continued success of this study. Please read the instructions that have been provided on the survey questionnaire prior to taking the survey. If you have any questions, please contact me at (304) 293-0848 or sross11@mix.wvu.edu.

The following hyperlink will take you to Round II of the survey: http://www.surveymonkey.com/s/G3SYPKN

If possible, please complete the online survey prior to midnight on Friday, April 16th. You will receive a final copy of the results at the conclusion of this investigation.

Thank you once again for your contribution!

Susan

Susan Ross

West Virginia University

College of Physical Activity \& Sport Sciences

P.O. Box 6116

Morgantown, WV 26506

(304) 293-0848 


\title{
Attachment in E-mail Sent to Round II Participants
}

\author{
Delphi Round II: Open Response Question
}

\section{INSTRUCTIONS:}

According to the Guidelines and Standards for Undergraduate Biomechanics (NASPE, 2003), upon completion of a biomechanics course the student should be able to:

1. observe and describe a movement technique accurately;

2. determine the anatomical and mechanical factors basic to the performance of an observed movement;

3. evaluate the suitability of a performer's technique with reference to the task at hand;

4. identify those factors that limit performance and establish a priority for change in those factors most likely to lead to improvement in performance.

The above stated outcome goals "should be examined across performers of varied gender, age, skill and fitness levels” (NASPE, 2003, p. 2).

In accomplishing one or more the above stated outcomes goals please (a) list 3 possible learning environments for teaching biomechanics content to prospective K-12 physical education teachers, (b) list a specific instructional method you would recommend for the learning environment, and (c) provide a brief description of the instructional method.

\# Example:

A. Learning Environment: Elementary Activity-Based Course

B. Instructional Method: Peer Observation

C. Description: Students (preservice physical education teachers) first experience with observing, identifying critical features of movement, and assessing movement technique is via a criteria sheet containing critical features of selected motor skills (e.g., throwing, striking, kicking). During class time, half the class performs the selected skill over several trials, while the other students observe movement responses and completes a checklist on their peers. The instructor circulates around the teaching area ensuring students who are assessing understand the critical features they are observing. In the case that most students are performing the skill well, "plant" at least one student who will perform the skill incorrectly. The activity simply exposes students to the process of observing in a dynamic environment, and analyzing (identifying the strengths and weakness in performance), as opposed to just watching. 


\section{Reference Sheet}

\section{Introduction}

The guidelines and standards for undergraduate biomechanics reinforce the importance of infusing biomechanical concepts in the preparation of practitioners (NAPSE, 2003). The infusion of biomechanical concepts and competencies in the PETE curriculum is intended to help physical educators make meaningful applications of the subject matter. Infusion will allow preservice physical educators to revisit core biomechanical content or perspectives in a variety of instructional contexts within the PETE program. An important initial task is to target specific learning environments for teaching core competencies and identify instructional methods for those learning environments.

In the subsequent section, examples of learning environments and instructional methods are provided to ensure the meaning of the terminology is clear among all Delphi panelists. These are only examples.

\section{Learning Environments}

The learning environment is the specific context in which prospective physical educators are or may potentially be exposed to biomechanics content within the PETE curriculum. Some examples include, but are not limited to:

Traditional Learning Environment (on-campus)

- Motor learning and development course

- Biomechanics (Classroom or Laboratory-based)

- Exercise physiology (Classroom or Laboratory-based)

- Elementary activity-based courses (e.g., lead-up games, elementary gymnastics, rhythms, etc)

- Middle/High school activity-based (e.g., team-related sports, individual or dual sports, lifetime activities, weight training, etc)

- Adapted physical education course

- Elementary/Secondary teaching methods

- Basic instruction courses (preservice teachers teach basic sport skills related to basketball, volleyball, gymnastics, and tennis to other college students who are enrolled in course)

Authentic Learning Environment (off-campus):

- Elementary school clinical or field-based experiences

- Middle/High School clinical or field-based experiences

Alternative Learning Environments

- After-school sport, physical activity and fitness program

- Sport instruction camp

- Fitness and wellness facility

- Community-based sport and physical activity establishments (e.g., YMCA) 
Instructional Methods

For the purpose of this study, instructional methods refer to the educational approach used to help prospective physical educators learn the content. Instructional methods are the "how to" in the delivery of biomechanics content in the targeted learning environment. Although more than one instructional method is typically incorporated within a single lesson (e.g., lecture overview followed by a lab-based application task), the methods used should help prospective teachers understand and be able to apply biomechanics concepts. The following framework is intended to provides some examples of instructional methods and differentiate between instructional variables. Please know this is only a frame of reference.

\section{Instructional Framework}

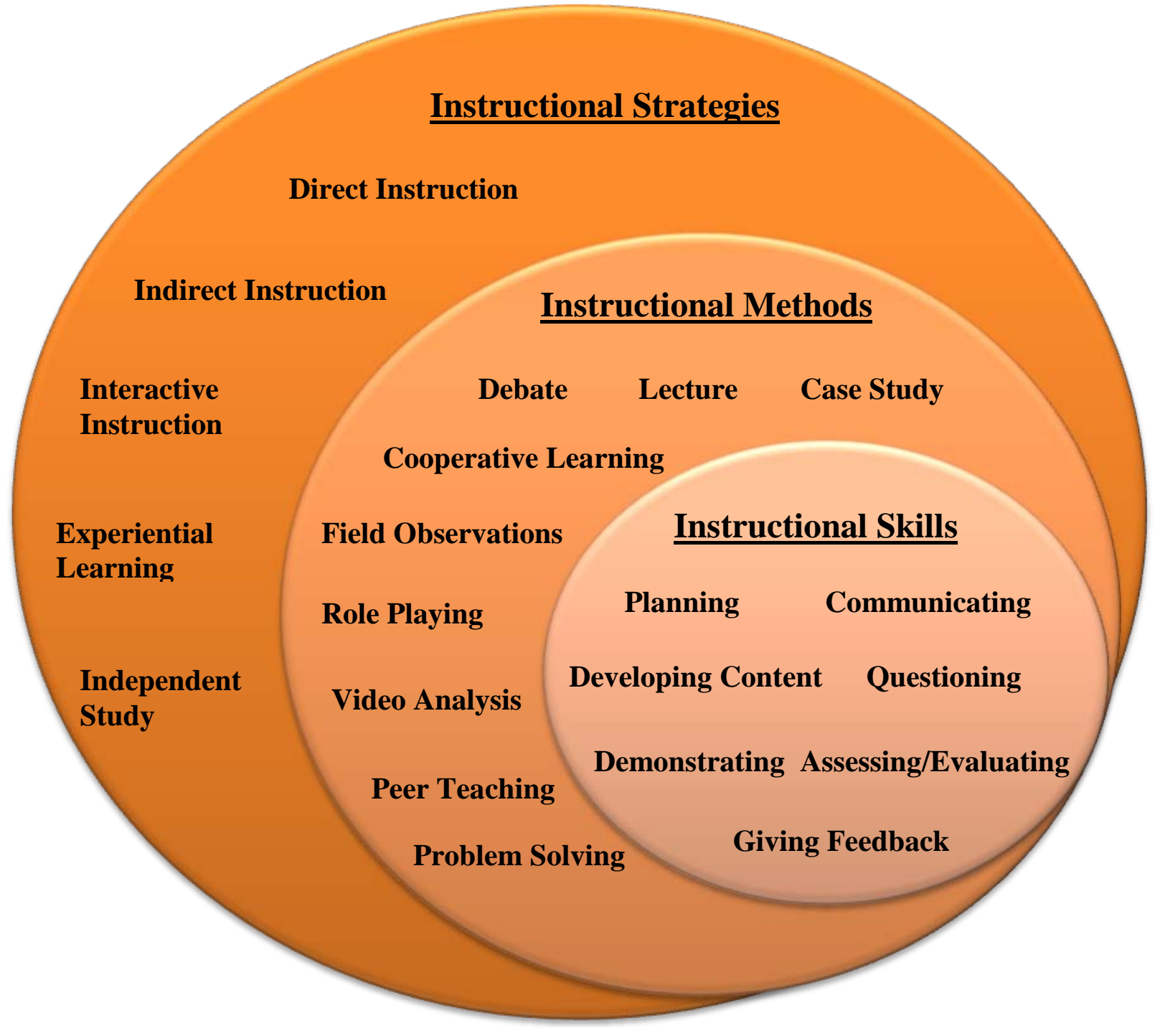




\section{Instructional Methods}

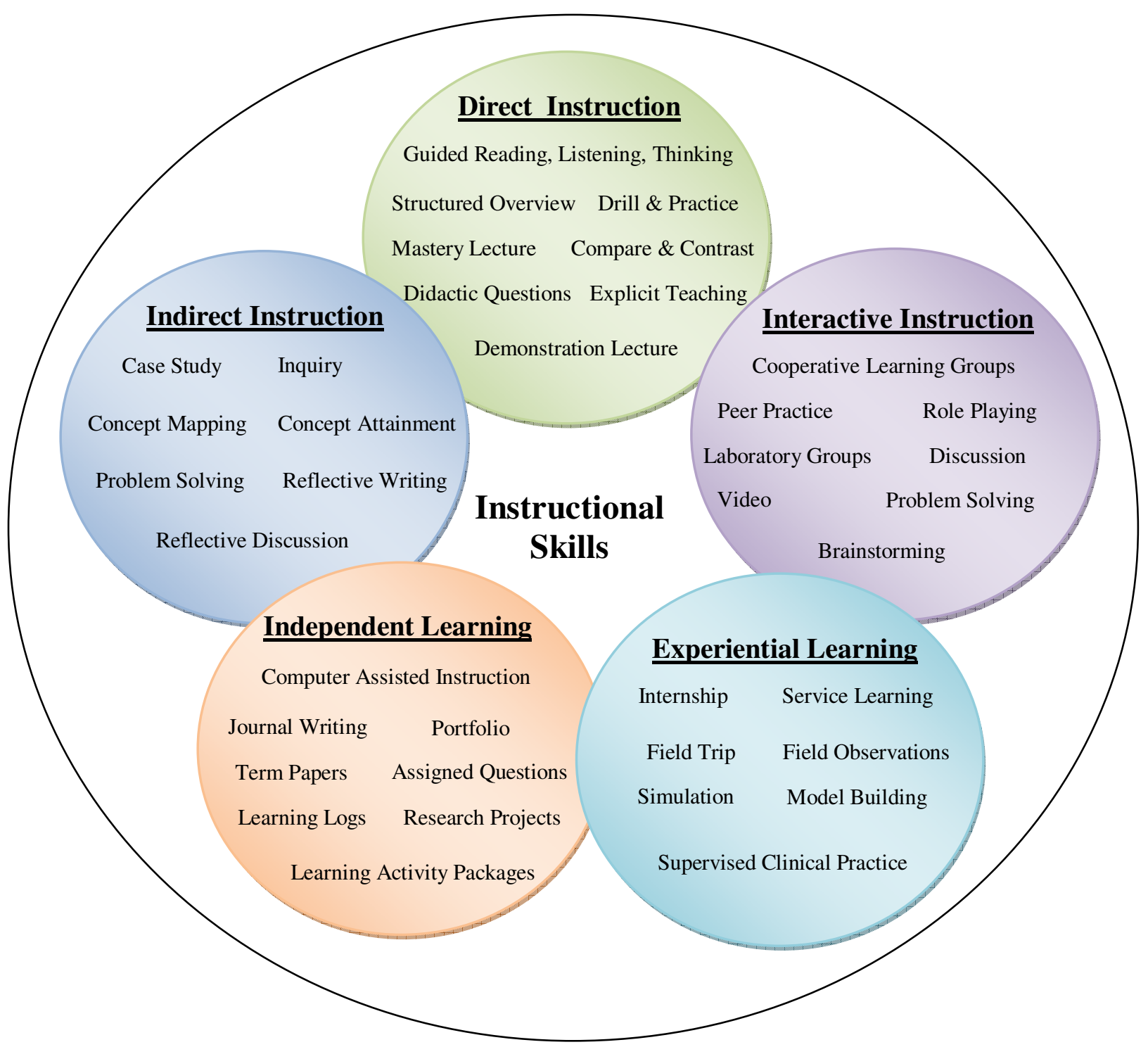

Adapted from Saskatchewan Education. (1991). Instructional approaches: A framework for professional practice. Regina, SK: Saskatchewan Education. 
Sample Round II Individual Rankings Sent to Participants with Round II E-mail Recommendations for Biomechanics in the Physical Education Teacher Education Curriculum

\section{Round II}

*Below you will find your individual rating (IR) and the average group rating (GR) from the previous round of investigation. Please use this information in making your selection on SurveyMonkey.

*Please keep in mind the following definitions of importance and relevance as they relate to this study:

IMPORTANCE - ITEM SHOULD BE UNDERSTOOD BY ALL PROSPECTIVE K-12 PHYSICAL EDUCATION TEACHERS. RELEVANCE - ITEM IS APPLICABLE TO THE INSTRUCTION OF PHYSICAL EDUCATION IN A K-12 SETTING.

\begin{tabular}{|c|c|c|c|c|}
\hline Concepts \& Competencies & \multicolumn{2}{|c|}{ Importance } & \multicolumn{2}{|c|}{ Relevance } \\
\hline Section 2: Introduction to Biomechanics & IR & GR & IR & GR \\
\hline \multicolumn{5}{|l|}{ 1. The student will be able to: } \\
\hline $\begin{array}{l}\text { a. define and explain the terms biomechanics, statics, dynamics, kinematics, and kinetics in relation to human } \\
\text { movement. }\end{array}$ & 4 & 4.08 & 4 & 3.58 \\
\hline b. describe the scope of scientific inquiry addressed by biomechanists. & 2 & 3.46 & 1 & 2.88 \\
\hline c. distinguish between qualitative and quantitative approaches for analyzing human movement. & 4 & 4.25 & 4 & 3.88 \\
\hline d. explain how to formulate questions for qualitative analysis of human movement. & 4 & 3.88 & 4 & 3.67 \\
\hline \multicolumn{5}{|l|}{ Section 3: Application of Biomechanics Competencies to Human Movement } \\
\hline \multicolumn{5}{|l|}{ 2. The student will be able to: } \\
\hline a. observe and describe a movement technique accurately & 5 & 4.79 & 5 & 4.75 \\
\hline b. determine the anatomical and mechanical factors basic to the performance of an observed movement & 4 & 4.58 & 4 & 4.48 \\
\hline c. evaluate the appropriateness of a performer's technique with reference to the movement task & 5 & 4.75 & 5 & 4.75 \\
\hline $\begin{array}{l}\text { d. identify factors that limit skillful performance and establish a priority for change in those factors most } \\
\text { likely to lead to improvement in performance. }\end{array}$ & 5 & 4.75 & 5 & 4.71 \\
\hline \multicolumn{5}{|l|}{ Section 4: Qualitative Analysis of Human Movement } \\
\hline \multicolumn{5}{|l|}{ 3. Preparation: Gathering Relevant Knowledge } \\
\hline $\begin{array}{l}\text { a. define the critical features of various motor skills and explain how they are identified in the preparation task } \\
\text { of qualitative analysis of movement. }\end{array}$ & 4 & 4.46 & 4 & 4.42 \\
\hline $\begin{array}{l}\text { b. explain how preparation in qualitative analysis of movement is related to effective teaching and } \\
\text { observation. }\end{array}$ & 2 & 4.25 & 2 & 4.00 \\
\hline c. explain how preparing for qualitative analysis can be integrated with planning for teaching. & 3 & 4.08 & 4 & 4.13 \\
\hline
\end{tabular}




\section{Observation: Developing a Systematic Observation Strategy}

a. explain how to compensate for perceptual limitations by planning a systematic observational strategy.

b. identify key elements of a systematic observational strategy.

c. identify several effective systematic observational strategies.

d. explain how all the senses can be integrated to improve observation.

4

\section{Evaluation and Diagnosis: Critical Thinking Within Qualitative Analysis}

a. explain why evaluation of performance errors is necessary for qualitative analysis.

b. discuss major difficulties in evaluating strengths and weaknesses of performance.

c. discuss strategies for prioritizing weaknesses that serve as performance diagnosis.

\begin{tabular}{ll|ll}
4 & 3.92 & 4 & 3.96 \\
2 & 4.00 & 2 & 3.96 \\
4 & 3.79 & 4 & 3.71 \\
3 & 3.67 & 3 & 3.58 \\
\hline 4 & 4.25 & 4 & 4.13 \\
2 & 4.17 & 2 & 4.04 \\
4 & 4.21 & 4 & 4.04 \\
\hline \multicolumn{4}{l}{} \\
4 & 4.63 & 4 & 4.63 \\
2 & 3.83 & 4 & 3.67 \\
2 & 3.75 & 2 & 3.46 \\
4 & 4.42 & 4 & 4.54 \\
5 & 4.46 & 5 & 4.50 \\
\hline
\end{tabular}

\section{Intervention: Strategies for Improving Performance}

a. identify a variety of intervention strategies (e.g., feedback, task modification, mechanical guidance)used in qualitative analysis to improve performance.

b. identify research supported guidelines for the provision of augmented verbal feedback.

c. list the functions of feedback as intervention in qualitative analysis.

d. describe how to develop appropriate cue words and phrases for improving skill performance.

e. identify the most appropriate intervention strategy (e.g., feedback, task modification, mechanical guidance) for improving skill performance across novice, intermediate, and expert performers. 


\begin{tabular}{|c|c|c|c|}
\hline \multicolumn{2}{|c|}{ Importance } & \multicolumn{2}{|c|}{ Relevance } \\
\hline IR & GR & IR & GR \\
\hline 1 & 3.26 & 1 & 2.83 \\
\hline 1 & 3.63 & 1 & 3.08 \\
\hline 1 & 3.38 & 1 & 2.75 \\
\hline 1 & 3.42 & 1 & 2.83 \\
\hline 1 & 2.42 & 1 & 2.04 \\
\hline 1 & 2.67 & 1 & 2.29 \\
\hline 1 & 2.63 & 1 & 2.33 \\
\hline 1 & 2.46 & 1 & 2.1 \\
\hline 1 & 2.67 & 1 & 2.39 \\
\hline 3 & 3.08 & 3 & 2.63 \\
\hline 4 & 4.50 & 4 & 4.46 \\
\hline
\end{tabular}

Section 5: Quantitative Analysis of Human Movement

7. Quantitative Reasoning and Problem Solving

a. categorize classes of quantitative problems and select appropriate techniques for analysis and problem solving.

b. interpret graphs and simple models which are used to explain human movement.

c. demonstrate an awareness of and proficiency with various computational skills to effectively interpret and use quantitative information.

d. identify current technology used to quantify biomechanical variables in human movement.

e. solve quantitative problems involving vector quantities using both graphic and trigonometric procedures.

f. solve quantitative problems involving angular kinematic quantities and the relationship between angular and linear kinematic quantities.

g. solve quantitative problems related to kinetic concepts.

h. solve basic quantitative problems using the equations of static equilibrium.

i. solve quantitative problems relating to the factors that cause or modify angular motion.

j. list possible sources of error in recorded movement data.

k. develop the ability to think critically about information and then develop effective strategies to problems relating to human movement and performance.

\section{Section 6: Anatomical Bases}

\section{Joint Structure and Function}

a. name and define the fundamental planes and axes.

b. describe and demonstrate joint movement with respect to plane and axis of motion.

c. explain the relationship between joint structure and function.

d. name and demonstrate the actions possible in each joint in other than the anatomical starting position.

e. state the factors contributing to joint range of motion and stability.

f. classify joints according to structure and explain the relationship between joint structure and its capacity for movement.

g. observe a joints range of motion qualitatively and state appropriate procedures for improving that range.

h. explain how the schedule of ossification of epiphyseal cartilage is related to the nature of activities suitable for different age groups.

i. observe human movement and explain the reasons for different joint actions and ranges of motion using knowledge of joint structure, stability, and mobility.

j. assess flexibility and create safe and effective stretches for the major muscle groups surrounding each joint.

k. perform an anatomical analysis of the joint actions and planes of motion for a selected motor skill.

\begin{tabular}{ll|ll}
1 & 4.04 & 1 & 3.71 \\
1 & 4.04 & 1 & 3.75 \\
4 & 4.33 & 4 & 3.88 \\
4 & 4.33 & 4 & 4.08 \\
4 & 4.29 & 4 & 4.00 \\
4 & 4.13 & 4 & 3.88 \\
5 & 4.46 & 5 & 4.21 \\
5 & 4.21 & 5 & 4.00 \\
3 & 4.25 & 3 & 4.04 \\
5 & 4.67 & 5 & 4.63 \\
3 & 4.29 & 3 & 3.88 \\
\hline
\end{tabular}




\begin{tabular}{cc|cc}
\multicolumn{2}{l}{ Importance } & \multicolumn{2}{c}{ Relevance } \\
IR & GR & IR & GR \\
\hline 4 & 4.54 & 4 & 4.42 \\
4 & 4.46 & 4 & 4.13 \\
3 & 4.21 & 3 & 3.71 \\
2 & 3.96 & 2 & 3.67 \\
4 & 4.04 & 4 & 3.83 \\
4 & 3.96 & 4 & 3.54 \\
\hline & & & \\
2 & 3.71 & 2 & 2.96 \\
2 & 3.71 & 2 & 2.92 \\
2 & 3.58 & 2 & 3.08 \\
4 & 3.25 & 4 & 2.79 \\
3 & 3.45 & 3 & 3.09 \\
\hline
\end{tabular}

Section 6: Anatomical Bases (cont.)

9. Muscle Mechanics

a. name the major muscles or muscle groups active in any given joint action.

b. identify the type(s) of muscular contraction (static, concentric, eccentric) occurring in any given joint action.

c. explain the cooperative action of muscles in controlling joint actions and identify the role (agonist, antagonist, stabilizer, neutralizer) played by the muscle(s) in a given movement.

d. explain the force-velocity and length-tension relationships of muscle and recognize their application in static positions and dynamic movements.

e. recognize the use of the stretch-shortening cycle of muscle in human movement and create effective training exercises that utilize this phenomenon.

f. describe the mechanical response of different muscle fiber types, the influence of training upon them, and the potential for muscle fiber type to influence performance.

\section{Neuromuscular Function}

a. name and define the basic structures (e.g., motor unit, muscle spindle and proprioceptors) of the neuromuscular system.

b. explain how the various receptors function, and describe the effect each has on musculoskeletal movement.

c. describe the anatomical bases for reflex acts and name and define examples of reflexes (e.g., stretch reflex, righting and supporting reflexes, reciprocal inhibition or co-contraction) affect human movement.

d. describe how recruitment and rate coding of motor units regulate muscle force production.

e. perform an analysis of the neuromuscular factors influencing the performance of a variety of motor skills.

\section{Section 7: Mechanical Bases}

\section{Basic Considerations}

a. define a movement system and determine the nature of the system's movement (i.e., linear, angular, general motion).

b. appropriately represent kinematic and kinetic quantities as vectors and use vectors, vector addition, and vector resolution to enhance the understanding of basic mechanical concepts (e.g., impact of the direction of resultant force application (external forces), the effect of changes in line of muscle pull upon the amount of force used to rotate a segment (internal forces).

\begin{tabular}{ll|ll}
2 & 3.71 & 3 & 3.38 \\
1 & 3.54 & 1 & 2.83 \\
\hline
\end{tabular}


12. Movement Kinematics

a. define the basic terms of distance, displacement, speed, velocity, and acceleration as they relate to linear and angular motion in human movements.

b. use kinematic variables to compare the quality of various motor performances (e.g., across skill level, fitness level, gender, age, body size and type, etc.).

c. explain the kinematic relationships between linear and angular motion and apply this relationship to improve motor skill performance (e.g., striking, throwing, kicking) and equipment design (e.g., sport, rehabilitation, work environment).

d. describe how the variables of release height, angle, and velocity affect projectile motion and apply these variables to a projectile activity to optimize performance.

e. explain how to plan and conduct an effective qualitative human movement analysis.

f. use simple concepts of motion description (kinematics) to analyze human motion in qualitative terms.

g. identify and describe the uses of available instrumentation for measuring kinematic quantities.

\section{Movement Kinetics}

a. define basic terms (e.g., force, inertia, mass, and weight) as they relate to linear motion in human movement.

b. define basic terms (e.g., torque, moment, moment of inertia, moment arm, radius) as they relate to angular motion.

c. identify Newton's laws of motion and gravitation and describe practical illustrations of the laws.

d. identify and provide examples of the angular analogues of Newton's laws of motion.

e. explain what factors affect friction and discuss the role of friction in daily activities and sports.

f. explain the effects of weight, normal reaction, friction, buoyancy, drag, and lift upon motor performance.

g. estimate the location of the center of gravity of persons in any position and describe how changes in location of the center of gravity and other mechanical factors that influence stability.

\begin{tabular}{ll|ll}
2 & 4.08 & 2 & 3.63 \\
4 & 4.25 & 4 & 4.04 \\
& & & \\
2 & 4.29 & 2 & 4.25 \\
& & & \\
2 & 4.29 & 2 & 4.38 \\
2 & 4.00 & 2 & 3.83 \\
4 & 4.21 & 4 & 3.96 \\
1 & 3.30 & 2 & 2.70 \\
\hline & & & \\
1 & 4.17 & 1 & 3.75 \\
1 & 4.08 & 1 & 3.63 \\
2 & 4.21 & 2 & 3.92 \\
2 & 4.00 & 2 & 3.46 \\
2 & 4.21 & 2 & 3.92 \\
2 & 4.13 & 2 & 3.92 \\
4 & 4.21 & 4 & 4.00 \\
& & & \\
2 & 3.88 & 2 & 3.46 \\
\hline
\end{tabular}




\begin{tabular}{|c|c|c|c|}
\hline \multicolumn{2}{|c|}{ Importance } & \multicolumn{2}{|c|}{ Relevance } \\
\hline IR & GR & IR & GR \\
\hline 1 & 3.17 & 1 & 2.71 \\
\hline 2 & 3.83 & 2 & 3.25 \\
\hline 2 & 3.79 & 3 & 3.17 \\
\hline 4 & 3.96 & 4 & 3.67 \\
\hline 4 & 4.21 & 4 & 4.08 \\
\hline 2 & 3.46 & 2 & 3.08 \\
\hline 2 & 3.88 & 2 & 3.54 \\
\hline 2 & 3.88 & 2 & 3.50 \\
\hline 2 & 3.87 & 2 & 3.74 \\
\hline 3 & 4.25 & 3 & 4.13 \\
\hline 4 & 4.42 & 4 & 4.21 \\
\hline 2 & 4.29 & 2 & 4.00 \\
\hline 5 & 4.30 & 5 & 4.22 \\
\hline 2 & 3.09 & 2 & 2.78 \\
\hline
\end{tabular}

\section{Section 8: Motor Skills: Principles \& Applications}

\section{Standing Posture}

a. identify and describe the skeletomuscular and neuromuscular antigravity mechanisms involved in volitional standing positions.

b. summarize the similarities and differences that occur in the relation of the line of gravity to various body landmarks with good and poor anteroposterior segmental alignment.

c. discuss the factors that affect the stability and energy cost of erect posture.

d. explain the effects that the variables of age, body build, strength, and flexibility have on the alignment of body segments in the standing posture. Discuss the factors that affect the stability and energy cost of erect posture.

e. name the values, if any, of good posture.

f. perform biomechanical analyses on the posture of individuals of different ages and body builds.

\section{Moving Objects: Pushing and Pulling}

a. classify activities involving push or pull patterns according to the nature of the force applications.

b. name and discuss anatomical and mechanical factors and principles that apply to representative push or pull activities.

c. analyze the performance of someone performing a push-pull skill under each of these force application conditions: momentary contact, projection, or continuous application.

\section{Moving Objects: Throwing, Striking, and Kicking}

a. classify activities involving sequential throwing, kicking, or striking patterns according to the nature of force applied.

b. name and discuss anatomical and mechanical factors that apply to representative throwing, kicking, or striking activities.

c. perform an analysis of someone engaging in a sequential throwing, kicking, or striking skill under each of these force application conditions: momentary contact, projection, continuous application.

d. plan and conduct a qualitative analysis of common object control skills.

e. plan and conduct a quantitative analysis of common object control skills. 


\begin{tabular}{|c|c|c|c|}
\hline \multicolumn{2}{|c|}{ Importance } & \multicolumn{2}{|c|}{ Relevance } \\
\hline IR & GR & IR & GR \\
\hline 2 & 3.83 & 2 & 3.71 \\
\hline 4 & 4.04 & 4 & 4.04 \\
\hline 3 & 4.21 & 3 & 4.00 \\
\hline 3 & 4.33 & 3 & 4.17 \\
\hline 5 & 4.42 & 5 & 4.38 \\
\hline 1 & 2.92 & 1 & 2.79 \\
\hline 4 & 4.04 & 4 & 3.67 \\
\hline 4 & 4.08 & 4 & 3.75 \\
\hline 3 & 3.75 & 3 & 3.38 \\
\hline 4 & 3.79 & 4 & 3.46 \\
\hline 3 & 3.96 & 3 & 3.67 \\
\hline 4 & 3.83 & 4 & 3.63 \\
\hline 3 & 4.13 & 3 & 3.92 \\
\hline 4 & 4.00 & 4 & 3.63 \\
\hline 4 & 3.71 & 4 & 3.54 \\
\hline
\end{tabular}




\begin{tabular}{c|c|cc}
\multicolumn{2}{c|}{ Importance } & \multicolumn{2}{c}{ Relevance } \\
\hline IR & GR & IR & GR \\
\hline 2 & 4.04 & 2 & 3.83 \\
2 & 3.92 & 2 & 3.63 \\
4 & 4.21 & 4 & 4.00 \\
4 & 4.00 & 4 & 3.75 \\
4 & 4.04 & 4 & 3.71 \\
\hline
\end{tabular}




\section{Biomechanics Study Round II}

\section{Survey I ntroduction}

Welcome to Round II of this modified Delphi investigation and thank you for your assistance in completing this research project titled "Recommendations for Biomechanics in the Physical Education Teacher Education Curriculum."

In this round, your task will be to rate each survey item a second time. As additional information, you will find the Delphi panel's average ratings for each item included in the email attachment that brought you to this survey. Your individual ratings of each item have also been provided for your consideration. Please read the instructions provided on the next page for further information prior to completing the survey.

A primary goal of this investigation is to reach an acceptable level of group consensus as to what knowledge in the area of biomechanics is most important and relevant in the preparation of physical education teachers. In order for a biomechanics competency to be kept and group consensus achieved in the final round, the competency needs to receive a mean rating of at least four or higher in the areas of importance AND relevance by at least 18 out of $24(75 \%)$ panel members.

Your completion of this second and final round survey is essential for the continued success of the study. While it is critical that you complete this final round of the rating process, your participation is entirely voluntary and you do not have to respond to every item on the survey. You may be assured of complete confidentiality regarding all of your responses. You will receive the final results of the study once all panel members have completed the survey.

If possible, please complete the survey by Friday, April 16th. If you have any questions, contact me at (304) 293-0848 or sross11@mix.wvu.edu. Thanks again for your assistance, cooperation, and contribution of your valuable time.

Sincerely,

Susan Ross

West Virginia University

College of Physical Activity \& Sport Sciences

sross11@mix.wvu.edu

(304) 293- 0848

The items that you are evaluating were adapted from:

* National Assocation for Sport and Physical Education Kinesiology Academy. (1980). Guidelines and standards for undergraduate kinesiology. J ournal of Physical Education and Recreation, 51(2), 19- 21.

* National Association for Sport and Physical Education. (2003). Guidelines for Undergraduate Biomechanics. Reston, VA: NASPE Publications.

*Hall, S.J . (1999). Basic Biomechanics. New York, NY: McGraw- Hill.

*Knudson, D.V., \& Morrison, C.S. (2002). 2nd Ed. Qualitative Analysis of Human Movement. Champaign, IL: Human Kinetics.

*Hamilton, N., Weimar, W., \& Luttgens, K. (2008). 11th Ed. Kinesiology: Scientific Basis of Human Motion. New York, NY: McGraw- Hill.

All are reproduced with the permission of the National Association for Sport and Physical Education, the Journal of Physical Education, Recreation, and Dance; as well as McGraw-Hill and Human Kinetics. 


\section{Biomechanics Study Round II}

\section{Survey I nstructions}

Thank you very much for your assistance in completing this research project. It is hoped that this study will result in the generation of a list of critical theoretical and applied biomechanics competencies the are recommended for inclusion in the physical education teacher education curriculum. After reading the following instructions, please complete the online survey within the next three weeks.

Please rate each questionnaire item a second time in the areas of IMPORTANCE and RELEVANCE. IMPORTANCE will refer to the item's value as a theoretical underpinning of the physical education profession(important for physical educators to "know"). RELEVANCE will refer to the item's practical and applied value to the P- 12 physical educator.

Please note that you are provided with both your individual rating (IR) and group mean ratings (GR) of each survey item from the first round (refer to email attachment that brought you to this page). This will allow you to view how your responses on each item compare against the overall opinion of the group. As you complete the survey a second time please reevaluate your previous viewpoint on each survey item based on the overall group statistical average. After further consideration, you may choose to keep your original Round I rating, or amend your previous rating based on the group average.

RATING SCALE:

A rating of (5) or (4) in BOTH IMPORTANCE and RELEVANCE means that you consider the item to be essential in the preparation of prospective P- 12 physical education teachers.

A rating of (3) means you have no opinion or are undecided regarding the IMPORTANCE and RELEVANCE of the item.

A rating of (2) or (1) on EITHER IMPORTANCE or RELEVANCE means the item is not essential for the preparation of prospective $\mathrm{P}-12$ physical education teachers.

If you choose not to respond to a particular item, please leave it blank.

Also, at the end of the survey you will find an additional set of questions asking for you to recommend possible learning environments and instructional methods for the delivery of biomechanics content to prospective physical educators in the PETE curriculum. You have been provided a document titled "Biomechanics Round II Survey Reference" as a reference for answering this questions. Completion of this round will conclude your participation in the study.

Thanks again and please feel free to contact me directly with any questions at (304) 293-0848 or sross11@mix.wvu.edu

A few reminders:

1-You must enter your name on the first page of the survey in order to continue. This is the only question you must answer.

2-You may return to the instructions page at any time by using the "Prev" buttons at the bottom of the survey pages. There is complete freedom (once you have entered your name) to go to any page within the survey and change your responses if necessary.

3- A survey completion bar will be at the top of each page in order to show your progress through the survey.

4- You can leave and return to the survey at any time. 


\section{Biomechanics Study Round II}

\section{Table of Contents}

Section 1: Participant Information

Section 2: Introduction to Biomechanics (Question 2)

Section 3: Application of Biomechanics Competencies to Human Movement (Question 3)

Section 4: Qualitative Analysis of Human Movement (Questions 4- 7)

Section 5: Quantitative Analysis of Human Movement (Question 8)

Section 6: Anatomical Bases (Questions 9-11)

Section 7: Mechanical Bases (Questions 12-14)

Section 8: Motor Skills: Principles and Applications (Questions 15-21)

Section 9: Open Ended Questions 


\section{Biomechanics Study Round II}

\section{Section 1: Participant I nformation}

* 1. Please enter your name:

Name: 


\section{Biomechanics Study Round II}

\section{Section 2: I ntroduction to Biomechanics}

\section{The student will be able to:}

a) define and explain the terms biomechanics, statics, dynamics, kinematics, and kinetics in relation to human movement.

b) describe the scope of scientific inquiry addressed by biomechanists.

c) distinguish between qualitative and quantitative approaches for analyzing human movement.

d) explain how to formulate questions for qualitative analysis of human movement.
Importance

Relevance
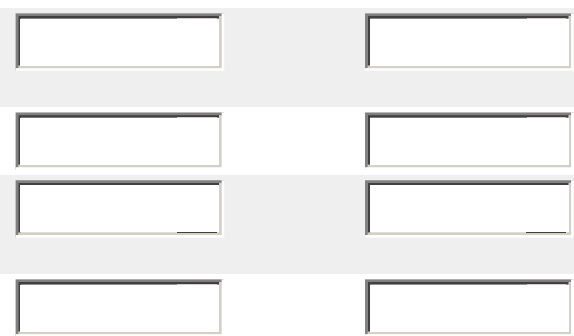


\section{Biomechanics Study Round II}

\section{Section 3: Application of Biomechanics Competencies to Human}

\section{Movement}

\section{The student will be able to:}

a) observe and describe a movement technique accurately

b) determine the anatomical and mechanical factors basic to the performance of an observed movement

c) evaluate the appropriateness of a performer's technique with reference to the movement task

d) identify factors that limit skillful performance and establish a priority for change in those factors most likely to lead to improvement in performance.
Importance
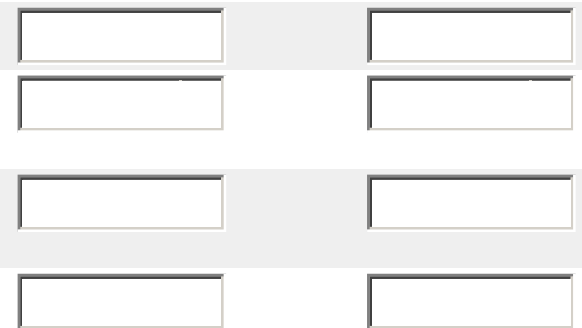


\section{Biomechanics Study Round II}

\section{Section 4 : Qualitative Analysis of Human Movement}

\section{Preparation: Gathering Relevant Knowledge}

\section{The student will be able to:}

a) define the critical features of various motor skills and explain how they are identified in the preparation task of qualitative analysis of

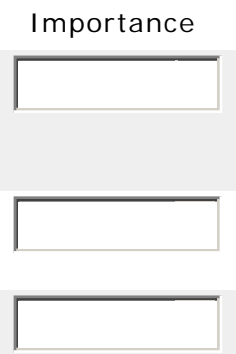
movement.
b) explain how preparation in qualitative analysis of movement is related to effective teaching and observation.
c) explain how preparing for qualitative analysis can be integrated with planning for teaching.

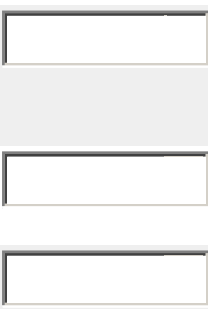

\section{Observation: Developing a Systematic Observation Strategy}

\section{The student will be able to:}

\section{a) explain how to compensate for perceptual limitations by planning a systematic observational strategy. \\ b) identify key elements of a systematic observational strategy. \\ c) identify several effective systematic observational strategies. \\ d) explain how all the senses can be integrated to improve observation.}

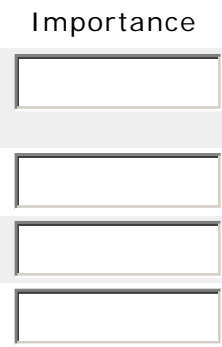

Relevance

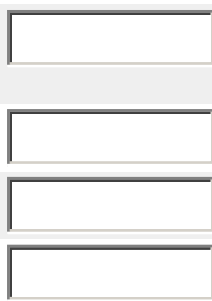

\section{Evaluation and Diagnosis: Critical Thinking Within Qualitative Analysis}
a) explain why evaluation of performance errors is necessary for qualitative analysis.
b) discuss major difficulties in evaluating strengths and weaknesses of performance.
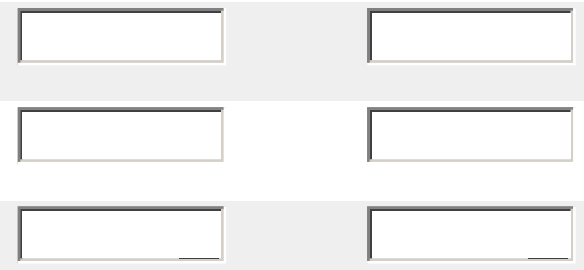


\section{Biomechanics Study Round II}

\section{I ntervention: Strategies for I mproving Performance}

\section{The student will be able to:}

a) identify a variety of intervention strategies (e.g., feedback, task modification, mechanical guidance) used in qualitative analysis to
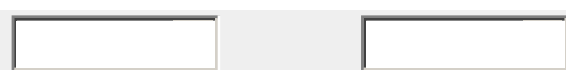
improve performance.

b) identify research supported guidelines for the provision of augmented verbal feedback.

c) list the functions of feedback as intervention in qualitative analysis.

d) describe how to develop appropriate cue words and phrases for improving skill performance.

e) identify the most appropriate intervention strategy (e.g., feedback, task modification, mechanical guidance) for improving skill performance across novice, intermediate, and expert performers. 


\section{Biomechanics Study Round II}

\section{Section 5: Quantitative Analysis of Human Movement}

\section{Quantitative Reasoning and Problem Solving}

\section{The student will be able to:}

a) categorize classes of quantitative problems and select appropriate techniques for analysis and problem solving.

b) interpret graphs and simple models which are used to explain human movement.

c) demonstrate an awareness of and proficiency with various computational skills to effectively interpret and use quantitative information.

d) identify current technology used to quantify biomechanical variables in human movement.

e) solve quantitative problems involving vector quantities using both graphic and trigonometric procedures.

f) solve quantitative problems involving angular kinematic quantities and the relationship between angular and linear kinematic quantities.

g) solve quantitative problems related to kinetic concepts.

h) solve basic quantitative problems using the equations of static equilibrium.

i) solve quantitative problems relating to the factors that cause or modify angular motion.

j) list possible sources of error in recorded movement data.

k) develop the ability to think critically about information and then develop effective strategies to problems relating to human movement

Importance
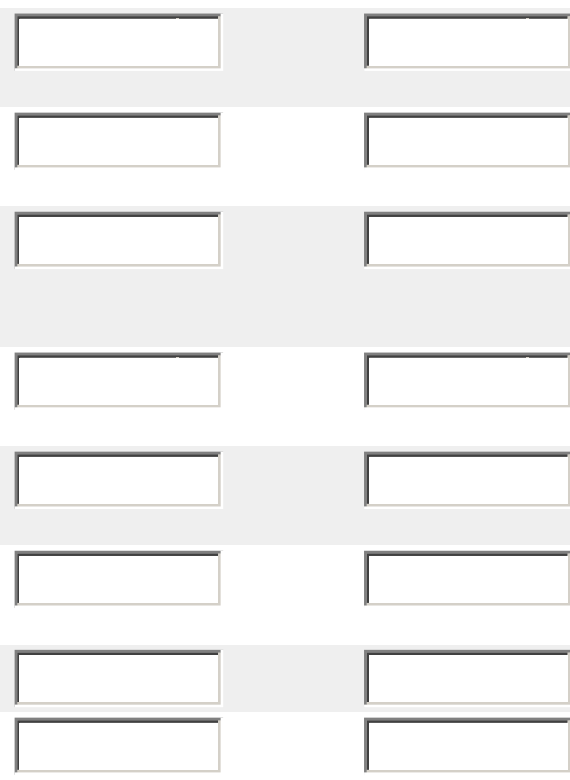
and performance. 


\title{
Biomechanics Study Round II
}

\section{Section 6: Anatomical Bases}

\section{J oint Structure and Function}

\section{The student will be able to:}

\begin{abstract}
a) name and define the fundamental planes and axes.
b) describe and demonstrate joint movement with respect to plane and axis of motion.

c) explain the relationship between joint structure and function.

d) name and demonstrate the actions possible in each joint in other than the anatomical starting position.

e) state the factors contributing to joint range of motion and stability.

f) classify joints according to structure and explain the relationship between joint structure and its capacity for movement.
\end{abstract}

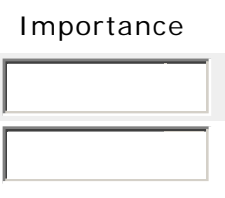

g) observe a joints range of motion qualitatively and state appropriate procedures for improving that range.

h) explain how the schedule of ossification of epiphyseal cartilage is related to the nature of activities suitable for different age groups.

i) observe human movement and explain the reasons for different joint actions and ranges of motion using knowledge of joint structure, stability, and mobility.

j) assess flexibility and create safe and effective stretches for the major muscle groups surrounding each joint.
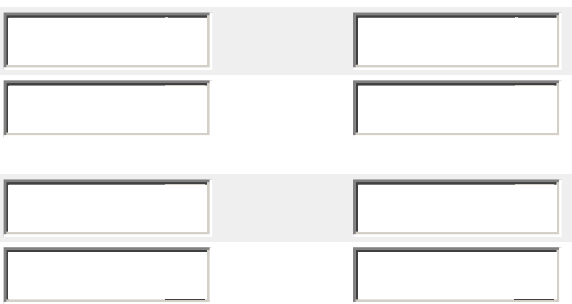

k) perform an anatomical analysis of the joint actions and planes of motion for a selected motor skill.
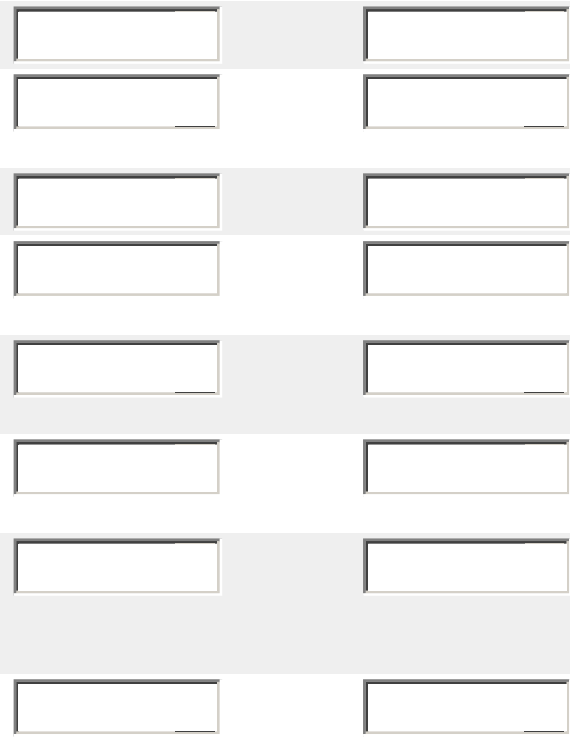


\section{Biomechanics Study Round II}

\section{Section 6: Anatomical Basis (continued)}

\section{Muscle Mechanics}

\section{The student will be able to:}

a) name the major muscles or muscle groups active in any given joint action.

b) identify the type(s) of muscular contraction (static, concentric, eccentric) occurring in any given joint action.

c) explain the cooperative action of muscles in controlling joint actions and identify the role (agonist, antagonist, stabilizer, neutralizer) played by the muscle(s) in a given movement.

d) explain the force-velocity and length-tension relationships of muscle and recognize their application in static positions and dynamic movements.

e) recognize the use of the stretch-shortening cycle of muscle in human movement and create effective training exercises that utilize this phenomenon.

f) describe the mechanical response of different muscle fiber types, the influence of training upon them, and the potential for muscle fiber
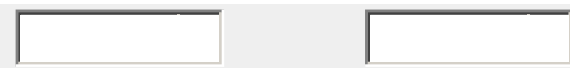
type to influence performance. 


\section{Biomechanics Study Round II}

\section{Section 6: Anatomical Basis (continued)}

\section{Neuromuscular Function}

\section{The student will be able to:}

a) name and define the basic structures (e.g., motor unit, muscle spindle and proprioceptors) of the neuromuscular system.

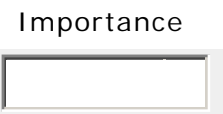

b) explain how the various receptors function, and describe the effect each has on musculoskeletal movement.

c) describe the anatomical bases for reflex acts and name and define examples of reflexes (e.g., stretch reflex, righting and supporting reflexes, reciprocal inhibition or co-contraction) affect human movement.

d) describe how recruitment and rate coding of motor units regulate muscle force production.

e) perform an analysis of the neuromuscular factors influencing the performance of a variety of motor skills.

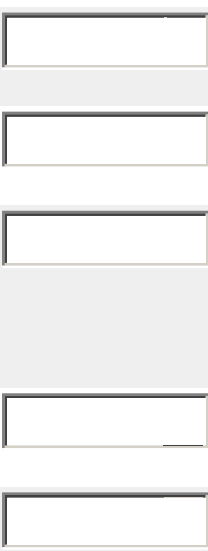




\section{Biomechanics Study Round II}

\section{Section 7: Mechanical Bases}

\section{Basic Considerations}

\section{The student will be able to:}

a) define a movement system and determine the nature of the system's movement (i.e., linear, angular, general motion).

b) appropriately represent kinematic and kinetic quantities as vectors and use vectors, vector addition, and vector resolution to enhance the understanding of basic mechanical concepts (e.g., impact of the direction of resultant force application (external forces), the effect of changes in line of muscle pull upon the amount of force used to rotate a segment (internal forces). 


\section{Biomechanics Study Round II}

\section{Section 7: Mechanical Basis (continued)}

\section{Movement Kinematics}

\section{The student will be able to:}

a) define the basic terms of distance, displacement, speed, velocity, and acceleration as they relate to linear and angular motion in human movements.

b) use kinematic variables to compare the quality of various motor performances (e.g., across skill level, fitness level, gender, age, body size and type, etc.).

c) explain the kinematic relationships between linear and angular motion and apply this relationship to improve motor skill performance
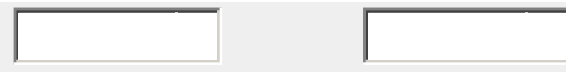
(e.g., striking, throwing, kicking) and equipment design (e.g., sport, rehabilitation, work environment).

d) describe how the variables of release height, angle, and velocity affect projectile motion and apply these variables to a projectile activity to optimize performance.

e) explain how to plan and conduct an effective qualitative human movement analysis.

f) use simple concepts of motion description (kinematics) to analyze human motion in qualitative terms.

g) identify and describe the uses of available instrumentation for measuring kinematic quantities.
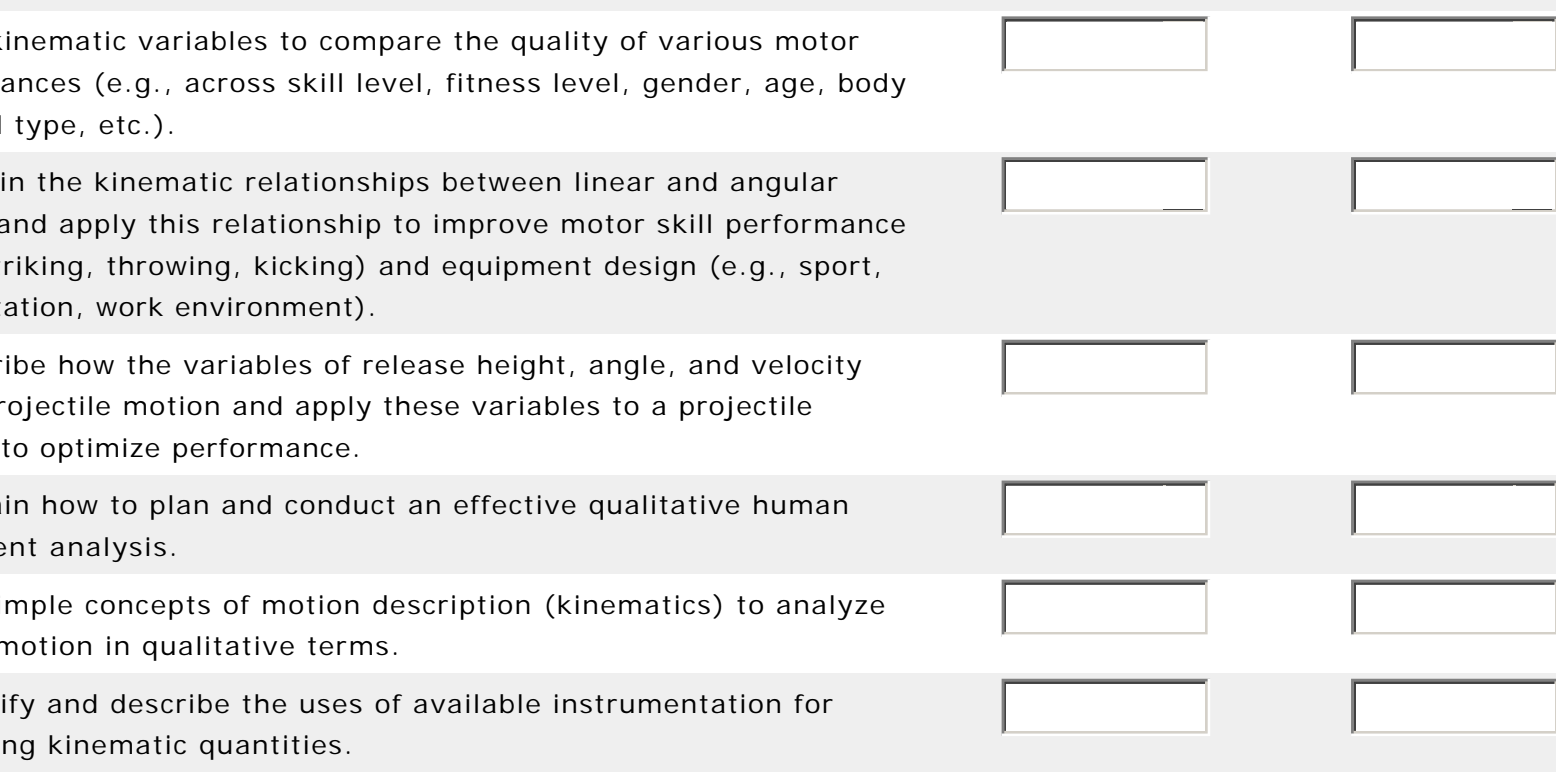


\section{Biomechanics Study Round II}

\section{Section 7: Mechanical Basis (continued)}

\section{Movement Kinetics}

\section{The student will be able to:}

a) define basic terms (e.g., force, inertia, mass, and weight) as they relate to linear motion in human movement.

b) define basic terms (e.g., torque, moment, moment of inertia, moment arm, radius) as they relate to angular motion.

c) identify Newton's laws of motion and gravitation and describe practical illustrations of the laws.

d) identify and provide examples of the angular analogues of Newton's laws of motion.

e) explain what factors affect friction and discuss the role of friction in daily activities and sports.

f) explain the effects of weight, normal reaction, friction, buoyancy, drag, and lift upon motor performance.

g) estimate the location of the center of gravity of persons in any position and describe how changes in location of the center of gravity and other mechanical factors that influence stability.

h) identify and explain the importance of impulse-momentum, workenergy, and the conservation of momentum to the production of
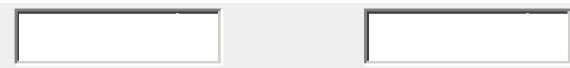

effective human movements. 


\section{Biomechanics Study Round II}

\section{Section 8: Motor Skills: Principles and Applications}

\section{Standing Posture}

\section{The student will be able to:}

a) identify and describe the skeletomuscular and neuromuscular antigravity mechanisms involved in volitional standing positions.

b) summarize the similarities and differences that occur in the relation of the line of gravity to various body landmarks with good and poor
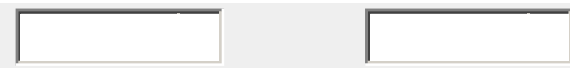
anteroposterior segmental alignment.

c) discuss the factors that affect the stability and energy cost of erect posture.

d) explain the effects that the variables of age, body build, strength, and flexibility have on the alignment of body segments in the standing posture.

e) name the values, if any, of good posture.

f) perform biomechanical analyses on the posture of individuals of different ages and body builds.
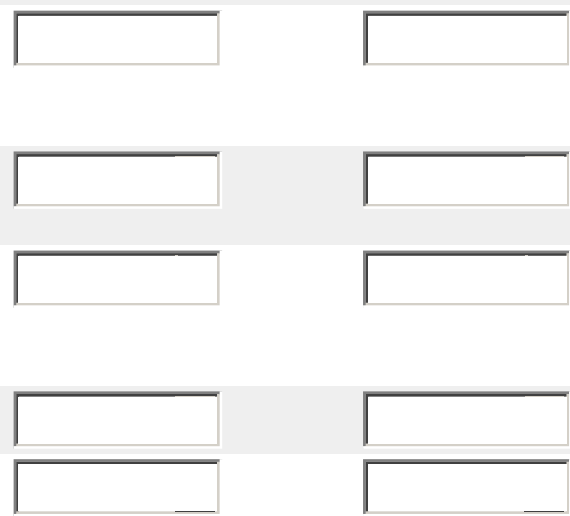


\section{Biomechanics Study Round II}

\section{Section 8: Motor Skills: Principles and Applications (continued)}

\section{Moving Objects: Pushing and Pulling}

a) classify activities involving push or pull patterns according to the nature of the force applications.

b) name and discuss anatomical and mechanical factors and principles that apply to representative push or pull activities.

c) analyze the performance of someone performing a push-pull skill under each of these force application conditions: momentary contact, projection, or continuous application.
Importance

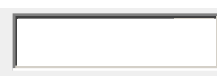

Relevance
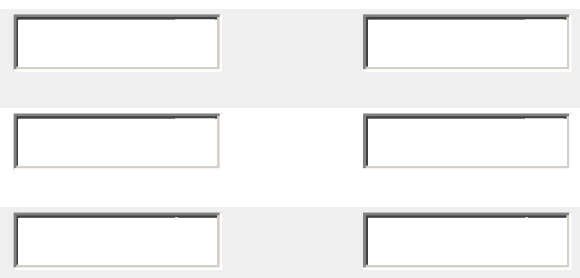


\section{Biomechanics Study Round II}

\section{Section 8: Motor Skills: Principles and Applications (continued)}

\section{Moving Objects: Throwing, Striking, and Kicking}

\section{The student will be able to:}

a) classify activities involving sequential throwing, kicking, or striking patterns according to the nature of force applied.

b) name and discuss anatomical and mechanical factors that apply to representative throwing, kicking, or striking activities.

C) perform an analysis of someone engaging in a sequential throwing, kicking, or striking skill under each of these force application

conditions: momentary contact, projection, continuous application.

d) plan and conduct a qualitative analysis of common object control skills.

e) plan and conduct a quantitative analysis of common object control skills.
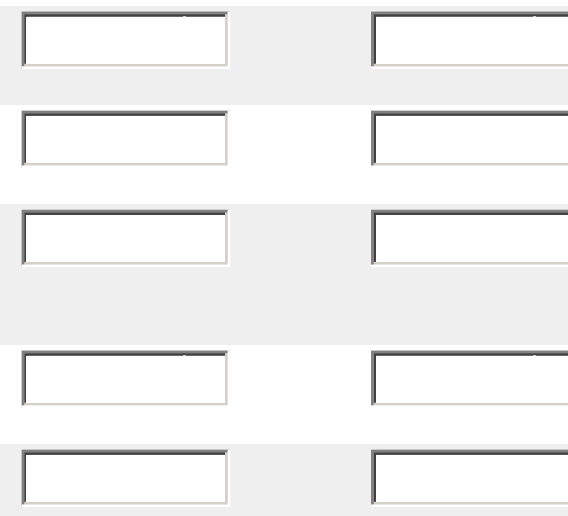

\section{Locomotion: Solid Surface}

\section{The student will be able to:}

a) identify and classify motor skills belonging in the categories that fall under the heading of moving one's body on the ground or on another resistant surface.

b) describe the anatomical and mechanical nature of motor skills representative of the major types of locomotor patterns.
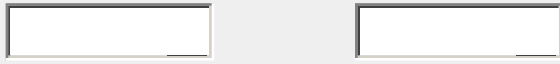

c) name and state anatomical and mechanical principles that apply to the locomotion patterns of walking, running, and jumping.

d) evaluate performance of motor skills representative of the major locomotor patterns in terms of application of the related
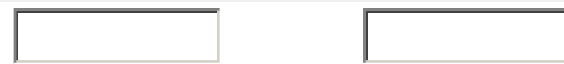
biomechanical principles.

e) plan and conduct a qualitative analysis of someone performing a locomotor skill.
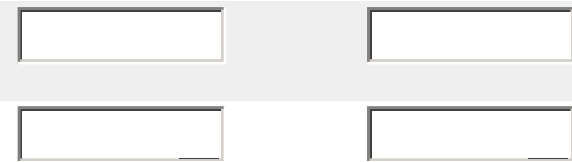

f) plan and conduct a quantitative analysis of someone performing a locomotor skill.
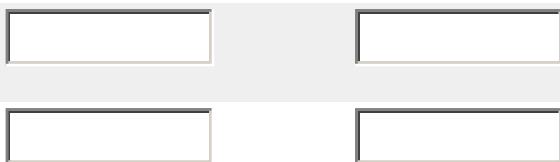


\section{Biomechanics Study Round II}

\section{Section 8: Motor Skills: Principles and Applications (continued)}

\section{Locomotion: The Aquatic Environment}

\section{The student will be able to:}

a) identify factors that contribute to the propulsion of a swimmer.

b) identify factors that impede the progress of a swimmer.

c) explain how the propulsive and resistive factors identified affect the length or frequency of a swimming stroke.

d) complete a biomechanical analysis of a swimming stroke by identifying the anatomical and mechanical factors important to success
Importance
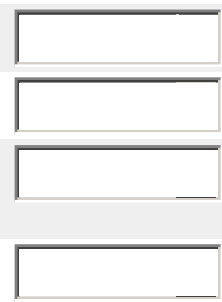

Relevance

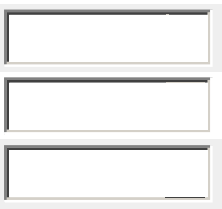
in the selected stroke, as well as those factors that appear to limit the particular performance.

\section{Locomotion: When Suspended and Free of Support}

\section{The student will be able to:}

a) explain how each of the following influences the action of swinging bodies: weight of the body, length of the pendulum, angular

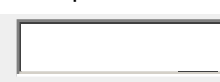

Relevance momentum, potential-kinetic energy, centripetal-centrifugal force, and friction.

b) describe how to initiate pendular action, increase the height of a swing, alter the period, change grips, and dismount safely.

c) explain how each of the following influences the flight path of unsupported bodies: angle of projection, vertical velocity, gravity, and angular momentum.

d) describe how to initiate and control rotation of unsupported bodies.

e) analyze the performance of a suspension and a nonsupport movement.
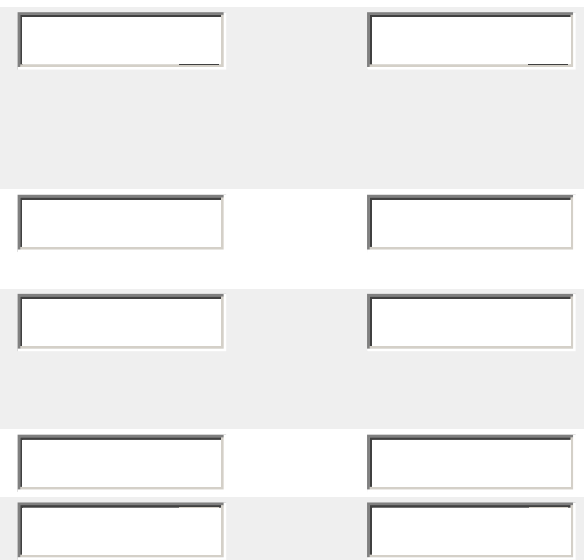


\section{Biomechanics Study Round II}

\section{Section 8: Motor Skills: Principles and Applications (continued)}

\section{I mpact}

Importance

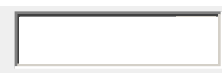

a) name the common problems associated with the diverse forms of receiving impact

b) explain how the work-energy, impulse-momentum, and pressurearea relationships apply to receiving the impact either of one's own body or of external objects.

c) state the principles related to avoiding injury while receiving impact and furnish an application for each.

d) state the principles related to maintaining and regaining equilibrium while receiving impact and furnish an application for each.

e) state the principles related to accuracy and control while receiving impact and furnish an application for each.
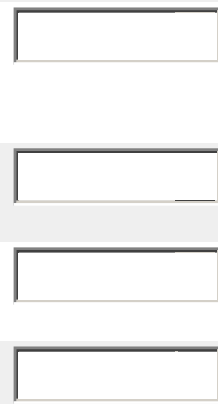

Relevance
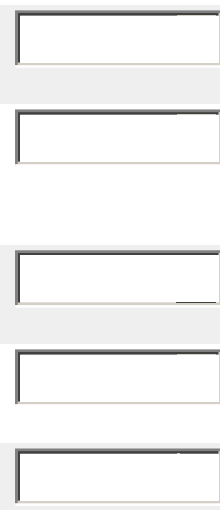


\section{Biomechanics Study Round II}

\section{Section 9: Recommendation 1}

\section{INTRODUCTION TO FINAL QUESTION}

According to the Guidelines and Standards for Undergraduate Biomechanics (NASPE, 2003), upon completion of a biomechanics course the student should be able to:

1. observe and describe a movement technique accurately;

2. determine the anatomical and mechanical factors basic to the performance of an observed movement;

3. evaluate the suitability of a performer's technique with reference to the task at hand; and, 4. identify those factors that limit performance and establish a priority for change in those factors most likely to lead to improvement in performance.

The infusion of biomechanical concepts and competencies in the PETE curriculum is also recommended for helping physical educators make meaningful applications of the subject matter. I nfusion will allow preservice physical educators to revisit core biomechanical content in a variety of instructional contexts within the PETE program. An important initial task is to target specific learning environments for teaching core competencies and identify instructional methods for those learning environments. Accordingly your recommendations for this area are valued and needed!

In the following section, please recommend at least one (up to three) learning environment(s) and instructional method(s) for delivering biomechanics content to prospective PreK-12 physical education teachers. You will need to advance to the next page in order to provide a second and third recommendation. Refer to the email attachment for reference in answering this final open response question.

\section{INSTRUCTIONS:}

1) Identify a possible learning environment for delivering biomechanics content to prospective P- 12 physical education teachers.

2) Identify a specific instructional method you would recommend for that learning environment.

3) Provide a description of the instructional method you identified.

\section{Learning Environment:}

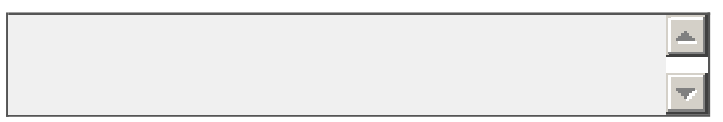

\section{Instructional Method:}

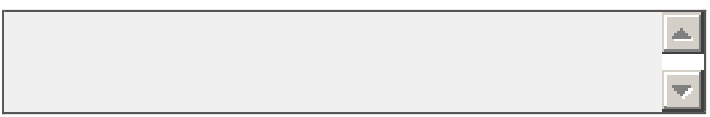

\section{Description of I nstructional Method:}




\section{Biomechanics Study Round II}

\section{Section 9: Recommendation 2}

1) Identify a possible learning environment for delivering biomechanics content to prospective P- 12 physical education teachers.

2) Identify a specific instructional method you would recommend for that learning environment.

3) Provide a description of the instructional method.

\section{Learning Environment:}

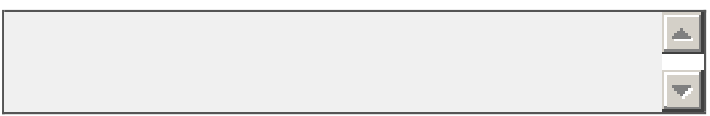

26. I nstructional Method:

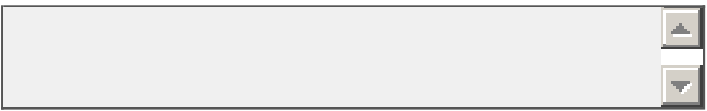

27. Description of I nstructional Method: 


\section{Biomechanics Study Round II}

\section{Section 9: Recommendation 3}

1) Identify a possible learning environment for delivering biomechanics content to prospective P- 12 physical education teachers.

2) Identify a specific instructional method you would recommend for that learning environment.

3) Provide a description of the instructional method.

\section{Learning Environment:}

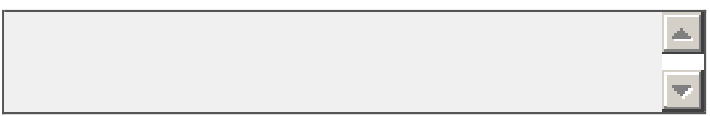

29. I nstructional Method:

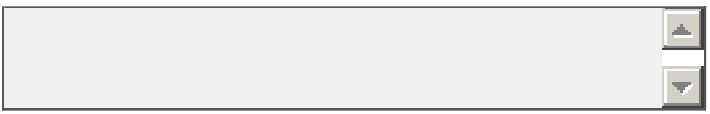

30. Description of I nstructional Method: 


\section{Biomechanics Study Round II}

\section{Thank you!}

Thank you for completing this survey, your input is greatly appreciated!

Once all Round II surveys have been completed and analyzed, I will e-mail you a copy of the results.

Please click the "Done" button below to finalize the survey.

Susan Ross

West Virginia University

College of Physical Activity \& Sport Sciences

sross11@mix.wvu.edu

(304) 293-0848 


\section{Appendix E}

Biomechanics Recommendations for the Physical Education Teacher Education Curriculum Delivery of Biomechanics Content 


\section{Response Categories}

1. Direct Instruction

2. Indirect Instruction

3. Interactive Instruction

4. Experiential Learning

5. Independent Study

6. Multi-model Instruction

7. Alternative Curriculum Models
Biomechanics Delphi Investigation

Recommended Learning Environments and Instructional Methods

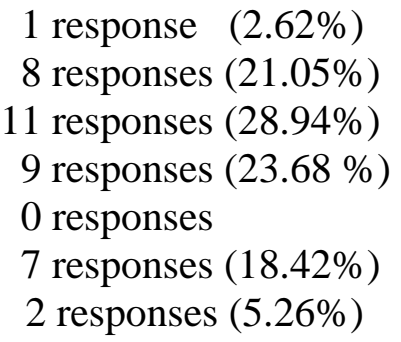

\begin{tabular}{|c|c|c|}
\hline Learning Environment & $\begin{array}{l}\text { Instructional } \\
\text { Method }\end{array}$ & Summary Description of Instructional Method \\
\hline \multicolumn{3}{|r|}{ Direct Instruction } \\
\hline Gymnasium & Didactic method & Lecture and demonstration. \\
\hline \multicolumn{3}{|r|}{ Indirect Instruction } \\
\hline $\begin{array}{l}\text { Analysis of Human Motion } \\
\text { Class }\end{array}$ & Case Studies & $\begin{array}{l}\text { Using video clips of motion, students discuss and analyze the key mechanical aspects } \\
\text { of movement and apply movement principles. }\end{array}$ \\
\hline Gymnasium & Guided discovery & $\begin{array}{l}\text { Pose problems and then let the students solve them -- give them students who do not } \\
\text { perform as well as they should and let teachers diagnose the error and work to correct } \\
\text { it. }\end{array}$ \\
\hline $\begin{array}{l}\text { Elementary/secondary field } \\
\text { experience }\end{array}$ & $\begin{array}{l}\text { Indirect Instruction } \\
\text {-Direct instruction }\end{array}$ & $\begin{array}{l}\text { Students in the field experience teach elementary/secondary students in schools } \\
\text { various skills related to the activity units. Students have to plan the lesson effectively } \\
\text { to include the proper techniques, instructional progressions, instructional cues, and } \\
\text { appropriate feedback for student learning. The instructor of the course is there also to } \\
\text { help provide suggestions to the teachers. Teachers are asked to video tape themselves } \\
\text { to assess their presentation styles and effectiveness. }\end{array}$ \\
\hline
\end{tabular}




\begin{tabular}{|c|c|c|}
\hline Learning Environment & $\begin{array}{l}\text { Instructional } \\
\text { Method }\end{array}$ & Summary Description of Instructional Method \\
\hline \multicolumn{3}{|r|}{ Indirect Instruction (continued) } \\
\hline $\begin{array}{l}\text { Basic Instructional course } \\
\text { (Teaching within an Activity- } \\
\text { Based Course) }\end{array}$ & $\begin{array}{l}\text { Video analysis of } \\
\text { self performing } \\
\text { skills }\end{array}$ & $\begin{array}{l}\text { Student's video tape themselves performing skill components previously identified as } \\
\text { critical for correct performance. Students are then asked to critique their own } \\
\text { performance and provide an assessment of how well the components were executed. } \\
\text { Students are asked to burn the video and the appropriate critique to a DVD for the } \\
\text { instructor to review for assessment. }\end{array}$ \\
\hline $\begin{array}{l}\text { Biomechanics (Classroom or } \\
\text { Laboratory-based) }\end{array}$ & Problem Solving & $\begin{array}{l}\text { Provide students with scenarios for which they must resolve a problem by } \\
\text { applying/using the learning outcomes. }\end{array}$ \\
\hline Biomechanics Class & $\begin{array}{l}\text { Indirect Instruction } \\
\text { - video analysis } \\
\text { and problem } \\
\text { solving }\end{array}$ & $\begin{array}{l}\text { A variety of subjects representing the various body types will be studied performing } \\
\text { the same task (ex. striking) with a variety of equipment (short handled and long } \\
\text { handled implements). Video analysis, peer practice, and problem solving will be used } \\
\text { as instructional methods. }\end{array}$ \\
\hline Classroom & $\begin{array}{l}\text { Videotape } \\
\text { analyses }\end{array}$ & $\begin{array}{l}\text { Observe videotapes of people/children performing motor skills - have students name } \\
\text { \& detect the correct/incorrect performance of the critical elements of motor skills }\end{array}$ \\
\hline $\begin{array}{l}\text { Middle/High school activity- } \\
\text { based }\end{array}$ & $\begin{array}{l}\text { Computer Assisted } \\
\text { Instruction }\end{array}$ & $\begin{array}{l}\text { Use computer assisted instructional programs to learn and apply their knowledge } \\
\text { related to biomechanics. This is appropriate in traditional (live) settings as well as } \\
\text { online learning. }\end{array}$ \\
\hline \multicolumn{3}{|r|}{ Interactive Instruction } \\
\hline $\begin{array}{l}\text { Teach the class embedded in } \\
\text { an activity course -- } \\
\text { gymnastics has a lot of } \\
\text { application. }\end{array}$ & Problem Solving & $\begin{array}{l}\text { Application of biomechanical principles in an activity-based course taken by physical } \\
\text { education teachers. Students should have labs and be able to see the how the } \\
\text { information from class impacts them as a teacher. I would have a series of problems } \\
\text { (not quantitative -- example, what must the person do to increase the number of } \\
\text { revolutions while doing a back somersault dive) and let the students use the } \\
\text { biomechanical principles to solve them. }\end{array}$ \\
\hline
\end{tabular}




\begin{tabular}{|c|c|c|}
\hline Learning Environment & $\begin{array}{l}\text { Instructional } \\
\text { Method }\end{array}$ & Summary Description of Instructional Method \\
\hline \multicolumn{3}{|r|}{ Interactive Instruction (continued) } \\
\hline In an activity setting & $\begin{array}{l}\text { Video Analysis } \\
\text { and Discussion - } \\
\text { Diagnostic and } \\
\text { corrective }\end{array}$ & $\begin{array}{l}\text { Have the student's video tape a student doing the movement and then have the } \\
\text { students break down the tape and what they are seeing. Then have them explain how } \\
\text { they would give feedback and correction to the student. }\end{array}$ \\
\hline Activity classes & Simulations & $\begin{array}{l}\text { Have them observe a peer doing a motor skill, and analyze the elements of the skill } \\
\text { their peer is doing correctly, incorrectly, and have them provide feedback and tasks to } \\
\text { improve performance). Have them observe a peer doing a motor skill, and analyze the } \\
\text { elements of the skill their peer is doing correctly, incorrectly, and have them provide } \\
\text { feedback. }\end{array}$ \\
\hline $\begin{array}{l}\text { Basic instruction courses that } \\
\text { include lifetime sports such as } \\
\text { inline skating, skiing, golfing, } \\
\text { hiking etc }\end{array}$ & $\begin{array}{l}\text { Systematic } \\
\text { observation of } \\
\text { teacher behaviors. } \\
\text { Video analysis in } \\
\text { combination with } \\
\text { peer teaching }\end{array}$ & $\begin{array}{l}\text { Prospective physical educators will be videotaped while teaching peers in lifetime } \\
\text { sports. The feedback provided during the actual teaching will then be analyzed using } \\
\text { the video footage. }\end{array}$ \\
\hline $\begin{array}{l}\text { Basic instructional course- } \\
\text { where key components of } \\
\text { skills are introduced. }\end{array}$ & $\begin{array}{l}\text { Peer practice- } \\
\text { observation and } \\
\text { analysis }\end{array}$ & $\begin{array}{l}\text { The students teach one another the components of selected skills and then analyze the } \\
\text { performances as the students are practicing and then moving into application of skills } \\
\text { in a more game-like setting. The class instructor has provided a checklist for the } \\
\text { teachers to follow with the appropriate skill components to be taught. The instructor's } \\
\text { role is to move around the class and offer feedback when needed. Having the students } \\
\text { work their non-dominant hand in learning the skill often creates an environment where } \\
\text { providing feedback become critical. }\end{array}$ \\
\hline Motor Development Classes & $\begin{array}{l}\text { Observation and } \\
\text { analysis }\end{array}$ & $\begin{array}{l}\text { As students are learning basic skills that occur over the lifespan, provide options to } \\
\text { observe human movement (children, older adults, athletes, etc.) and analyze the } \\
\text { motion. }\end{array}$ \\
\hline
\end{tabular}




\begin{tabular}{|c|c|c|}
\hline Learning Environment & $\begin{array}{l}\text { Instructional } \\
\text { Method }\end{array}$ & Summary Description of Instructional Method \\
\hline \multicolumn{3}{|r|}{ Interactive Instruction (continued) } \\
\hline Simulation Lab & $\begin{array}{l}\text { Simulation - } \\
\text { observation and } \\
\text { analysis }\end{array}$ & $\begin{array}{l}\text { A student performs skill. Peers observe and videotape performance. Immediately after } \\
\text { observation (same class) peers identify critical aspects of skill and strength and } \\
\text { weakness of that selected performance, i.e., elements in need of correction for } \\
\text { decreased injury potential and improved performance. Students are to complete } \\
\text { qualitative analysis of videotape. In the assignment students are tasked to identify: } \\
\text { strength and weaknesses, aspects that provide injury potential, aspects that could } \\
\text { improve performance. The summary of the assignment should include a comparison } \\
\text { of the observation and video tape analyses. }\end{array}$ \\
\hline $\begin{array}{l}\text { Variety of Learning } \\
\text { Environments }\end{array}$ & $\begin{array}{l}\text { Simulation Lab in } \\
\text { which students } \\
\text { observe and } \\
\text { analyze peer } \\
\text { movement } \\
\text { performance. }\end{array}$ & $\begin{array}{l}\text { A student performs skill. Peers observe and videotape performance. Immediately after } \\
\text { observation (same class) peers identify critical aspects of skill and strength and } \\
\text { weakness of that selected performance, i.e., elements in need of correction for } \\
\text { decreased injury potential and improved performance. Students are to complete } \\
\text { qualitative analysis of videotape. In the assignment students are tasked to identify: } \\
\text { strength and weaknesses, aspects that provide injury potential, aspects that could } \\
\text { improve performance. The summary of the assignment should include a comparison } \\
\text { of the observation and video tape analyses. }\end{array}$ \\
\hline Elementary Methods Course & Peer observation & $\begin{array}{l}\text { A preservice teachers first experience with observing, identifying critical features of } \\
\text { movement, and assessing movement technique is via a criteria sheet containing } \\
\text { critical features of selected motor skills (e.g., throwing, striking, kicking). During } \\
\text { class time, half the class performs the selected skill over several trials, while the other } \\
\text { students observe movement responses and completes a checklist on their peers. The } \\
\text { instructor circulates around the teaching area ensuring students who are assessing } \\
\text { understand the critical features they are observing. In the case that most students are } \\
\text { performing the skill well, "plant" at least one student who will perform the skill } \\
\text { incorrectly. The activity simply exposes students to the process of observing in a } \\
\text { dynamic environment, and analyzing (identifying the strengths and weakness in } \\
\text { performance), as opposed to just watching. }\end{array}$ \\
\hline
\end{tabular}




\begin{tabular}{|c|c|c|}
\hline Learning Environment & $\begin{array}{l}\text { Instructional } \\
\text { Method }\end{array}$ & Summary Description of Instructional Method \\
\hline \multicolumn{3}{|r|}{ Interactive Instruction (continued) } \\
\hline Secondary Teaching Methods & $\begin{array}{l}\text { Problem-based } \\
\text { learning }\end{array}$ & $\begin{array}{l}\text { Partners in class would be assigned a biomechanical principle for which they are } \\
\text { responsible to teach to their peers. They will investigate the principle, design a video } \\
\text { segment demonstrating the concept and applying it to various movement forms. They } \\
\text { will design a PPT presentation to share the concept and the video in class. The group } \\
\text { will add an assessment piece that may be included in the final course evaluation of } \\
\text { performance. }\end{array}$ \\
\hline $\begin{array}{l}\text { MS/HS Activity Based } \\
\text { Courses }\end{array}$ & Peer Teaching & $\begin{array}{l}\text { Using the Sport Education curriculum model, students will be assuming various roles } \\
\text { (coach, trainer, captain, etc) on their team, taking part in skill practice on their home } \\
\text { courts. Following teacher demonstration and explanation, the coach will use a well } \\
\text { developed task card with graphics and cues to observe and share feedback with team } \\
\text { members. Team members would take turns observing and assessing performance to } \\
\text { provide feedback. }\end{array}$ \\
\hline \multicolumn{3}{|r|}{ Experiential Learning } \\
\hline Clinical Field Experience - HS & Video Analysis & $\begin{array}{l}\text { A dance scheme of work (unit of instruction) would be designed for HS students to } \\
\text { learn to assess their own performance and determine how to improve. Each day, dance } \\
\text { steps would be taught, learners would work with their own dance troupe to design a } \\
\text { dance routine. At the close of each lesson each dance troupe would video their } \\
\text { performance. At the start of the following lesson troupes would observe their previous } \\
\text { performance, identify areas where improvement is needed, and consult materials and } \\
\text { resources available in class to improve their performance. At the close of the scheme, } \\
\text { troupes would show a portfolio of their growth and discuss how they produced it. }\end{array}$ \\
\hline K-12 Physical Education class & $\begin{array}{l}\text { Clinical practice- } \\
\text { microteaching }\end{array}$ & $\begin{array}{l}\text { Have the student teach a skill one on one with a student from the regular PE class. } \\
\text { Have them analysis and provide feedback to the student. }\end{array}$ \\
\hline $\begin{array}{l}\text { Authentic settings... on campus } \\
\text { at a elementary/MS/HS }\end{array}$ & $\begin{array}{l}\text { Peer teaching } \\
\text { coupled with field } \\
\text { experiences }\end{array}$ & $\begin{array}{l}\text { University professor and college students participate in a field experience with student } \\
\text { at local elementary/MS and HS to see the progression of development. }\end{array}$ \\
\hline $\begin{array}{l}\text { Middle/High school activity- } \\
\text { based }\end{array}$ & $\begin{array}{l}\text { Simulations } \\
\text { (Clinical practice) }\end{array}$ & $\begin{array}{l}\text { Students simulate the roles of teacher, coach, and biomechanist to learn and } \\
\text { demonstrate their learning related biomechanics. }\end{array}$ \\
\hline
\end{tabular}




\begin{tabular}{|c|c|c|}
\hline Learning Environment & $\begin{array}{l}\text { Instructional } \\
\text { Method }\end{array}$ & Summary Description of Instructional Method \\
\hline \multicolumn{3}{|r|}{ Experiential Learning (continued) } \\
\hline Campus Pre-school & Field Observation & $\begin{array}{l}\text { See \#26 (Observe the PE professor teach motor skills to preschool children, and } \\
\text { record what statements (feedback) they used to correct the pre-school children's motor } \\
\text { skills). Observe the PE professor teach motor skills to preschool children, and record } \\
\text { what statements (feedback) they used to correct the pre-school children's motor skills. }\end{array}$ \\
\hline $\begin{array}{l}\text { Adapted physical education } \\
\text { course - clinical practice }\end{array}$ & $\begin{array}{l}\text { Field observation - } \\
\text { case study }\end{array}$ & $\begin{array}{l}\text { Supervised clinical practice; students will be observing an adapted physical education } \\
\text { class and supervised guidance directed to analyze accommodations put in place to } \\
\text { allow ape students to be successful. }\end{array}$ \\
\hline $\begin{array}{l}\text { Activity-based courses (all } \\
\text { levels and abilities; P-12+, } \\
\text { including adapted PE) }\end{array}$ & $\begin{array}{l}\text { Experiential } \\
\text { learning }\end{array}$ & $\begin{array}{l}\text { Field observations of P-12 (or older) students engaged in activity courses and } \\
\text { observing specific performances and behaviors; then recording observations in } \\
\text { learning logs. They could observe activities representing different types of movement } \\
\text { (e.g., locomotion, throwing, swimming, etc.). Perform qualitative analyses of } \\
\text { movements observed, making appropriate recommendations. }\end{array}$ \\
\hline $\begin{array}{l}\text { Alternative Learning } \\
\text { Environment } \\
\text { Athletic/sport/physical activity } \\
\text { games and practices }\end{array}$ & $\begin{array}{l}\text { Field Observation } \\
\text { followed by } \\
\text { instruction }\end{array}$ & $\begin{array}{l}\text { Observe skilled and unskilled athletes performing movements relevant to sporting } \\
\text { situations. Choose a single athlete as a case study and perform a qualitative analysis; } \\
\text { write-up results and recommendations. The biomechanics student could then teach } \\
\text { technique improvement to the athlete. Additionally, the biomechanics student could } \\
\text { prepare and present the information to either a student or faculty group (practice } \\
\text { teaching). }\end{array}$ \\
\hline Biomechanics lab class & $\begin{array}{l}\text { Experiential } \\
\text { learning }\end{array}$ & \\
\hline
\end{tabular}




\begin{tabular}{|c|c|c|}
\hline Learning Environment & $\begin{array}{l}\text { Instructional } \\
\text { Method }\end{array}$ & Summary Description of Instructional Method \\
\hline \multicolumn{3}{|r|}{ Multimodal Instruction } \\
\hline Biomechanics Course & Lecture and Lab & $\begin{array}{l}\text { Part lecture on principles clearly illustrated with media and students doing self, peer } \\
\text { and together analysis in lab. } \\
\text { Preservice physical education teachers will learn about biomechanical concepts in } \\
\text { lecture, which may include traditional information from the instructor as well as other } \\
\text { learning methods. Instructors will be responsible for the depth of coverage for each } \\
\text { area, depending on the needs of the students. In the lab the students should have } \\
\text { hands-on experiences designed to illustrate important course concepts and to allow for } \\
\text { qualitative and quantitative analyses of motion. A wide variety of experiences and } \\
\text { movements should be included, with many different sports and every-day activities. }\end{array}$ \\
\hline $\begin{array}{l}\text { Biomechanics Course } \\
\text { (classroom AND laboratory- } \\
\text { based) }\end{array}$ & Lecture and lab & $\begin{array}{l}\text { The lab should including interactive instruction and experiential learning. Students } \\
\text { participating in demonstration-type activities either individually or in small groups } \\
\text { with a qualified instructor supervising to guide learning, give instruction, and } \\
\text { demonstrations. }\end{array}$ \\
\hline $\begin{array}{l}\text { Face-to-face; Laboratory; } \\
\text { Interactive online delivery }\end{array}$ & $\begin{array}{l}\text { Direct instruction } \\
\text { infused with } \\
\text { experiential } \\
\text { learning }\end{array}$ & $\begin{array}{l}\text { (1) Typical lecture, discussion and/or interactive online delivery (WebCampus, } \\
\text { Blackboard) (2) Hands-on laboratory practical experiential activities }\end{array}$ \\
\hline Activity-based courses & $\begin{array}{l}\text { Direct Instruction } \\
\text { and Peer Teaching }\end{array}$ & $\begin{array}{l}\text { Learning an activity new to the student: } \\
\text { Students who want to be physical educators should experience a wide variety of } \\
\text { activities. To best learn what their future students may experience, they should take } \\
\text { activity courses in less familiar movements. Students will be introduced to the } \\
\text { movement and learn about the movement and its particular movement characteristics } \\
\text { through a myriad of teacher directed instructional methods. } \\
\text { Subsequently, prospective physical educators should be required to teach specific } \\
\text { aspects of a skill, even if they have little or no experience with the movement. This } \\
\text { will require the students to learn about the biomechanical aspects of the movement } \\
\text { skill, how to prioritize them, and how to apply them in a teaching environment. Other } \\
\text { students in the course would be required to be "learning participants" or evaluators of } \\
\text { the lesson being provided. }\end{array}$ \\
\hline
\end{tabular}




\begin{tabular}{|c|c|c|}
\hline Learning Environment & $\begin{array}{l}\text { Instructional } \\
\text { Method }\end{array}$ & Summary Description of Instructional Method \\
\hline \multicolumn{3}{|r|}{ Multimodal Instruction (continued) } \\
\hline $\begin{array}{l}\text { Course in Analysis of } \\
\text { Movement that is more } \\
\text { descriptive and qualitative with } \\
\text { a course in Biomechanics }\end{array}$ & $\begin{array}{l}\text { Lecture and Lab } \\
\text { for both }\end{array}$ & $\begin{array}{l}\text { Part lecture on principles clearly illustrated with media and students doing self, peer } \\
\text { and together analysis in lab }\end{array}$ \\
\hline $\begin{array}{l}\text { 1) peer teaching 2) field } \\
\text { experience }\end{array}$ & $\begin{array}{l}\text { 1) lecture 2) field } \\
\text { experience }\end{array}$ & Field experience with REAL children \\
\hline $\begin{array}{l}\text { Biomechanics Course with Lab } \\
\text { Component }\end{array}$ & $\begin{array}{l}\text { Combination of } \\
\text { lecture, discussion, } \\
\text { and hands-on } \\
\text { experiences }\end{array}$ & $\begin{array}{l}\text { Preservice physical education teachers will learn about biomechanical concepts in } \\
\text { lecture, which may include traditional information from the instructor as well as other } \\
\text { learning methods. Instructors will be responsible for the depth of coverage for each } \\
\text { area, depending on the needs of the students. In the lab the students should have } \\
\text { hands-on experiences designed to illustrate important course concepts and to allow for } \\
\text { qualitative and quantitative analyses of motion. A wide variety of experiences and } \\
\text { movements should be included, with many different sports and every-day activities. }\end{array}$ \\
\hline \multicolumn{3}{|r|}{ Alterative Curriculum Models } \\
\hline $\begin{array}{l}\text { Integration of Biomechanics in } \\
\text { other Physical Education } \\
\text { courses }\end{array}$ & Various & $\begin{array}{l}\text { Other courses such as adapted physical education and teaching methods should } \\
\text { require the students to apply biomechanical concepts within content specific to those } \\
\text { courses as well as the development and implementation of lesson plans which may } \\
\text { occur. Students who are expected to integrate the ideas outside of the biomechanics } \\
\text { course will experience a spiraling of biomechanical concepts throughout the } \\
\text { curriculum. Biomechanical content will be more valuable and recognized as such by } \\
\text { students before and after graduation. }\end{array}$ \\
\hline
\end{tabular}




\begin{tabular}{|c|c|c|}
\hline Learning Environment & $\begin{array}{l}\text { Instructional } \\
\text { Method }\end{array}$ & Summary Description of Instructional Method \\
\hline \multicolumn{3}{|c|}{ Alterative Curriculum Models (continued) } \\
\hline $\begin{array}{l}\text { All Traditional Environments } \\
\text { (classrooms with laboratory } \\
\text { activities and games and } \\
\text { sports) and as many authentic } \\
\text { and alternative environments } \\
\text { as possible }\end{array}$ & $\begin{array}{l}\text { All varied and } \\
\text { useful instructional } \\
\text { methods }\end{array}$ & $\begin{array}{l}\text { Biomechanics content should be taught in traditional settings and infused and } \\
\text { integrated into all other settings so that students begin to realize the interdisciplinary } \\
\text { nature of understanding and improving movement which relies upon an understanding } \\
\text { of kinesiological sciences (e.g., anatomy, motor behavior, biomechanics, exercise } \\
\text { physiology concepts) and human behavior. Instructional methods need to be adapted } \\
\text { to the specific concept(s), student(s) and resources. }\end{array}$ \\
\hline
\end{tabular}

